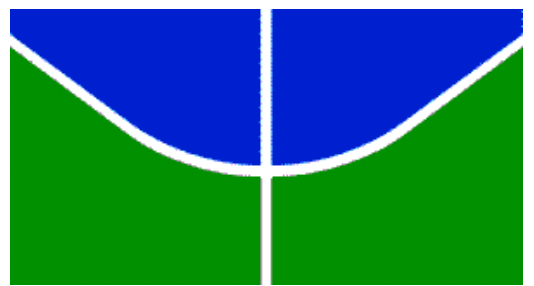

Universidade de Brasília

Instituto de Química - IQ

Programa de Pós-Graduação em Química

\title{
Síntese de Análogos de Bis-chalconas Simétricos e Não Simétricos
}

Najla Leão Doroteio

Dissertação de Mestrado

Orientador: Prof. Dr. Wender Alves da Silva

Brasília-DF

2016 
"O conhecimento é limitado, ao contrário da imaginação que engloba o mundo inteiro, estimulando o progresso e dando luz à evolução."

Albert Einstein 


\section{FOLHA DE APROVAÇÃO}

Comunicamos a aprovação da Defesa de Dissertação de Mestrado do (a) aluno (a) Najla Leão Doroteio, matrícula no 14/0194461, intitulada "Síntese de Análogos de Bis-Chalconas Simétricas e Não Simétricas", apresentada no (a) Sala de Reuniões do Instituto de Química (IQ) da Universidade de Brasília (UnB) em 1 de dezembro de 2016.

Prof. Dr. Wender Alves da Silva

Presidente de Banca (IQ/UnB)

Prof. Dr. Angelo Henrique de Lira Machado Membro Titular (IQ/UnB)

Prof.a Dra. Vanda Maria de Oliveira Membro Titular (UCB)

Prof.a Dra. Angélica de Fátima Silva Barreto Membro Suplente (IQ/UnB)

Em 1 de dezembro de 2016.

$\square$ Caixa Postal 4478 - CEP: 70904-970 - Brasilia - DF - BRASIL

? (61) $3107-3805$

www.unb.br/iq/pg posgiq@unb.br 


\section{Agradecimentos}

Aos meus pais: Dora e Gilson por me ensinarem a dar valor ao trabalho e ao conhecimento. Mãe sou eternamente grata por me receber com seu sorriso todos os dias durante esses anos e por me apoiar nos meus momentos de fraqueza. Pai você não está mais aqui, mas nunca esquecerei como me inspirou quando eu ainda era apenas uma garotinha. Muitíssimo obrigada.

Ao meu irmão Bruno pela "competição de conhecimento" e brincadeiras que fazia nas raras ocasiões em que nos encontrávamos.

Ao meu orientador Prof. Wender por me aceitar como aluna, pela paciência e por acreditar de mim mesmo quando eu já tinha desistido.

Ao meu namorado Guilherme por ser o meu companheiro, amigo e um grande suporte. Seu abraço me salvou várias vezes. Obrigada por ser essa pessoa maravilhosa que acredita em mim.

Ao grupo LaPSCA. João Victor, Saulo, Felipe aprendi muito com vocês, especialmente a arte da gambiarra.

Aos colegas Thaíssa, Gisele, Lennine, Paula e Verônica pela sabedoria, a amizade e as risadas. Também a Angélica e Kadu pelos espectros de RMN.

Aos meus amigos Ana Gabriela, Adrian e Ítalo. Obrigada por tudo, até pela falta de comunicação, que causou um pequeno tumulto em nossos encontros nos últimos meses.

Aos professores Vanda Maria, Rafael Oliveira, Peter Bakuzis e Ângelo Machado por me permitirem enxergar a Química Orgânica de um jeito diferente.

Ao pessoal da central analítica: Carime (LIMA) por me ensinar a usar o espectrofluorímetro. Ao Cleber por me ensinar a usar o espectrofotômetro.

A CAPES pelo apoio financeiro. 


\section{Lista de Acrônimos}

COSY - homonuclear COrrelation SpectroscopY

HSQC - Heteronuclear Single Quantum Coherence

HOMO - Orbital ocupado de maior energia

UV-Vis - Faixa de radiação que abrange o ultravioleta próximo e o visível

$\mathbf{S}_{\mathbf{0}}$ - Estado fundamental

$\mathbf{S}_{\mathbf{1}}-$ Primeiro estado excitado

$\mathbf{S}_{\mathbf{2}}-$ Segundo estado excitado

CHS - Chalcona Sintase 


\section{Índice}

1. Referencial Teórico

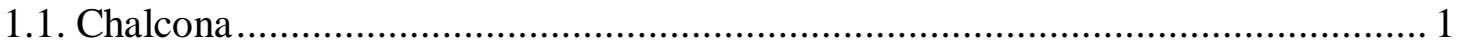

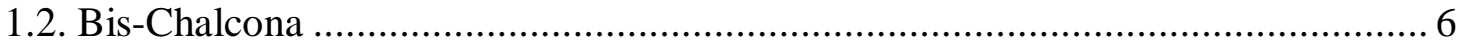

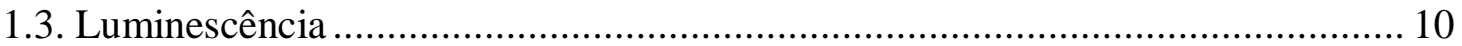

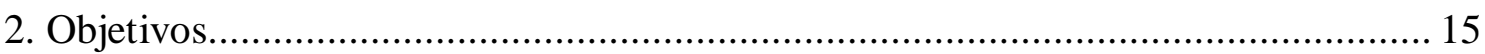

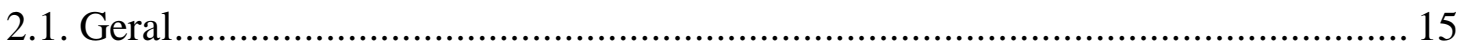

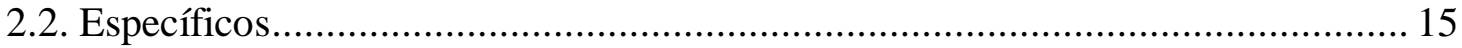

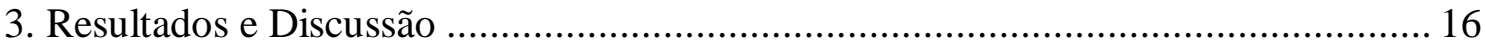

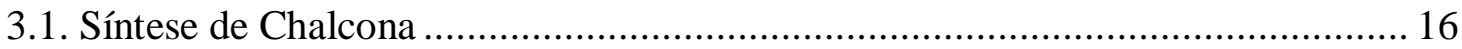

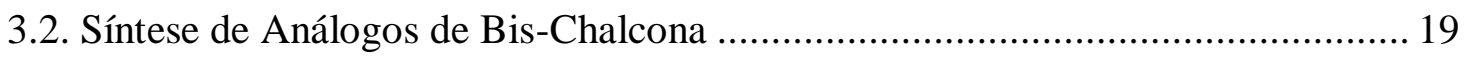

3.2.1. Etapa de Proteção (MÉTODO A) ................................................................... 19

3.2.2. Síntese de Análogos de Bis-Chalconas (MÉTODO A) .................................... 22

3.2.3. Síntese de Análogos de Bis-Chalcona via Esterificação com Cloreto de Ácido

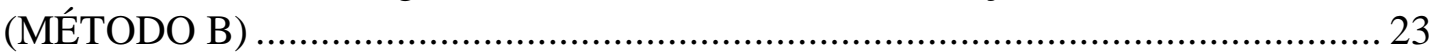

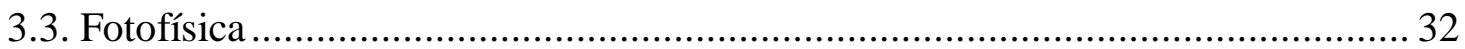

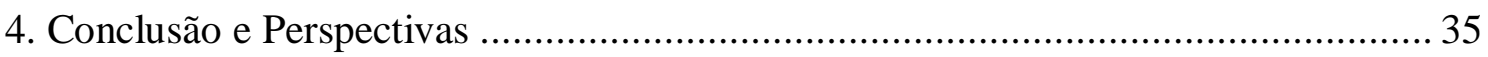

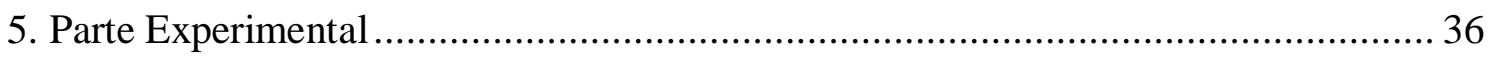

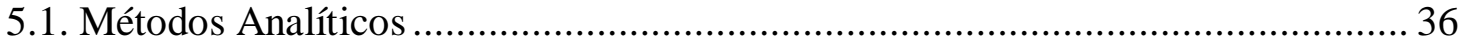

5.1.1. Ressonância Magnética Nuclear ........................................................................ 36

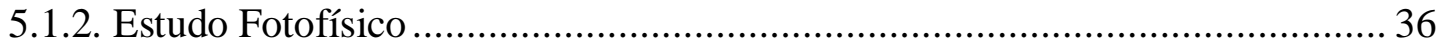

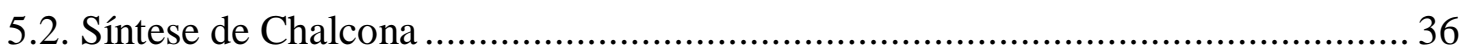

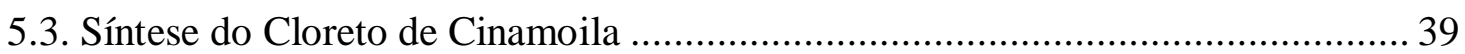

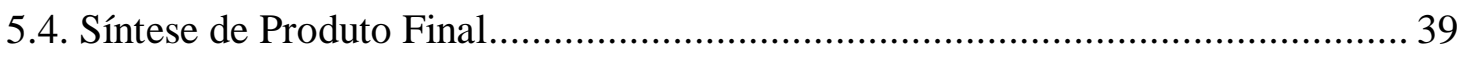

6. Referências Bibliográficas...................................................................................... 43

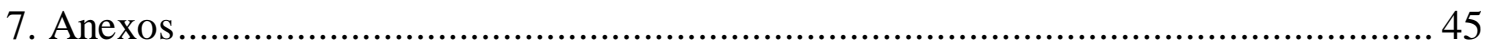

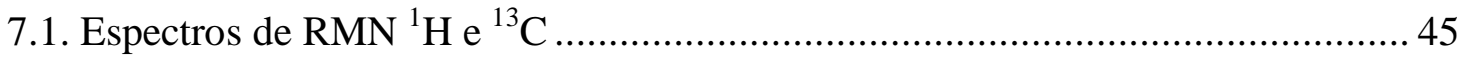

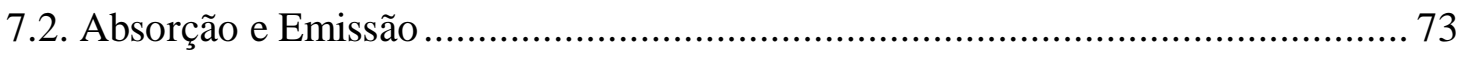




\section{Índice de Figuras}

Figura 1.Classe dos "flavonoides menores" e suas características estruturais (adaptado da referência 1) 1

Figura 2. Exemplo de chalcona isolada da raiz do alcaçuz. (adaptado da referência 9).

Figura 3. Estrutura simplificada dos isômeros E/Z das chalconas (adaptado da referência 14). 3

Figura 4. Exemplo de chalcona com propriedade anti-inflamatória (adaptada da referência 25) 5

Figura 5. chalcona estudada por Gaber (adaptado da referência 26)..... .6

Figura 6. Exemplo simplificado de bis-chalcona: dichalcona (A) e isodichalcona (B). (Adaptado da referência 29). .7

Figura 7. Exemplo de bis-chalcona simétrica e inibidor seletivo da ABCG2 (retirado da referência 38). .8

Figura 8. Núcleos mais utilizados em sínteses de bis-chalconas simétricas.................... 9

Figura 9. Diagrama de Jablonski simplificado (adaptado da referência 44)...................10

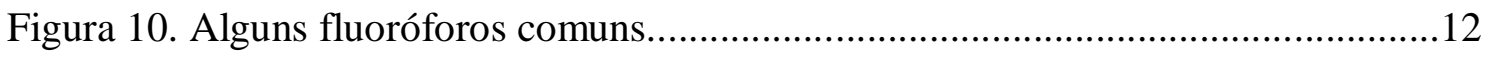

Figura 4. Modelo push-pull (adaptado da referência 45)...........................................13

Figura 5. Estruturas do DMAC e DMA (adaptados das referências 47 e 48)..............12

Figura 6. Arquitetura molecular das chalconas (adaptado da referência 28)...............14

Figura 7. Espectro do composto 6 obtido através de análise de $\mathrm{RMN}-{ }^{1} \mathrm{H}\left(\mathrm{CDCl}_{3}, 600\right.$ $\mathrm{MHz})$.

Figura 8. Espectro da região aromática do composto 9 obtido através de análise de $\mathrm{RMN}-{ }^{1} \mathrm{H}(\mathrm{CDCl} 3,600 \mathrm{MHz})$ 21 
Figura 9. Espectro e expansão da região aromática do primeiro análogo de bis-chalcona

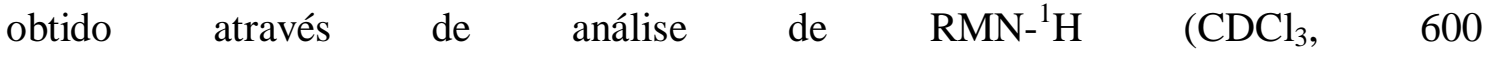
$\mathrm{MHz})$

Figura 10. Espectro e expansão da região aromática do primeiro análogo de bischalcona obtido através de análise de $\mathrm{RMN}-{ }^{1} \mathrm{H}(\mathrm{CDCl} 3,600 \mathrm{MHz})$.

Figura 19. Design de híbrido escopoletina-ácido cinâmico (adaptado da referência 49)

Figura 11. Espectro do composto 18 obtido através de análise de $\mathrm{RMN}-{ }^{1} \mathrm{H}\left(\mathrm{CDCl}_{3}, 600\right.$

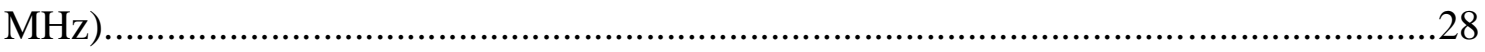

Figura 12. Expansão da região aromática do composto 18 ...........................................29

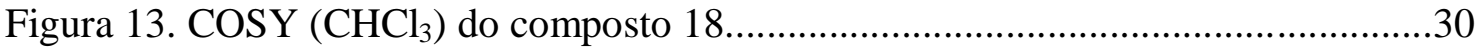

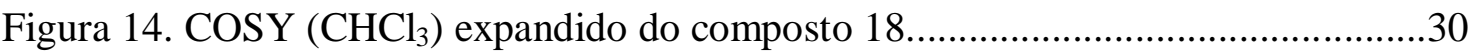

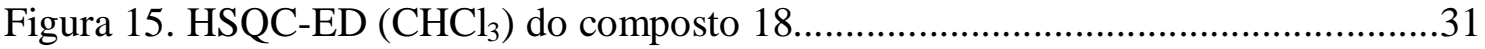

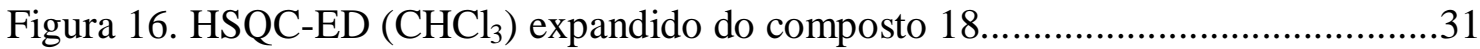

Figura 17. Espectros de absorção e emissão UV/Vis do composto 13............................32 


\section{Índice de Esquemas}

Esquema 1. Mecanismo simplificado da biossíntese da trihidróxichalcona (adaptado da referência 11)

Esquema 2. Mecanismo simplificado da síntese de chalcona: 1) síntese via catálise ácida e básica; 2) síntese de flavona em meio ácido utilizando a 2-hidróxi-acetofenona

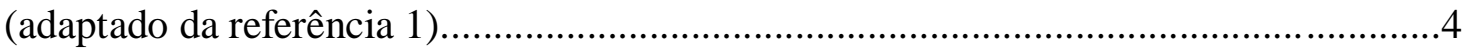

Esquema 3. Mecanismo simplificado da reação de Claisen-Schmidt (adaptado da

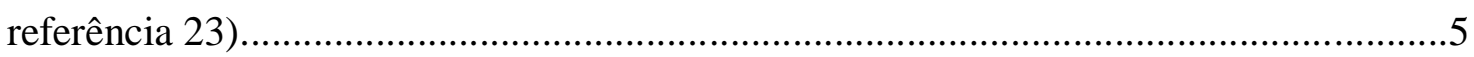

Esquema 4. Bis-chalcona promissora no tratamento anti-malária (Adaptado da

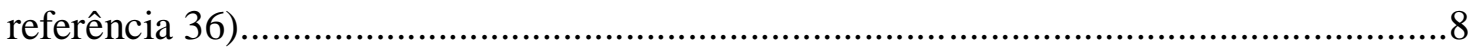

Esquema 5. Metodologia comum para a síntese de bis-chalcona simétrica (adaptado da

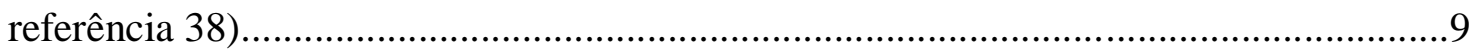

Esquema 6. Síntese das bis-chalconas 1 e 2 a partir do tereftaldeído (Adaptado da

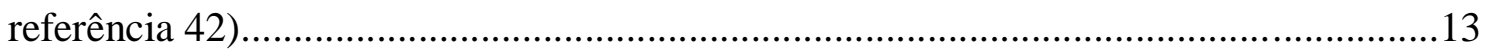

Esquema 7.Rota sintética idealizada para a obtenção do análogo de bis-chalcona..........15

Esquema 8. Mecanismo da reação aldólica mediada por base.......................................16

Esquema 9. Modelo de orbitais segundo a teoria do orbital de fronteira (retirado da

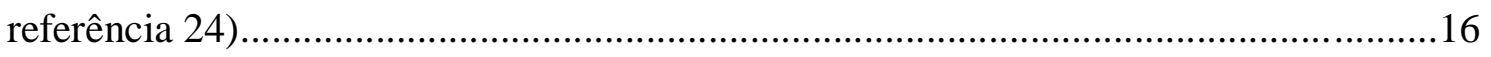

Esquema 10. Mecanismo da etapa de acetilação do fenol.............................................20

Esquema 11. Síntese de bis-chalcona a partir dos compostos 9 e $10 \ldots \ldots \ldots \ldots \ldots \ldots \ldots \ldots \ldots \ldots . . .22$

Esquema 12. Reação de esterificação de um fenol......................................................25 


\section{Índice de Tabelas}

Tabela 1. Chalconas isoladas a partir da síntese descrita por Silva et. al. ${ }^{10}$...................18

Tabela 2. Derivados de chalcona obtidos a partir da reação de acetilação do fenol.......20

Tabela 3. Síntese de análogos de bis-chalconas, seguindo a metodologia de Chen e

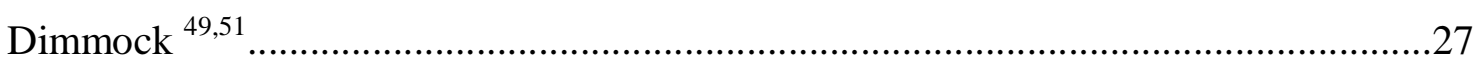

Tabela 4. Resultados obtidos a partir do estudo fotofísico dos sete análogos de bis-

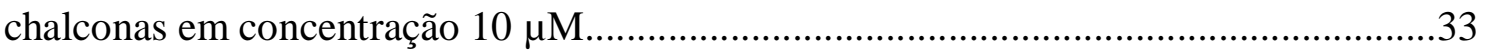




\section{Resumo}

A busca pelo planejamento e modificação molecular de compostos tem grande relevância na química sintética, tornando possível a implementação e otimização de técnicas para a síntese de novos análogos. Diversas estratégias de modificação ou otimização permitem a obtenção de novos análogos ativos de estrutura simplificada. Chalconas são modelos interessantes para o estudo de novas substâncias com potencial aplicação tecnológica, pois representam uma classe de metabólitos de vasta distribuição natural. Estudos recentes reportam a expansão do sistema pi das chalconas originando derivados denominados "bis-chalcona" como protótipos promissores no tratamento de doenças. Entretanto, as bis-chalconas ainda são um campo pouco explorado. Nessa perspectiva, foram sintetizados oito análogos de bis-chalcona partindo da 4hidroxiacetofenona e 3-hidroxiacetofenona, pois o grupo fenol permite a versatilidade sintética para a síntese de novos análogos. Os análogos de bis-chalcona obtidos foram caracterizados por experimentos 2D de ressonância magnética nuclear para melhor clareza quanto à correlação entre os prótons (COSY) e entre hidrogênios e carbonos (HSQC). Finalmente, foram realizados ensaios fotofísicos de absorção e emissão objetivando potencial aplicação tecnológica como em sondas fluorescentes, por exemplo. 


\begin{abstract}
The search for molecular planning and modification of compounds has great relevance in synthetic chemistry, making possible to implement and optimize the techniques for the synthesis of new analogs. Several modification or optimization strategies allow the acquisition of new active analogues of simplified structure. Chalcones are interesting models for the study of new substances with potential technological application, since they represent a class of metabolites of vast natural distribution. Recent studies have reported the expansion of the chalcone pi system originating "bis-chalcone" derivatives as promising prototypes for the treatment of diseases. However, bis-chalcones are still an unexplored field. From this perspective eight analogs of bis-chalcone were synthesized starting from 4-hydroxyacetophenone and 3-hydroxyacetophenone, since the phenol group allows synthetic versatility for the synthesis of novel analogs. The obtained bis-chalcone analogues were characterized by 2D nuclear magnetic resonance experiments for better clarity regarding the correlation between the protons (COSY) and between hydrogens and carbons (HSQC). Finally, photophysical absorption and emission tests were carried out aiming at the potential technological application as fluorescent probes, for example.
\end{abstract}




\section{Referencial Teórico}

\subsection{Chalcona}

Chalconas (1,3-diaril-2-propen-1-ona) são metabólitos naturais pertencentes à família dos flavonoides, mais conhecidos como "flavonoides menores", grupo que inclui as 2-hidróxichalcona, 2-OH-dihidrochalcona, 2'-OH-retro-chalcona, auronas e auronóis (Figura 1). Para efeito didático, atribui-se a letra A para o fragmento proveniente da acetofenona, enquanto a letra B corresponde à fração do aldeído aromático. $^{1}$<smiles>O=C(/C=C/c1ccccc1)c1ccccc1O</smiles>

2-OH-chalcona<smiles>O=C(CCc1ccccc1)c1ccccc1O</smiles>

2-OH-dihidrochalcona<smiles>O=C(/C=C/c1ccccc1O)c1ccccc1</smiles>

2'-OH-retro-chalcona<smiles>O=C1/C(=C/c2ccccc2)Oc2ccccc21</smiles>

Aurona<smiles>O=C(c1ccccc1)c1oc2ccccc2c1O</smiles>

Auronol

Figura 18.Classe dos "flavonoides menores" e suas características estruturais (adaptado da referência 1).

As chalconas são consideradas precursores na biossíntese dos flavonóis e ocorrem naturalmente em pigmentos de pétalas, folhas, frutas e raízes como nas espécies Angelica, Glycyrrhiza, Piper e Ruscus que vem sendo utilizadas em muitos tratamentos médicos na Ásia, África e América do Sul. ${ }^{2,3}$

Chalconas apresentam propriedades antioxidante, ${ }^{4}$ anti-inflamatória, 5 antiinfeciosa, ${ }^{6}$ antibiótica, ${ }^{7,8}$ dentre outras. A licochalcona A (Figura 2) é um

\footnotetext{
${ }^{1}$ Grotewold, E. (2006). The Science of Flavonoids. New York. Springer Science + Business Media, Inc.

${ }^{2} \mathrm{Ni}$, L.; Meng, C. Q.; Sikorski, J. A.; Exp. Opn. 2004, 14, 1669-1691.

3 Brown, D. (1995). Encyclopedia of Herbs and Their Uses. New York. Folkard C (Ed.) Dorling Kindersley Publishing, Inc.

${ }^{4}$ Haraguchi, H.; Ishikawa, H.; Mizutani, K.; Tamura, Y.; Kinoshita, T.; Bioorg. Med. Chem. 1998, 6(3), 339-347.

${ }^{5}$ Zhao, F.; Nozawa, H.; Daikonnya, A.; Kondo, K.; Kitanaka, S.; Biol. Pharm. Bull. 2003, 26(1), 61-65.

${ }^{6}$ Zhai, L.; Chen, M.; Blom, J.; Theander, T. G.; Christensen, S. B.; Kharazmi, A.; J. Antimicro. Chemother. 1999, 43, 793-803.

${ }^{7}$ Haraguchi, H.; Tanimoto, K.; Tamura, Y.; Mizutani, K.; Kinoshita, T.; Phytochem. 1998, 48(1), 125129.

${ }^{8}$ Chiaradia, L. D.; Martins, P. G. A.; Cordeiro, M. N. S.; Guido, R. V. C.; Ecco, G.; Andricopulo, A. D.; Yunes, R. A.; Vernal, J.; Nunes, J. R.; Terenzi, H.; J. Med. Chem. 2012, 55, 390-402.
} 
antioxidante forte isolado da raiz do alcaçuz e apresenta forte atividade contra bactérias como Bacillus subtilis, Staphylococcus aureus e Micrococcus luteus. Esse efeito está relacionado à característica estrutural do fragmento $\alpha, \beta$-insaturado que permite a conjugação entre os grupos aromáticos, além de sofrer adição de Michael ao grupo tiol em organismos vivos, por exemplo. ${ }^{9},{ }^{10}$

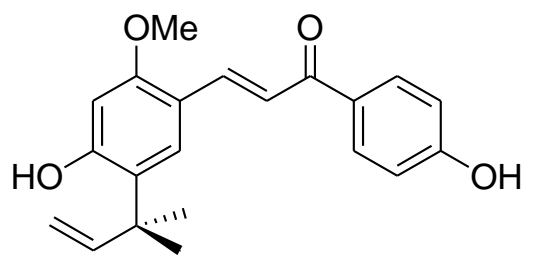

Licochalcona A

Figura 19. Exemplo de chalcona isolada da raiz do alcaçuz. (adaptado da referência 9).

Chalconas podem ser obtidas na natureza por meio da condensação da $p$-Cumaroil-CoA - um derivado da $L$-fenilalanina - com três moléculas de Malonil-CoA. A reação é catalisada pela chalcona sintase (CHS) que está presente no interior das células nas plantas, mas pode ser ativada apenas a nível proteico com auxílio de radiação UV e eliciadores bióticos que induzem a biossíntese do flavonóide a nível de transcrição. ${ }^{11}$

O Esquema 1 demonstra a rota biossíntética da trihidróxichalcona descrita por Dao et. al. ${ }^{12}$ na qual a produção da chalcona requer a condensação de uma molécula de p-Cumaroil-CoA e três moléculas de Malonil-CoA catalisada pela CHS. A reação inicia com a transferência da fração cumaroil a partir da molécula inicial de $p$-Cumaroil-CoA ao tiol no sítio ativo da cisteína (Cys164) presente na enzima. Após três etapas sequenciais de condensação descarboxilativa com o Acetil-CoA proveniente da Malonil-CoA, uma condensação de Claisen intramolecular regioespecífica forma um novo anel de seis membros a partir do policetídeo para gerar a chalcona. ${ }^{11,12,13}$

\footnotetext{
${ }^{9}$ Nowakowska, Z; Eur. J. Med. Chem. 2007, 42, 125-127.

${ }^{10}$ Silva, W. A.; Andrade, C. K. Z.; Napolitano, H. B.; Vencato, I.; Lariucci, C.; de Castro, M. R. C.; Camargo, A. J.; J. Braz. Chem. Soc. 2013, 24(1), 133-144.

${ }^{11}$ Morita, H.; Takahashi, Y.; Nogushi, H.; Abe, I.; Biochem. Biophys. Res. Comm. 2000, 279, 190-195.

${ }^{12}$ Dao, T. T. H.; Linhorst, H. J. M.; Verpoorte, R.; Phytocham. Ver. 2011, 10, 397-412.

${ }^{13}$ Schröder, J.; The Chalcone Stilbene-Synthase type Family of Condensing Enzymes. In: Comprehensive Natural Products Chemistry. Sankawa U, 1999, 749-771.
} 

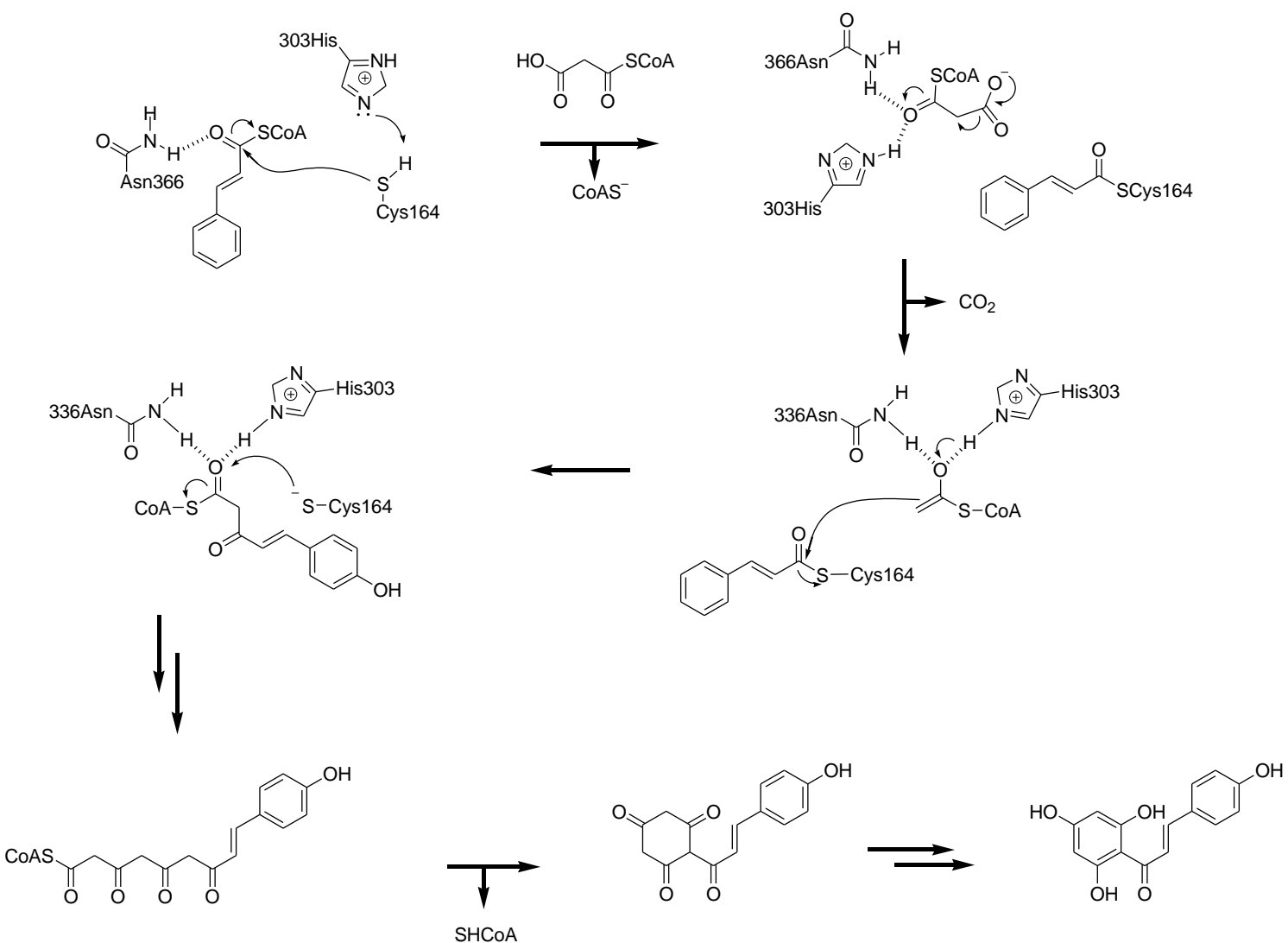

Esquema 13. Mecanismo simplificado da biossíntese da trihidróxichalcona (adaptado da referência 11).

A Figura 3 ilustra as duas formas isoméricas das chalconas, na qual o isômero trans é considerado termodinamicamente favorável. O trabalho de Larsen et al. ${ }^{14} \mathrm{a}$ respeito dos isômeros $E$ e $Z$ das chalconas aponta que a atividade contra o Plasmodium falciparum é praticamente inativa nos estereoisômeros $Z$. Tal fato pode ser explicado pela substituição no fragmento $\alpha, \beta$-insaturado ou até fatores conformacionais, uma vez que estudos mostram que substituintes alquila influenciam de maneira secundária a atividade anti-parasita das chalconas. ${ }^{15}$<smiles>C=CC1CC1</smiles>

Isômero $E$<smiles>O=C(/C=C/c1ccccc1)c1ccccc1</smiles>

Isômero $Z$

Figura 20. Estrutura simplificada dos isômeros E/Z das chalconas (adaptado da referência 14).

\footnotetext{
${ }^{14}$ Larsen, M.; Kromann, H.; Kharazmi, A.; Nielsen, S. F.; Bioorg. Med. Chem. Lett. 2005, 15, 4858-4861.

${ }^{15}$ Nielsen, S. F.; Kharazmi, A.; Christensen, S. B.; Bioorg. Med. Chem. 1998, 6, 937-945.
} 
Chalconas foram sintetizadas pela primeira vez em laboratório no fim dos anos 1800 , mas ainda não haviam sido isoladas de fonte natural até $1910 .^{16}$

No âmbito da química sintética, pode-se facilmente obter chalconas por meio da condensação aldólica tipo Claisen-Schmidt entre uma acetofenona e o benzaldeído na presença de um catalisador ácido ou básico (Esquema 2). Por ser uma síntese de baixo custo, a condensação aldólica catalisada por base é usualmente a rota preferida para a síntese da chalcona, ${ }^{17,18}$ Adicionalmente alguns estudos demonstram maior rendimento quando comparada com catalisadores ácidos como $\mathrm{HCl} \mathrm{e} \mathrm{H}_{2} \mathrm{SO}_{4} \cdot{ }^{19}, 20,21,22$ Ademais, a catálise ácida pode gerar a ciclização da chalcona, levando à formação de uma mistura racêmica de flavonas quando se utiliza derivados 2-hidróxi-acetofenona (Figura 5). ${ }^{1}$<smiles>CC(=O)c1ccccc1O</smiles>

Esquema 14. Mecanismo simplificado da síntese de chalcona: 1) síntese via catálise ácida e básica; 2) síntese de flavona em meio ácido utilizando a 2-hidróxi-acetofenona (adaptado da referência 1).

No Esquema 3 está apresentado o mecanismo simplificado para a condensação aldólica de Claisen-Schmidt em meio básico envolve a adição de um enolato (nucleófilo) a um aldeído ou cetona (eletrófilo). Inicialmente, a base abstrai um hidrogênio ácido da cetona formando o respectivo enolato que ataca o grupo carbonila

\footnotetext{
${ }^{16}$ Shimokoriyama, M.; Flavanones, Chalcones and Aurones. Geissman TA, The Macmillan Company, New York, 1962: 186-313.

${ }^{17}$ Evranos Aksöz, B.; Ertan, R.; J. Pharm. Sci. 2011, 36, 223-242.

${ }^{18}$ Davey, W.; Gwilt, J. R.; J. Chem. Soc. 1957, 1008-1014.

${ }^{19}$ Saiyad, I. Z.; Nadkarni, D. R.; Wheeler, T. S.; J. Chem. Soc. 1937, 1737-1739.

${ }^{20}$ Shenoi, R. B.; Shah, R. C.; Wheeler, T. S.; J. Chem. Soc. 1940, 247-251.

${ }^{21}$ Feuestein, W.; Kostanecki, S. V.; Chem. Ber. 1898, 31.

${ }^{22}$ Mahal, H. S.; Enkataraman, K.; J. Chem. Soc. 1933, 616-617.
} 
levando ao produto aldólico ( $\beta$-hidróxi-carbonila). Posteriormente, o grupo hidróxi é eliminado por mecanismo $\mathrm{E}_{1} \mathrm{CB}$ e forma a cetona $\alpha, \beta$-insaturada. ${ }^{23,}{ }^{24}$ Essa reação é possível devido à presença do oxigênio que faz com que o HOMO do carbono seja mais reativo, aumentando sua energia ao doar elétrons não ligantes para o orbital $\pi^{*} \mathrm{C}=\mathrm{C} .{ }^{25}$

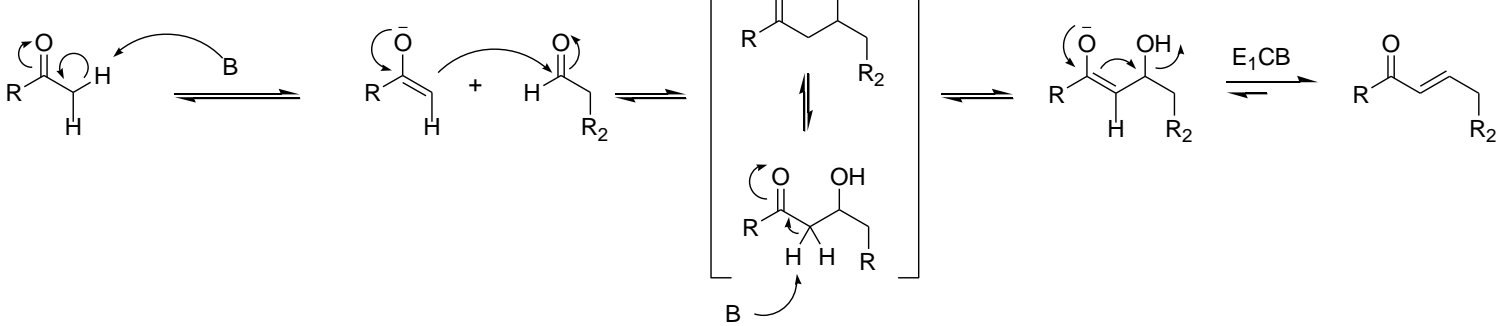

Esquema 15. Mecanismo simplificado da reação de Claisen-Schmidt (adaptado da referência 23).

Ao longo dos anos os estudos a respeito das propriedades das chalconas tem demonstrado o amplo espectro de sua potencial aplicação. Em 2008, Chiaradia et. al. ${ }^{26}$ avaliaram o poder de inibição de chalconas sintetizadas a partir da 2,4,6-trimetóxiacetofenona (TMA) contra a produção de nitrito (NO) no endotélio. Diversas propriedades estruturais das chalconas foram estudadas para melhor entender $\mathrm{o}$ mecanismo de ação das chalconas no tratamento da tuberculose. Cálculos de relação estrutura-atividade (REA) justificam que a melhor atividade dos produtos sintetizados está relacionada com a maior contribuição de HOMO do fragmento TMA (Figura 4), isto é, tendem a atuar como "âncoras" doadoras de elétrons em domínios receptores. ${ }^{25}$

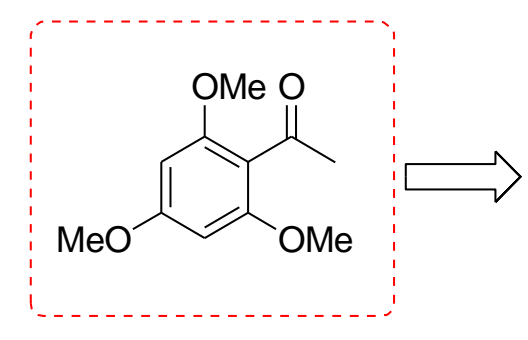

TMA<smiles>COc1cc(OC)c(C(=O)/C=C/c2ccc([N+](=O)[O-])cc2)c(OC)c1</smiles>

Antiinflamatório

Figura 4. Exemplo de chalcona com propriedade anti-inflamatória (adaptada da referência 25).

\footnotetext{
${ }^{23}$ Claisen, L.; Lowman, O.; Zeitschrift für Chemie. 1868, 651-654.

${ }^{24}$ Kürti, L.; Czakó, B. (2005). Strategic Application of Named Reactions in Organic Synthesis. California, Elsevier Inc.

${ }^{25}$ Fleming, I. (2010). Molecular Orbitals and Organix Chemical Reactions. Cambridge, John Wiley \& Sons, Ltd.

${ }^{26}$ Chiaradia, L. D.; dos Santos, R.; Vitor, C. E.; Vieira, A. A.; Leal, P. C.; Nunes, R. J.; Calixto, J. B.; Yunes, R. A.; Bioorg. Med. Chem. 2008, 16, 658-667.
} 
Procurando compreender o comportamento fotofísico da 3-(4dimetilaminofenil)-1-tiofen-2-il-propenona (DMATP), Gaber et. al. ${ }^{27}$ sintetizaram e avaliaram alguns parâmetros da DMATP em solventes de diversas polaridades (Figura 5). O aumento da polaridade dos solventes tornava possível o deslocamento batocrômico na banda de UV/Vis, indicando transições permitidas do tipo $\pi \rightarrow \pi^{*}$. O fluxo de elétrons na transferência interna de carga acontecia a partir do grupo dimetilamino para o fragmento tiofeno, evidenciado pelo red shift em solventes polares. Entretanto, o rendimento quântico $(\phi)$ calculado para o DMATP, isto é a razão entre os fótons emitidos e absorvidos, ${ }^{28}$ mostrou-se menor para solventes polares próticos. Isso ocorre devido às interações de hidrogênio entre as moléculas do solvente e o grupo carbonila que se torna mais carregado negativamente após a excitação. ${ }^{29}$

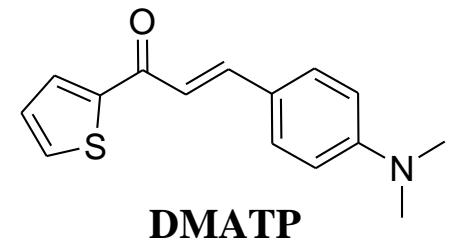

3-(4-dimetilaminofenil)-1-tiofen-2-il-propenona

Figura 5. chalcona estudada por Gaber (adaptado da referência 26).

Tendo em vista o amplo espectro de aplicação das chalconas, diversos outros estudos na literatura apontam para a modificação estrutural de tais compostos, de modo a potencializar suas propriedades auxiliando no design de novos compostos com potencial ação biológica. Dentre as modificações estruturais mais comuns na literatura uma que se destaca é a expansão do sistema conjugado das chalconas, resultando em moléculas classificadas como "bis-chalconas".

\subsection{Bis-chalcona}

Os primeiros trabalhos a respeito das bis-chalconas ocorreram na década de 70 devido ao grande interesse nas propriedades espectrais das chalconas. Na Figura 6 estão exemplos das primeiras bis-chalconas sintetizadas por Tsukerman et al que relatam o estudo luminescente do sistema conjugado expandido das chalconas classificadas no

\footnotetext{
${ }^{27}$ Gaber, M.; El-Daly, S. A.; Fayed, T. A.; El-Sayed, Y. S.; Optics \& Laser Tec. 2008, 40, 528-537.

${ }^{28}$ Skoog, D. A.; West, D. M.; Hooler, F. J.; Stanley, R. C.; Fundamentos de Química Analítica, Tradução da $8^{\mathrm{a}}$ ed.; Ed. Thomson: São Paulo, SP, 2008.

${ }^{29}$ Zhou, B.; Jiyang, P.; Lu, J.; Xing, C.; Arch. Pharm. Chem. Life Sci. 2016, 349, 539-552.
} 
trabalho como dichalconas (1) e isodichalconas (2). ${ }^{30}$ Os experimentos mostraram que a introdução de grupos doadores ou o aumento do sistema conjugado leva a um deslocamento para o vermelho (red shift) significativo nos derivados de bis-chalconas. Os autores acreditam que isso se dá pela rápida diminuição da energia da transição $\pi \rightarrow \pi^{*}{ }^{31}$

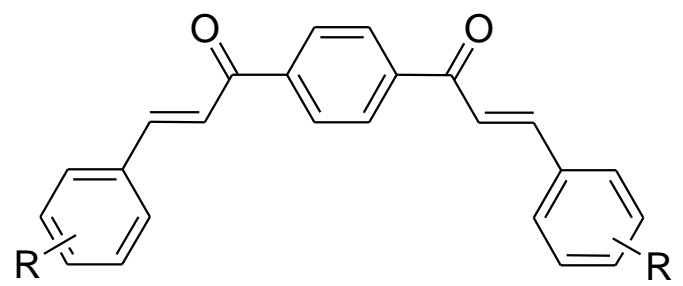

A

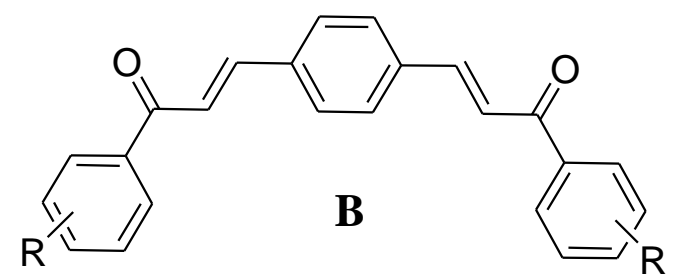

Figura 6. Exemplo simplificado de bis-chalcona: dichalcona (A) e isodichalcona (B). (Adaptado da referência 29).

Devido ao interesse na síntese de heterociclos biologicamente ativos, estudos relatam que as bis-chalconas apresentam propriedades anti-malária, ${ }^{32}$ citotóxica, ${ }^{33}$ antiinflamatória, ${ }^{34}$ antibiótica ${ }^{35}$ e fungicida. ${ }^{36}$

Um exemplo da atividade anti-malária dos análogos de bis-chalconas foi relatado por Domínguez et al. ${ }^{37}$ no qual foram sintetizados análogos a partir de bisuril-acetofenonas com o objetivo de avaliar sua atividade in vitro e in vivo. Os compostos foram sintetizados via condensação aldólica, onde obtiveram rendimentos variados (17-98\%). Entretanto, somente um dos compostos sintetizados foi identificado como o mais ativo nos testes in vitro contra Plasmodium berghei (Esquema 4). Os testes in vivo contra Plasmodium berghei reduziu a parasitemia, adiando a progressão da

\footnotetext{
${ }^{30}$ Tsukerman, S. V.; Maslennikova, V. P.; Nikitchenko, V. M.; Lavroshin, V. F.; Zhurnal Prikladnoi Spektroskopii. 1970, 12(1), 91-96.

${ }^{31}$ Nurmukhmetov, R. N.; Belaits, A. L.; Shigorin, D. N.; Shner, V. F. Zh. Fiz. Khim. 1967, 41, 3107.

${ }^{32}$ Ram, V. J.; Saxena, A. S.; Srivastava, S.; Chandra, S.; Bioorg. Med. Chem. Lett. 2000, 10, 2159-2161.

${ }^{33}$ Modzelewska, A.; Pettit, C.; Achanta, G.; Davidson, N. E.; Huang, P.; Khan, S. R.; Bioorg. Med. Chem. 2006, 14, 3491-3495.

${ }^{34}$ Reddy, M. V. B.; Shen, Y.; Ohkoshi, E.; Bastow, K. F.; Qian, K.; Lee, K.; Wu, T.; Eur. J. Med. Chem. 2012, 47, 97-103.

${ }^{35}$ Husain, A.; Rashid, M.; Mishra, R.; Kumar, D.; Acta Poloniae Pharmaceutica - Drug Research. 2013, 70(3), 443-449.

${ }^{36}$ Mobinikhaledi, A.; Kalhor, M.; Jamalifar, H.; Med. Chem. Res. 2012, 21, 1811-1816.

${ }^{37}$ Domínguez, J. N.; de Domínguez, N. G.; Rodrigues, J.; Acosta, M. E.; Caraballo, N.; León, C.; J. Enzyme Inhib. Med. Chem. 2012, 28(6), 1267-1273.
} 
malária, especula-se que os grupos metóxi presentes nos anéis externos favoreçam a adição de grupos nucleofílicos, o que permite a acumulação de medicamento na heme, tornando-o um regulador da atividade anti-malária. ${ }^{38}$

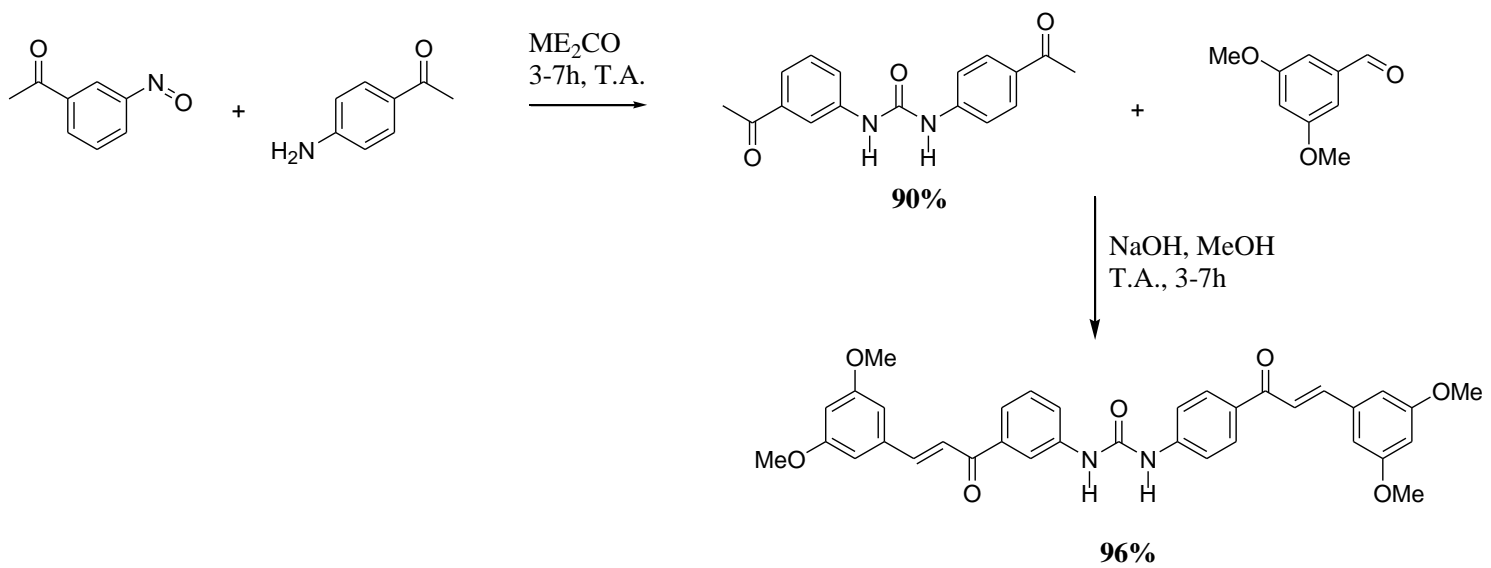

Esquema 16. Bis-chalcona promissora no tratamento anti-malária (Adaptado da referência 36).

Tangente às propriedades citotóxicas dos dienos conjugados, Di Pietro et. al. ${ }^{39}$ relatam a síntese e screening de duas séries de bis-chalconas simétricas para sua habilidade em inibir o efluxo de fármaco a partir de células HEK293 transfectadas com ABCG2. A Figura 7 mostra duas dessas bis-chalconas simétricas.<smiles>COc1cccc(OC)c1/C=C/C(=O)c1ccc(C(=O)/C=C/c2c(OC)cccc2OC)cc1</smiles>

$\mathbf{C}$<smiles>COc1cc(OC)cc(C(=O)/C=C/c2ccc(/C=C/C(=O)c3cc(OC)cc(OC)c3)cc2)c1</smiles>

D<smiles>COc1ccc2[nH]cc(CCNC(=O)c3cc(=O)c4c(OCc5ccc(Br)cc5)cccc4o3)c2c1</smiles>

$\mathbf{E}$

Figura 7. Exemplo de bis-chalcona simétrica e inibidor seletivo da ABCG2 (retirado da referência 38).

ABCG2 é uma proteína da membrana celular composta de 655 aminoácidos, constituindo a metade de um transportador que contém apenas um domínio de ligação de nucleotídeos citosólica e um domínio transmembrana com seis extensões $\alpha$ helicoidais. ${ }^{38,40}$ A Figura 8 ilustra um inibidor seletivo (E) previamente desenvolvido e

\footnotetext{
${ }^{38}$ Domínguez, J. N.; León, C.; Rodrigues, J.; de Domínguez, N. G.; Gut, J.; Rosenthal, P. J.; J. Med. Chem. 2005, 48, 3654-3658.

${ }^{39}$ Winter, E.; Neuenfeldt, P. D.; Chiaradia-Delatorre, L. D.; Gauthier, C.; Yunes, R. A.; Nunes, R. J.; Creczynski-Pasa, T. B.; Di Pietro, A.; J. Med. Chem. 2014, 57, 2930-2941.

${ }^{40}$ Natarajan, K.; Xie, Y.; Baer, M. R.; Ross, D. D.; Biochemical Pharmacology. 2012, 83, 1084-1103.
} 
estudado por sua eficácia em inibir o efluxo de fármaco mediado pela ABCG2. ${ }^{41}$ Os resultados da avaliação biológica em células tumorais mostraram que os dois compostos mais promissores ( $\mathbf{C}$ e $\mathbf{D}$ ) se comportam como inibidores seletivos da proteína ABCG2 e parecem simular o substrato sem serem transportados para o interior das células transfectadas, revelando um mecanismo diferente do apresentado por inibidores já conhecidos. ${ }^{38}$

A síntese das bis-chalconas se dá usualmente pela escolha de um núcleo aromático que permita a condensação aldólica, geralmente tereftaldeído ou diacetilbenzeno (Figura 8).<smiles>O=Cc1ccc(C=O)cc1</smiles>

Tereftaldeído<smiles>CC(=O)c1ccc(C(C)=O)cc1</smiles>

Diacetilbenzeno

Figura 8. Núcleos mais utilizados em sínteses de bis-chalconas simétricas.

O uso de tais substratos permite a preparação de dois derivados que se diferenciam estruturalmente no posicionamento das cetonas $\alpha, \beta$-insaturadas. Essa característica estrutural demonstra grande importância nas propriedades biológicas das bis-chalconas. ${ }^{38}$ Diversas condições para a síntese de bis-chalconas simétricas foram reportadas na literatura, tais como: micro-ondas, ${ }^{42}$ ultrassom, ${ }^{43}$ catálise ácida ${ }^{44}$. O Esquema 4 ilustra a metodologia mais comum para a síntese de bis-chalcona simétrica, que envolve a reação entre $1 \mathrm{~mol}$ do núcleo escolhido para $2 \mathrm{~mol}$ de um aldeído ou cetona.

O mecanismo de síntese não é muito diferente do observado para chalconas, uma vez que se processa via condensação de Claisen-Schmidt.
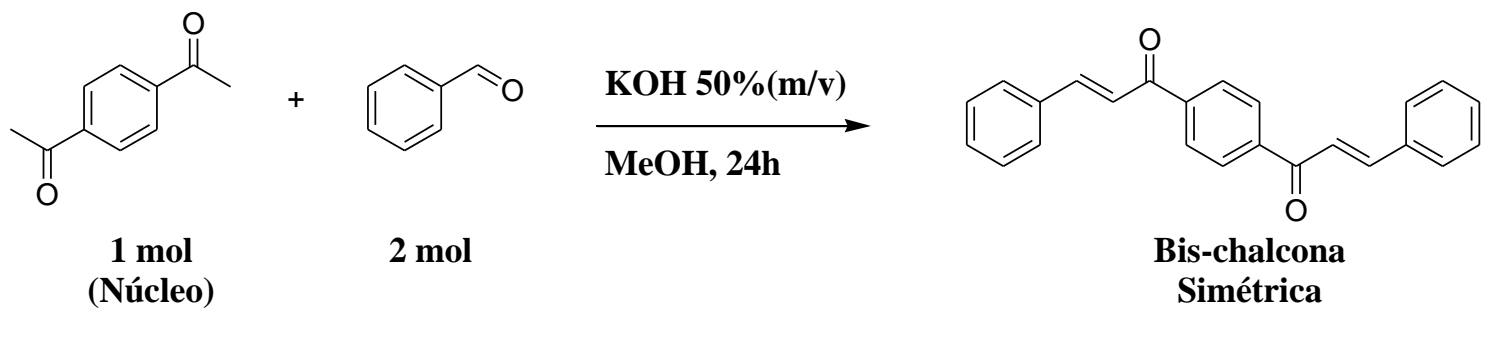

Esquema 17. Metodologia comum para a síntese de bis-chalcona simétrica (adaptado da referência 38).

\footnotetext{
${ }^{41}$ Valdameri, G.; Genoux-Bastide, E.; Peres, B.; Gauthier, C.; Guitton, J.; Terreux, R.; Winnischofer, S. M. B.; Rocha, M. E. M.; Boumendjel, A.; Di Pietro, A.; J. Med. Chem. 2012, 55, 966-970.

${ }^{42}$ Asiri, A. M.; Khan, S. A.; Mat. Lett. 2011, 65, 1749-1752.

${ }^{43}$ Asiri, A. M.; Marwani, H. M.; Alamry, K. A.; Al-Amoudi, M. S.; Khan, S. A.; El-Daly, S. A.; Int. J. Electrochem. Sci. 2014, 9, 799-809.

${ }^{44}$ Siddiqui, Z. N.; Khan, T.; J. Braz. Chem. Soc. 2014, 25(6), 1002-1011.
} 


\subsection{Luminescência}

O fenômeno luminescente é definido como a emissão de luz por uma substância partindo de um estado eletrônico excitado. ${ }^{45}$ Para atingir o estado excitado é necessário o fornecimento de energia para a substância que pode ocorrer por reação química, quimioluminescência e bioluminescência, ou por luz, fotoluminescência. ${ }^{27}$

Os processos que ocorrem entre a absorção e a emissão de luz são usualmente ilustrados pelo diagrama de Jablonski (Figura 10), nomeado em homenagem a Alexander Jablonski, considerado o pai da espectroscopia de fluorescência, que desenvolveu uma teoria fundamental para a elucidação dos processos luminescentes. A Figura 9 apresenta o diagrama de Jablonski simplificado, no qual estão destacados os estados eletrônicos e vibracionais e formas de relaxação. ${ }^{44,27}$

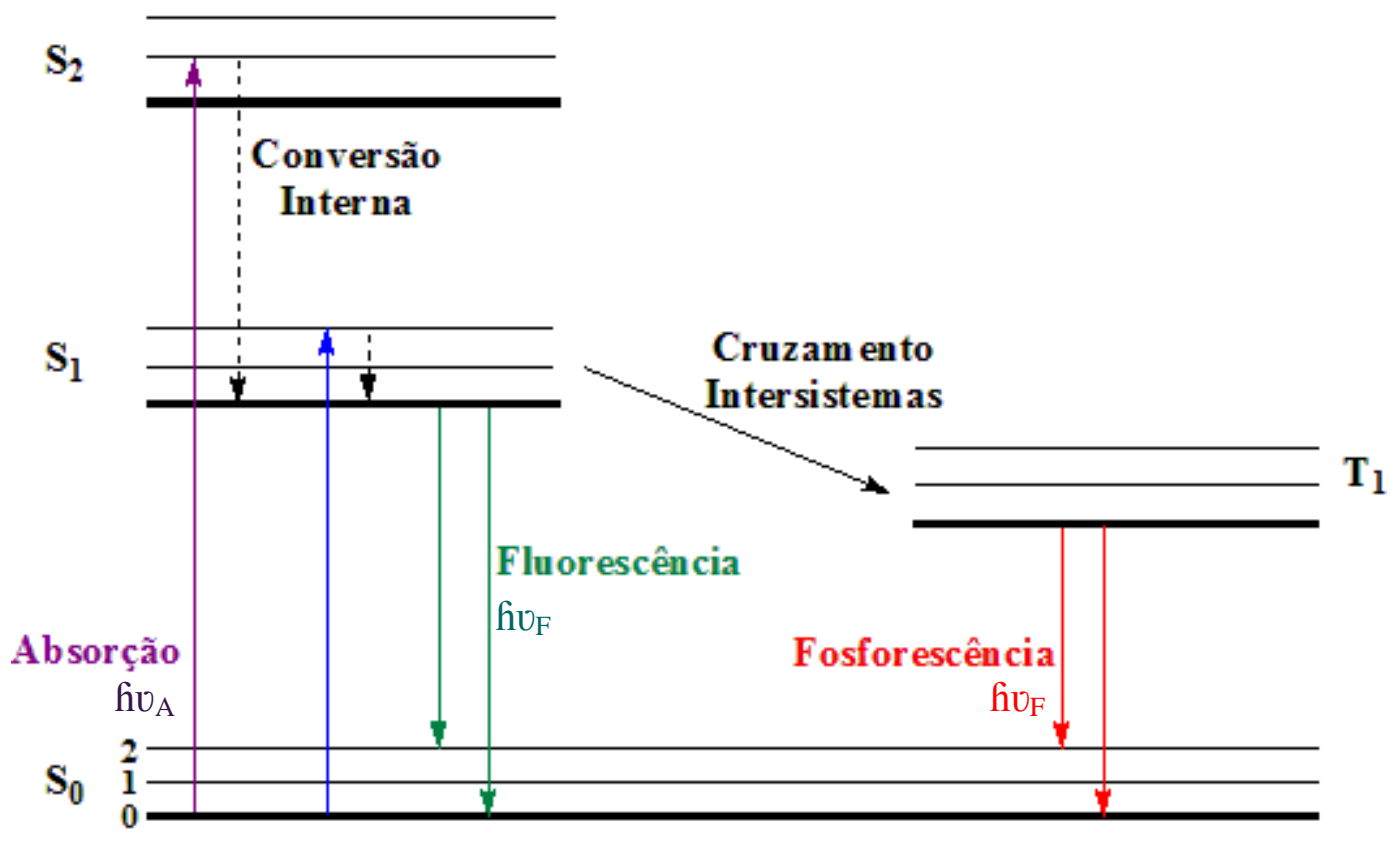

Figura 9. Diagrama de Jablonski simplificado (adaptado da referência 44).

O estado simpleto fundamental, primeiro e segundo estados eletrônicos excitados são designados como $\mathrm{S}_{0} \mathrm{e}, \mathrm{S}_{1}$ e $\mathrm{S}_{2}$, respectivamente. O primeiro estado tripleto é $\mathrm{T}_{1}$. Os mecanismos de relaxação não-radiativos envolvem a conversão interna (rápida relaxação de $S_{2} \rightarrow S_{1}$ ) e o cruzamento intersistemas (inversão de spin a partir de $S_{1} \rightarrow T_{1}$ ). A fosforescência resulta da emissão de fóton no primeiro estado tripleto para o estado simpleto fundamental, $\mathrm{T}_{1} \rightarrow \mathrm{S}_{0}$. Essa é uma transição proibida e lenta $\left(10^{-3}\right.$ a $\left.1 \mathrm{~s}\right)$. Por outro lado, a fluorescência ocorre do estado simpleto excitado para o estado simpleto fundamental, $\mathrm{S}_{1} \rightarrow \mathrm{S}_{0}$, e ocorre de $10^{-9}$ a $10^{-6} \mathrm{~s}^{44}$

\footnotetext{
${ }^{45}$ Lakowicz, J. R.; Principles of Fluorescence Spectroscopy. $3^{\mathrm{a}}$ ed.; Springer: Nova York, USA, 2006.
} 
Uma das características do fenômeno de fluorescência mostra que a energia de emissão de uma substância é tipicamente menor que a energia de absorção, uma vez que a fluorescência ocorre em comprimentos de onda maiores. Esse fenômeno foi observado pela primeira vez por Sir. G. G. Stokes em 1852 e é denominado deslocamento de Stokes. Uma causa comum resulta do rápido decaimento para o menor nível vibracional de $S_{1}$. Adicionalmente, fluoróforos podem apresentar um deslocamento de Stokes mais distantes devido ao efeito do solvente, reações em estado excitado, formação de complexo e/ou transferência de energia. ${ }^{44}$

Compostos que apresentam propriedades fluorescentes são denominados fluoróforos. Na Figura 10, estão dispostos alguns núcleos conhecidos que apresentam esta propriedade, dentre eles a quinina, fluoresceína e laranja de acridina.<smiles>C=CC1CN2CCC1C[C@H]2O</smiles>

Quinina<smiles>O=C1C=CC2=C(c3ccccc3C(=O)O)C3C=CC(O)=CC3OC2=C1</smiles>

Fluoresceína<smiles>CN(C)c1ccc2cc3ccc(N(C)C)cc3nc2c1</smiles>

\section{Laranja de Acridina}

Figura 10. Alguns fluoróforos comuns.

Para que uma molécula orgânica apresente atividade fluorescente, é necessário que apresente alguns requisitos. $\mathrm{O}$ interesse em torno do núcleo chalcona se dá devido à sua estrutura molecular do tipo doador-aceptor-doador (D-A-D) ou push-pull. A Figura 16 ilustra essa arquitetura, no qual o grupo carbonila $\alpha, \beta$-insaturado é o fragmento aceptor, enquanto que os substituintes nos grupos fenil atuam como doadores no estado excitado. ${ }^{46}$ Por esse motivo, as chalconas substituídas apresentam o que é necessário

\footnotetext{
${ }^{46}$ Alvim, H. G. O.; Fagg, E. L.; Oliveira, A. L.; Oliveira, H. C. B.; Freitas, S. M.; Xavier, M. A. E.; Soares, T. A.; Gomes, A. F.; Gozzo, F. C.; Silva, W. A.; Neto, B. A. D.; Org. Biomol. Chem. 2013, 11, 4764.
} 
para a atividade fluorescente. Tais características são: rigidez estrutural, planaridade, ligações $\pi$-conjugadas, grupos aromáticos e anéis condensados. ${ }^{47}$

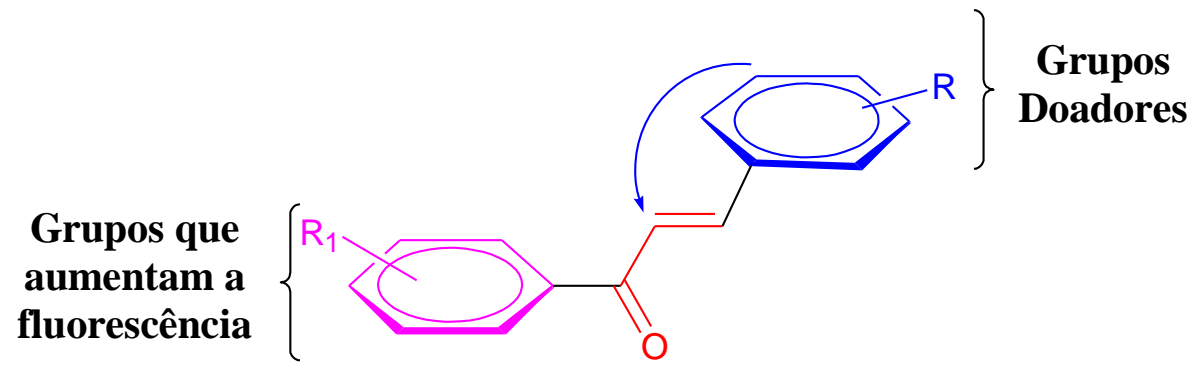

Aceptor

Figura 21. Modelo push-pull (adaptado da referência 45).

A presença de grupos com caráter doador nos anéis aromáticos favorece o fluxo dos elétrons, sendo então possível a transferência interna de carga (TIC) ou intramolecular charge transfer (ICT). Moléculas com fluorescência TIC geralmente contém não apenas um grupo doador de elétrons, mas também grupos aceptores em sua estrutura. Sob certas condições, moléculas contendo não apenas um grupo doador, mas também grupos aceptores podem gerar a transferência interna de carga ou, em alguns casos, a transferência interna de carga torcida (TICT). Compostos que apresentam essas características vem sendo utilizados como sondas fluorescentes para a determinação de DNA. O trabalho de Yang et. al. reporta a investigação da interação de fluorescência TIC do 4'-n,n-dimetilamino-4-amino-chalcona (DMAC) com o DNA em solução aquosa (Figura 12). ${ }^{48}$<smiles>CNc1ccc(/C=C/C(=O)c2ccc(N)cc2)cc1</smiles>

DMAC

4'-n,n-dimetilamino-4-amino-chalcona

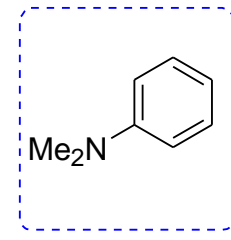

DMA

Figura 22. Estruturas do DMAC e DMA (adaptados das referências 47 e 48).

O DMAC possui uma transferência interna de carga resultante da polarização molecular no estado excitado, uma vez que contêm ambos os grupos doador (dimetilamino) e aceptor (enona) em sua estrutura. ${ }^{47}$ A transferência interna de carga (TIC) é caracterizada pelo aumento no deslocamento de Stokes com aumento na polaridade do solvente apontando para uma forte estabilização no estado excitado da

\footnotetext{
${ }^{47}$ Pavia, D. L.; Lampman, G. M.; Kriz, G. S.; Introduction To Spectroscopy. $3^{\mathrm{a}}$ ed.; Thomson Learning, Inc.: Washington, USA, 2001.

${ }^{48}$ Yang, X.; Shen, G. Yu, R.; Microchemical Journal. 1999, 62, 394-404.
} 
molécula em solventes polares. Consequentemente, a excitação do estado TIC envolve o deslocamento de carga do grupo dimetilanilino (DMA) doador para o fragmento carbonila $\alpha, \beta$-insaturado, e o momento de dipolo do estado excitado resultante é maior que o momento de dipolo do estado fundamental. ${ }^{49}$

Estudos a respeito das propriedades luminescentes das bis-chalconas despertam o interesse por estas apresentarem arquitetura molecular doador-aceptordoador bem como as chalconas. Asiri et. al. ${ }^{41}$ investigaram as propriedades fotofísicas de bis-chalconas sintetizadas a partir do tereftaldeído (Esquema 6). O estudo da fluorescência foi realizado em dimetilformamida (DMF), clorofórmio $\left(\mathrm{CHCl}_{3}\right)$ e diclorometano $\left(\mathrm{CH}_{2} \mathrm{Cl}_{2}\right)$. Os resultados mostram que em DMF, o comprimento de onda máximo $\left(\lambda_{\max }\right)$ nas bandas de absorção aumentam em $10 \mathrm{~nm}$ do composto $\mathbf{F}(350 \mathrm{~nm})$ para o composto $\mathbf{G}$ (360 nm). Isso se dá pela forte capacidade doadora do tiofeno em relação ao furano somado a interação com o solvente. Adicionalmente, o espectro de fluorescência de ambos compostos revela uma dupla fluorescência que pode ser atribuída à transferência interna de carga torcida (TICT). Essas características, somadas ao alto valor do coeficiente de extinção da bis-chalcona $\mathbf{G}\left(\varepsilon=39318 \mathrm{M}^{-1} \mathrm{~cm}^{-1}\right) \mathrm{e}$ deslocamento para o vermelho favorece o design e desenvolvimento de novos fluoróforos doador-aceptor com propriedades de emissão comutável. ${ }^{41,42}$<smiles>[X]c1cc(C)cc(C(C)=O)c1[N+](=O)[O-]</smiles>
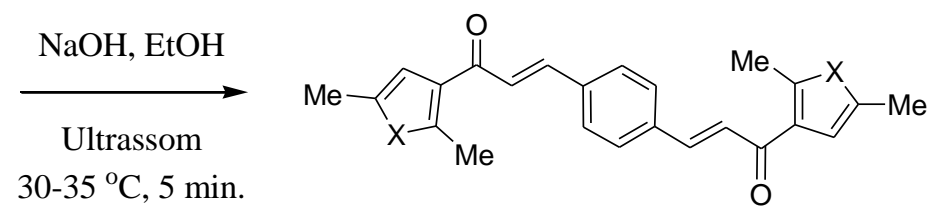

F. $X=O, \mathbf{7 2 \%}$
G. $X=S, 75 \%$

Esquema 18. Síntese das bis-chalconas 1 e $\mathbf{2}$ a partir do tereftaldeído (Adaptado da referência 42).

Um estudo recente de Zhou et. al. ${ }^{28}$ aponta para os efeitos estruturais nas propriedades fluorescentes das chalconas. Primeiro, um grupo doador forte na posição 4 no anel B é essencial para a fluorescência. Segundo, a conformação planar do centro chalcona abrangendo ambos os anéis e a enona é importante, pois compostos impedidos estericamente diminuem significantemente o rendimento quântico. Terceiro, grupos doadores fracos e, ou retiradores no anel A influenciam fortemente no valor do rendimento quântico. Quarto, a interação interna entre hidrogênios com o fragmento cetônico deve ser evitada. Finalmente, um sistema conjugado expandido resulta no deslocamento para o vermelho (Figura 13). ${ }^{28}$

\footnotetext{
${ }^{49}$ Rurack, K.; Dekhtyar, M. L.; Bricks, J. L.; Resch-Genger, U.; Rettig, W.; J. Phys, Chem. A. 1999, 103, 9626-9635.
} 


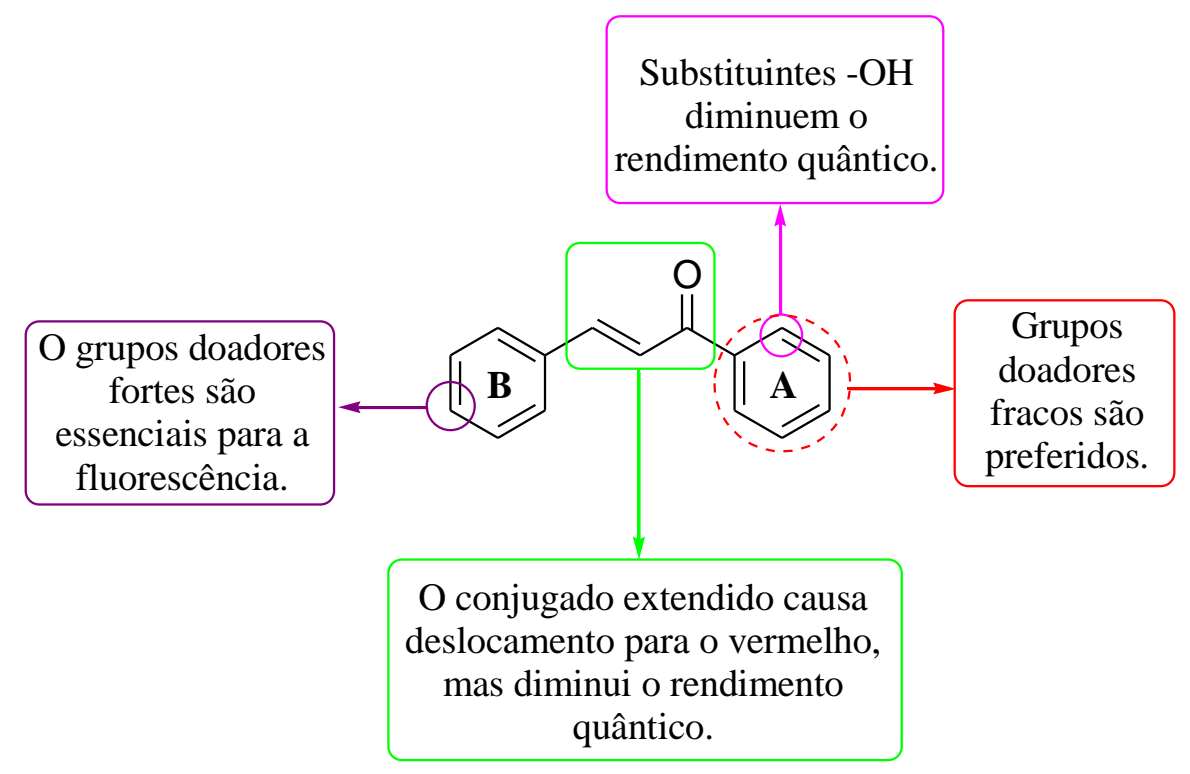

Figura 23. Arquitetura molecular das chalconas (adaptado da referência 28). 


\section{Objetivos}

\subsection{Objetivos Gerais}

Com o intuito de sintetizar tanto análogos simétricos como não simétricos de bis-chalcona, foi pensado um substrato que permitisse a síntese via condensação aldólica. Para tal, idealizou-se um núcleo diferente dos supracitados e que pudesse ser obtido a partir dos reagentes disponíveis em laboratório.

Considerando a simplicidade na obtenção sintética do núcleo chalcona, optou-se por preparar um intermediário com um fragmento fenil éster. O Esquema 6 ilustra a síntese partindo de uma 4-OH-chalcona até o produto análogo de bis-chalcona.

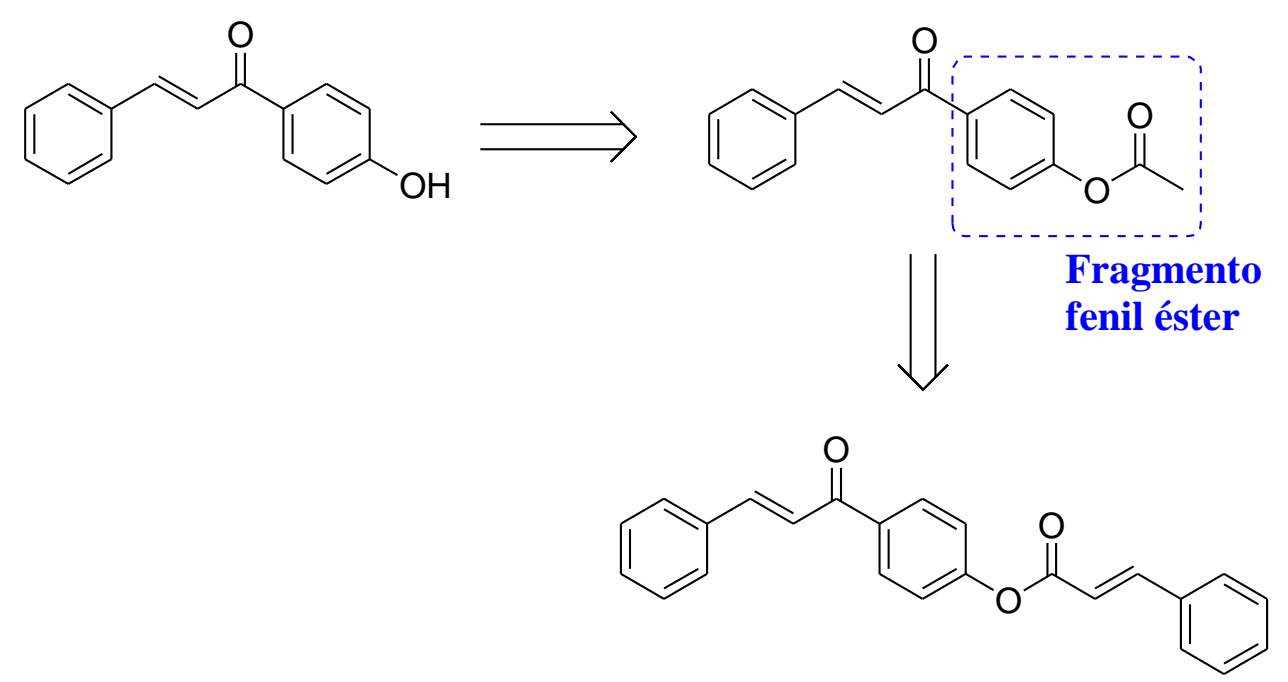

Esquema 19.Rota sintética idealizada para a obtenção do análogo de bis-chalcona.

\subsection{Objetivos Específicos}

- Síntese de novos análogos de bis-chalconas contendo um éster fenílico;

- Expansão do sistema pi das chalconas;

- Avaliação das propriedades fotofísicas por meio de espectroscopia UV/Vis e fluorimetria; 


\section{Resultados e Discussão}

\subsection{Síntese de Chalcona}

Dos diversos métodos de síntese de chalcona existentes na literatura, optou-se pela condensação aldólica descrita por Silva et. al. ${ }^{10}$ - um método simples e rápido no qual reagentes existentes em nosso laboratório foram utilizados.

A metodologia consistiu na adição da 4-hidróxi acetofenona, previamente solubilizada em etanol a uma solução de $30 \%$ de $\mathrm{NaOH}$ em banho de gelo durante 20 minutos. Em seguida, adicionou-se o aldeído e a reação foi mantida sob agitação durante 24 horas. Ao fim do período reacional, o produto foi neutralizado com ácido clorídrico $1 \mathrm{M}$. O precipitado formado foi filtrado e recristalizado em etanol. O mecanismo da reação está ilustrado no Esquema 7 abaixo:

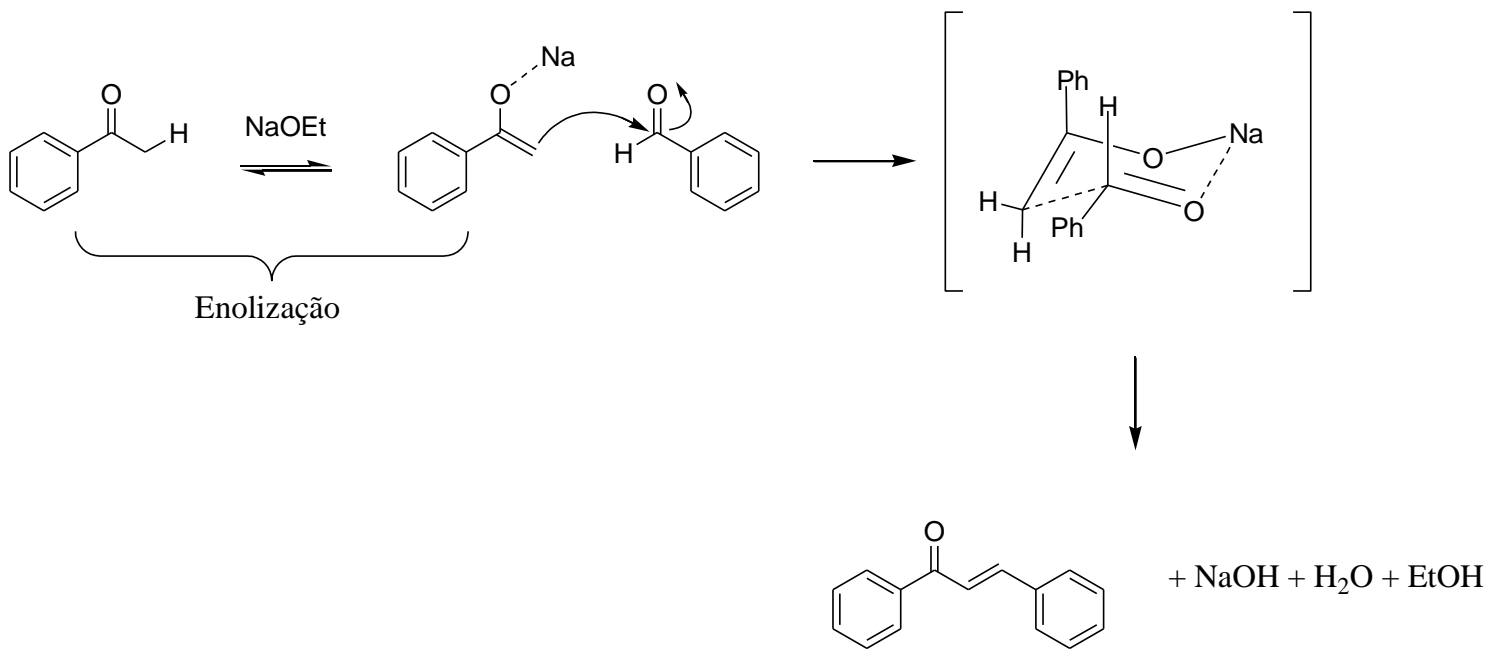

Esquema 20. Mecanismo da reação aldólica mediada por base.

A presença do metal $\left(\mathrm{Na}^{+}\right)$diminui a eletronegatividade do átomo de oxigênio, diminuindo a energia de seu orbital $\mathrm{p}_{\mathrm{z}}$. A diferença de energia entre o orbital $\mathrm{p}_{z}(C)$ e $\mathrm{p}_{z}$ $\left(\mathrm{O} \rightarrow \mathrm{Na}^{+}\right)$aumenta logo eles se misturam menos eficientemente. O Esquema 8 mostra como o LUMO se torna menos energético e menos simétrico, resultando no aumento da reatividade frente à nucleófilos. ${ }^{24}$

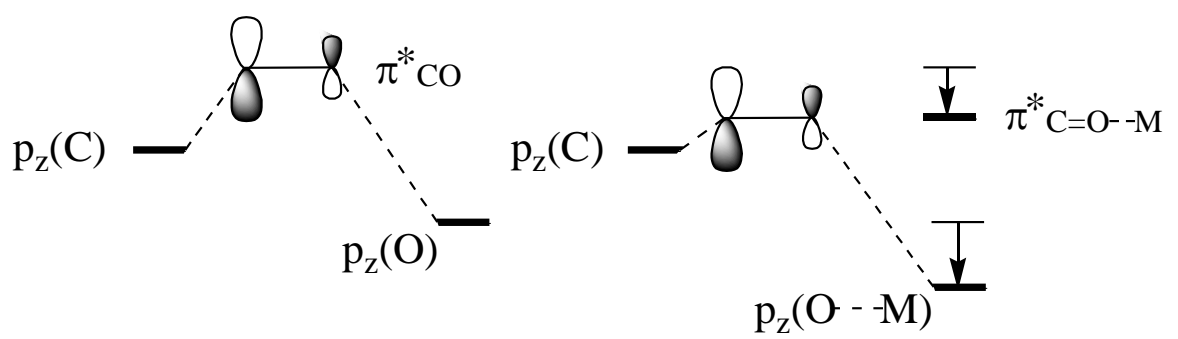

Esquema 21. Modelo de orbitais segundo a teoria do orbital de fronteira (retirado da referência 24) 
A síntese das chalconas foi realizada por meio da reação de condensação aldólica tipo Claisen-Schmidt como já citado na literatura. No total foram sintetizados 8 derivados de chalcona com rendimentos entre $44 \%$ a $82 \%$.

Tabela 5. Chalconas isoladas a partir da síntese descrita por Silva et. al. ${ }^{10}$

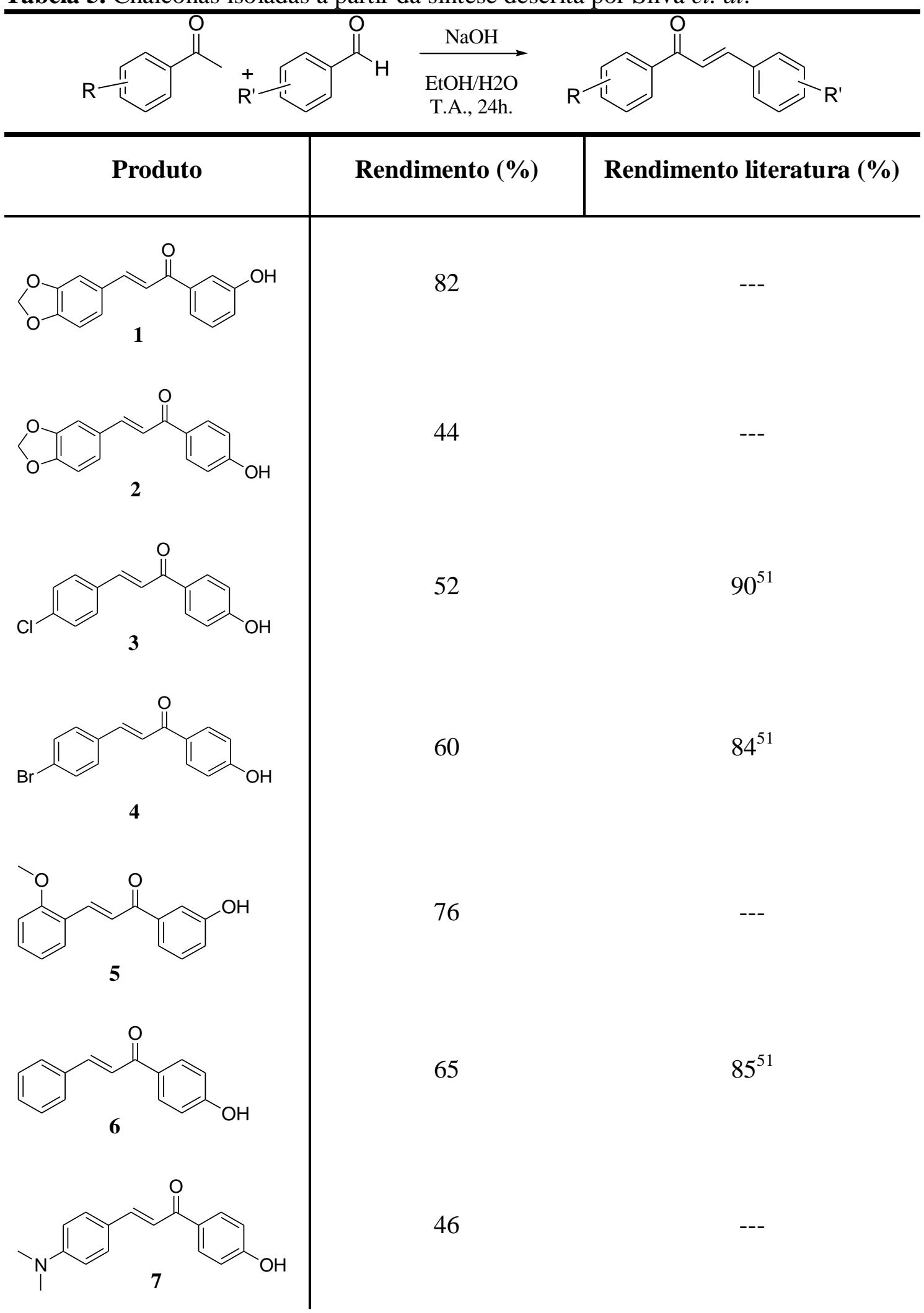


<smiles>CN(C)c1ccc(/C=C/C(=O)c2cccc(O)c2)cc1</smiles>

8

* Todas as reações foram feitas em duplicata.

Os rendimentos obtidos são inferiores aos rendimentos na literatura. Tal fato pode ser justificado pela condição dos reagentes, visto que não foi realizada purificação prévia dos aldeídos sólidos.

A diferença do rendimento entre os compostos 1-2 e 7-8 está associada ao posicionamento da hidroxila no grupo fenol, pois quando posicionada em para confere maior estabilidade ao enolato, necessitando de um maior tempo reacional. O Esquema 7 mostra o estado de transição segundo o modelo Zimmerman-Traxler, de modo que é possível observar a interação entre os átomos de carbono durante a condensação aldólica e entre o metal e os dois oxigênios carbonílicos.

A principal evidência da formação das chalconas foi observada no espectro $\mathrm{RMN}-{ }^{1} \mathrm{H}(600 \mathrm{MHz})$, onde é possível verificar um par de dupletos na região entre 7 e 8 ppm referentes aos hidrogênios olefínicos $\left(J_{\text {Trans }}=15,6 \mathrm{~Hz}\right)$. Para fins de exemplificação, dispõem-se abaixo, na Figura 15, os picos referentes aos hidrogênios do composto 6 . 


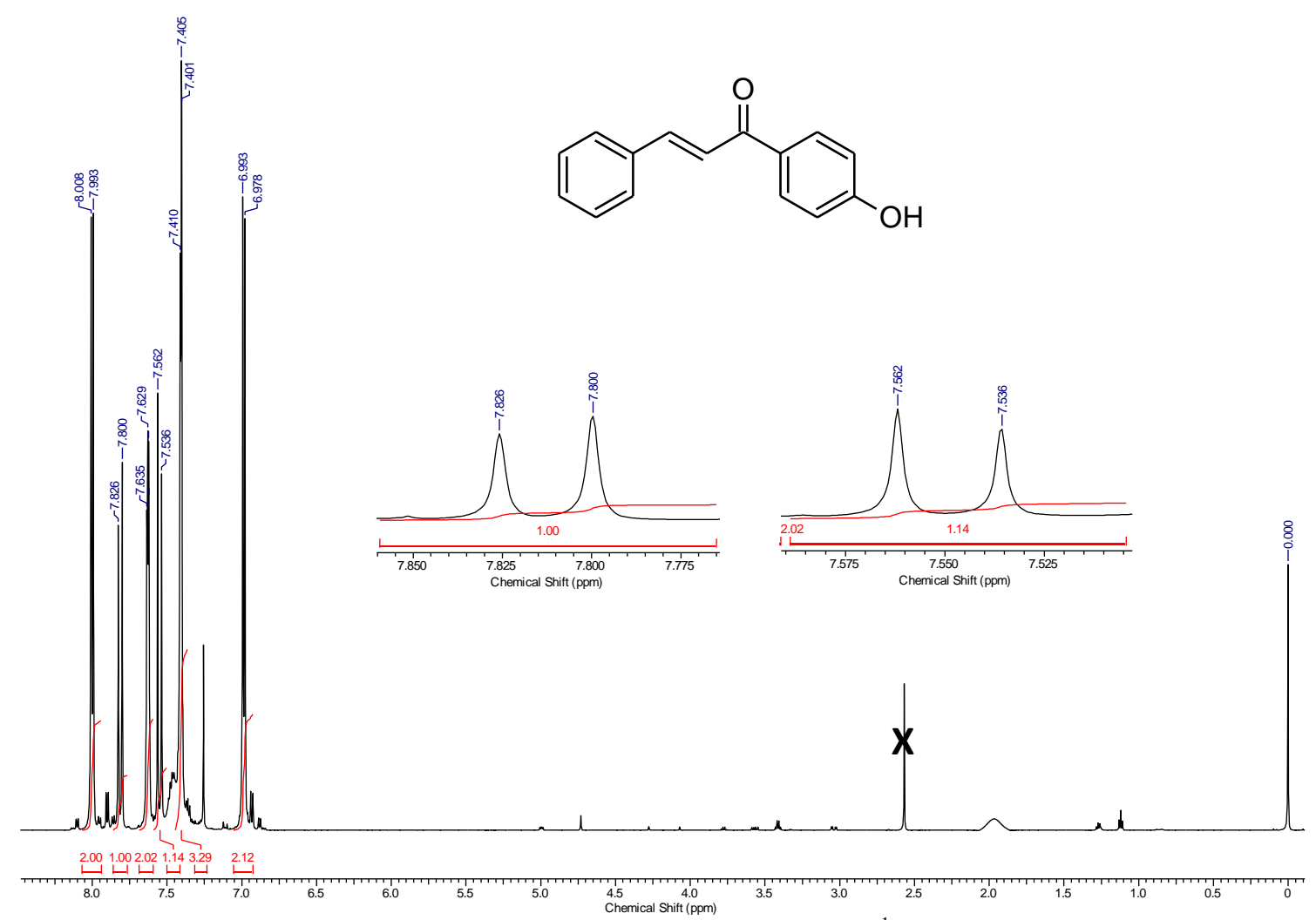

Figura 24. Espectro do composto 6 obtido através de análise de $\mathrm{RMN}-{ }^{1} \mathrm{H}\left(\mathrm{CDCl}_{3}, 600 \mathrm{MHz}\right)$.

As chalconas obtidas foram utilizadas em reações posteriores para a obtenção de bis-chalconas conforme os métodos A e B.

\subsection{Síntese de Análogos de Bis-Chalcona}

\subsubsection{Etapa de Proteção (MÉTODO A)}

Para dar prosseguimento a síntese dos análogos de bis-chalconas, foi realizada a proteção do fenol das chalconas 1 e 2. Para tal, realizou-se uma acetilação com anidrido acético em meio básico. A reação foi acompanhada por CCD (Cromatografia em Camada Delgada) durante 3-6 horas até que o reagente fosse completamente consumido. Por fim, o produto orgânico foi extraído em acetato de etila, evaporado, e purificado por coluna cromatográfica utilizando acetato de etila $20 \%$ /hexano $80 \%$ como eluente. $\mathrm{O}$ mecanismo de reação da etapa de proteção está apresentado no Esquema 8 abaixo:

A primeira etapa dessa reação ocorreu de forma lenta, com a desprotonação do fenol, seguida pelo ataque ao grupo carbonila do anidrido acético. Nesse momento, a estabilidade do produto depende de quão bem os grupos se ligam ao carbono tetraédrico e liberam o ânion $\mathrm{EtOO}^{-}$como grupo de saída. 


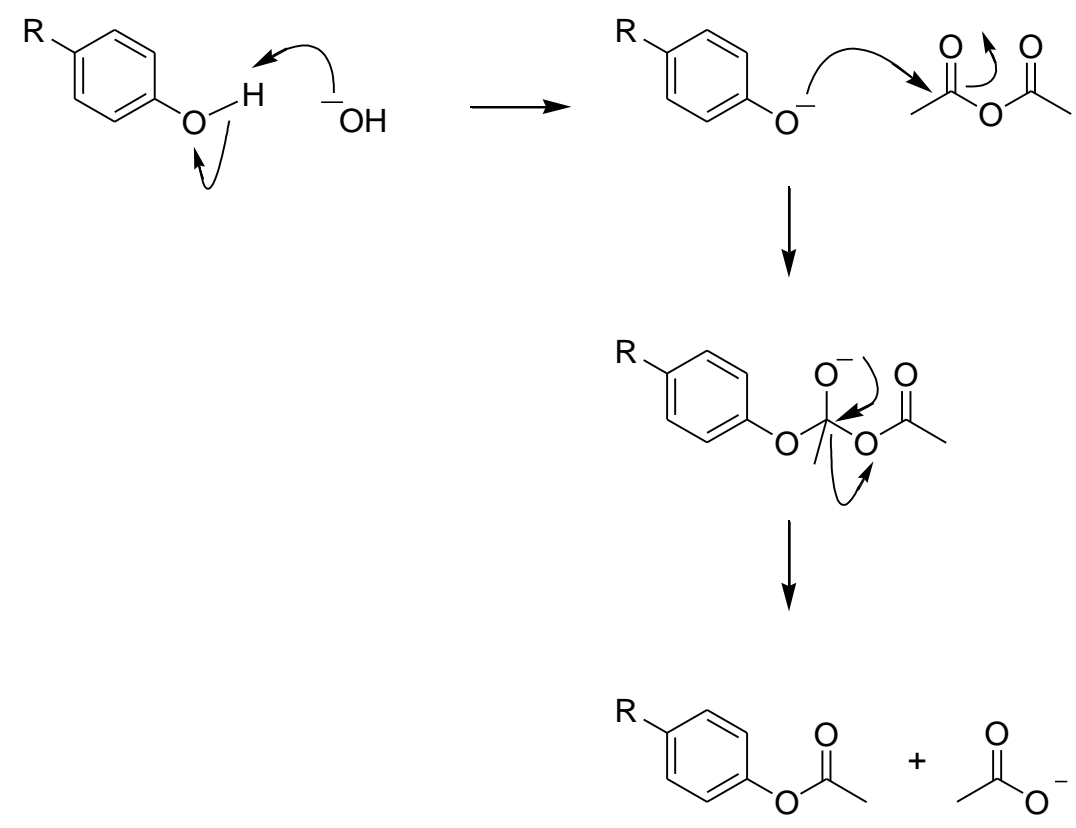

Esquema 22. Mecanismo da etapa de acetilação do fenol.

Tabela 6. Derivados de chalcona obtidos a partir da reação de acetilação do fenol.

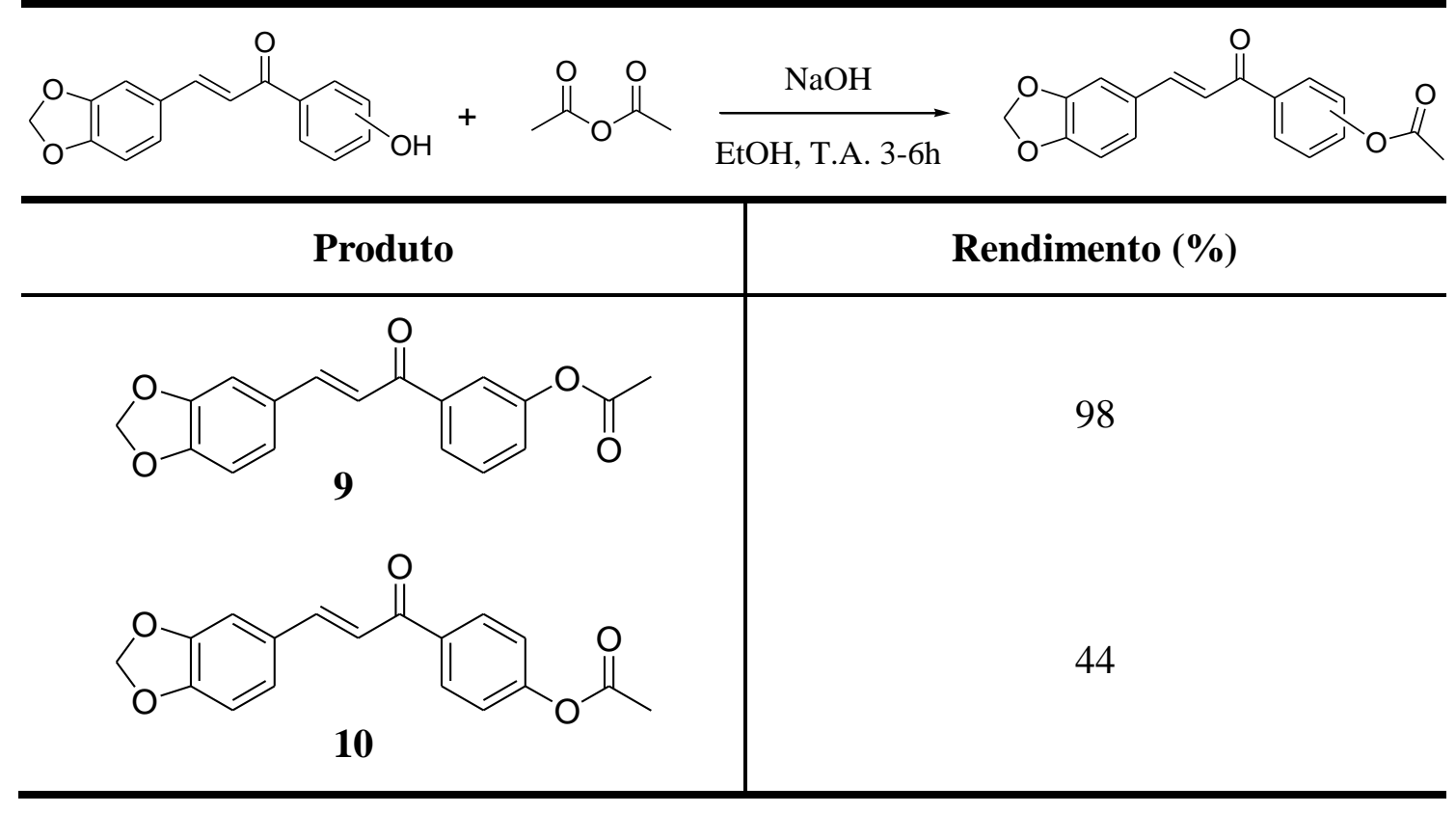

O derivado de chalcona 9 foi caracterizados por RMN- ${ }^{1} \mathrm{H}$. Na Figura 16 observa-se um simpleto característico dos dois hidrogênios do grupo metileno dióxi em 6,12 ppm. Adicionalmente, há um simpleto em 2,32 ppm relativo aos três hidrogênios do grupo acetil. 


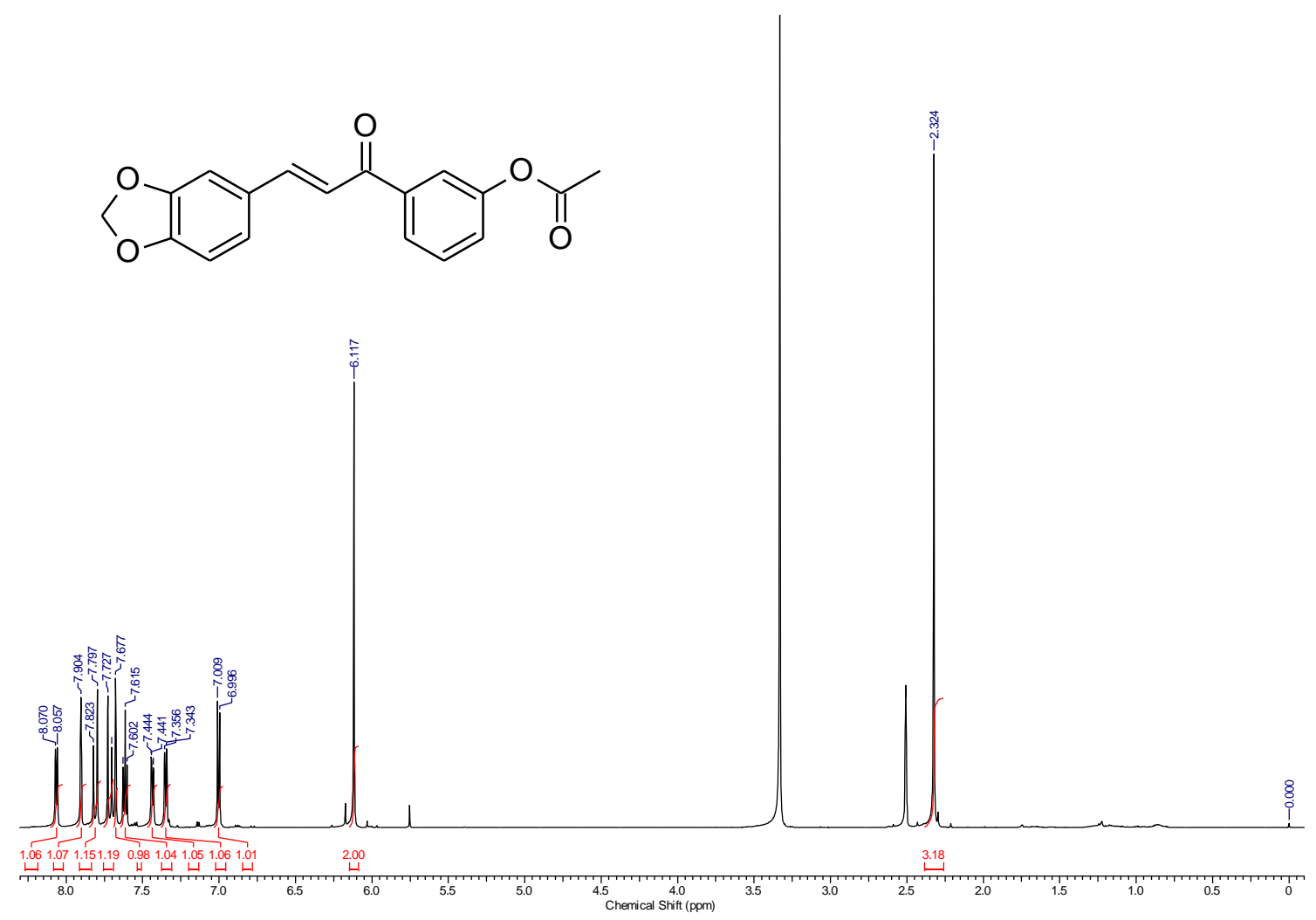

Figura 25. Espectro da região aromática do composto 9 obtido através de análise de $\mathrm{RMN}-{ }^{1} \mathrm{H}(\mathrm{CDCl} 3$, $600 \mathrm{MHz})$.

A Figura 17 trás a expansão da região aromática do derivado $\mathbf{9}$, onde o par de dupletos referente aos hidrogênios olefínicos encontram-se entre 7 e $8 \mathrm{ppm}\left(J_{\text {trans }}=15,6\right.$ $\mathrm{Hz})$.

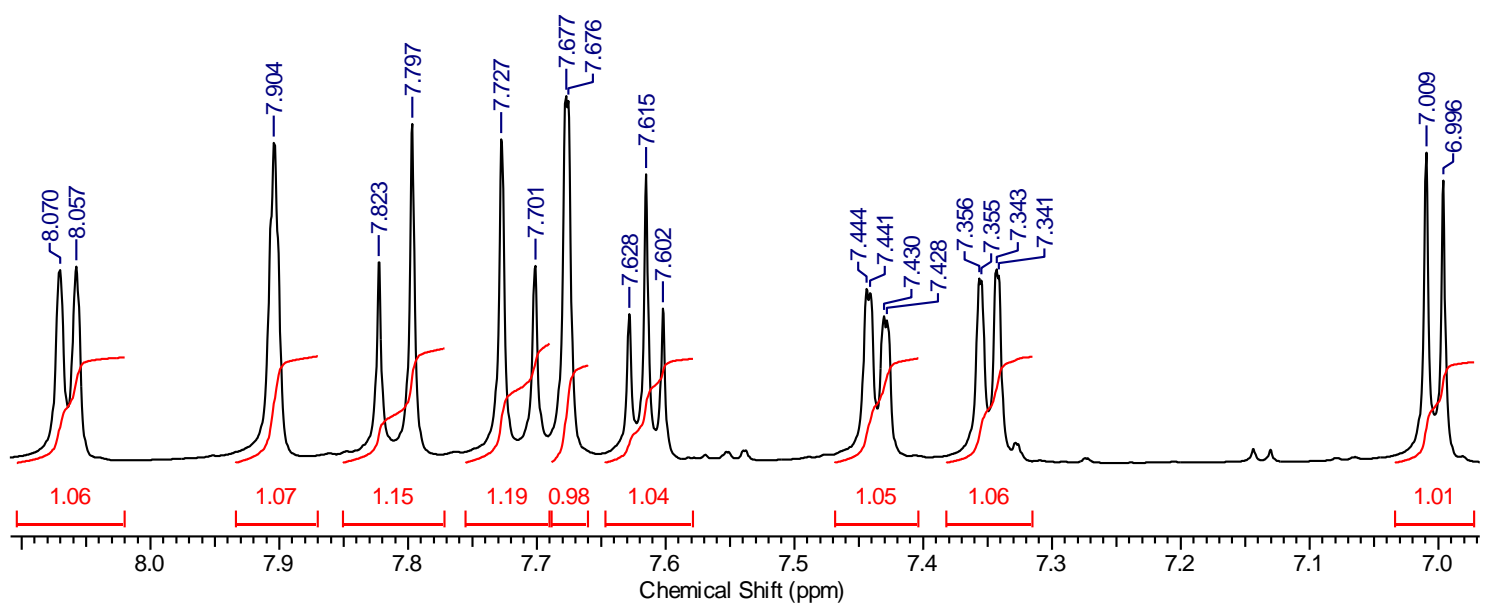

Figura 26. Expansão da região aromática do composto 9. 


\subsubsection{Método A: Síntese de Análogos de Bis-Chalconas}

Partindo dos derivados de chalcona 9 e 10, realizou-se uma última condensação aldólica, desta vez no éster fenílico. Para tal, adicionou-se $10 \mathrm{~mL}$ de etanol seco a pequenos pedaços de sódio metálico em atmosfera inerte, de modo a formar etóxido de sódio in situ. O derivado de chalcona 9 foi adicionado a mistura reacional após total dissolução do sódio metálico e, em seguida, adicionou-se o aldeído. A reação foi acompanhada por CCD durante 2-4 horas. Por fim, o produto foi extraído na fase orgânica com acetato de etila, evaporado e recristalizado em etanol. O Esquema 9 ilustra a etapa final da síntese para obtenção de análogos de bis-chalconas.

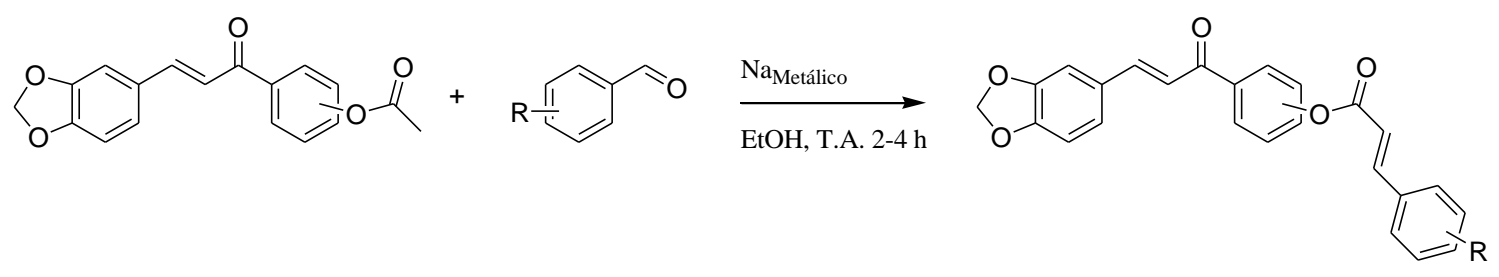

Esquema 23. Síntese de bis-chalcona a partir dos compostos 9 e 10.

O primeiro composto obtido foi caracterizado por $\mathrm{RMN}-{ }^{1} \mathrm{H}$, no qual se observa apenas os picos referentes ao composto 2 . Com o desaparecimento do pico diagnóstico em $\delta 2,32$ ppm referente aos prótons do grupo acetil.

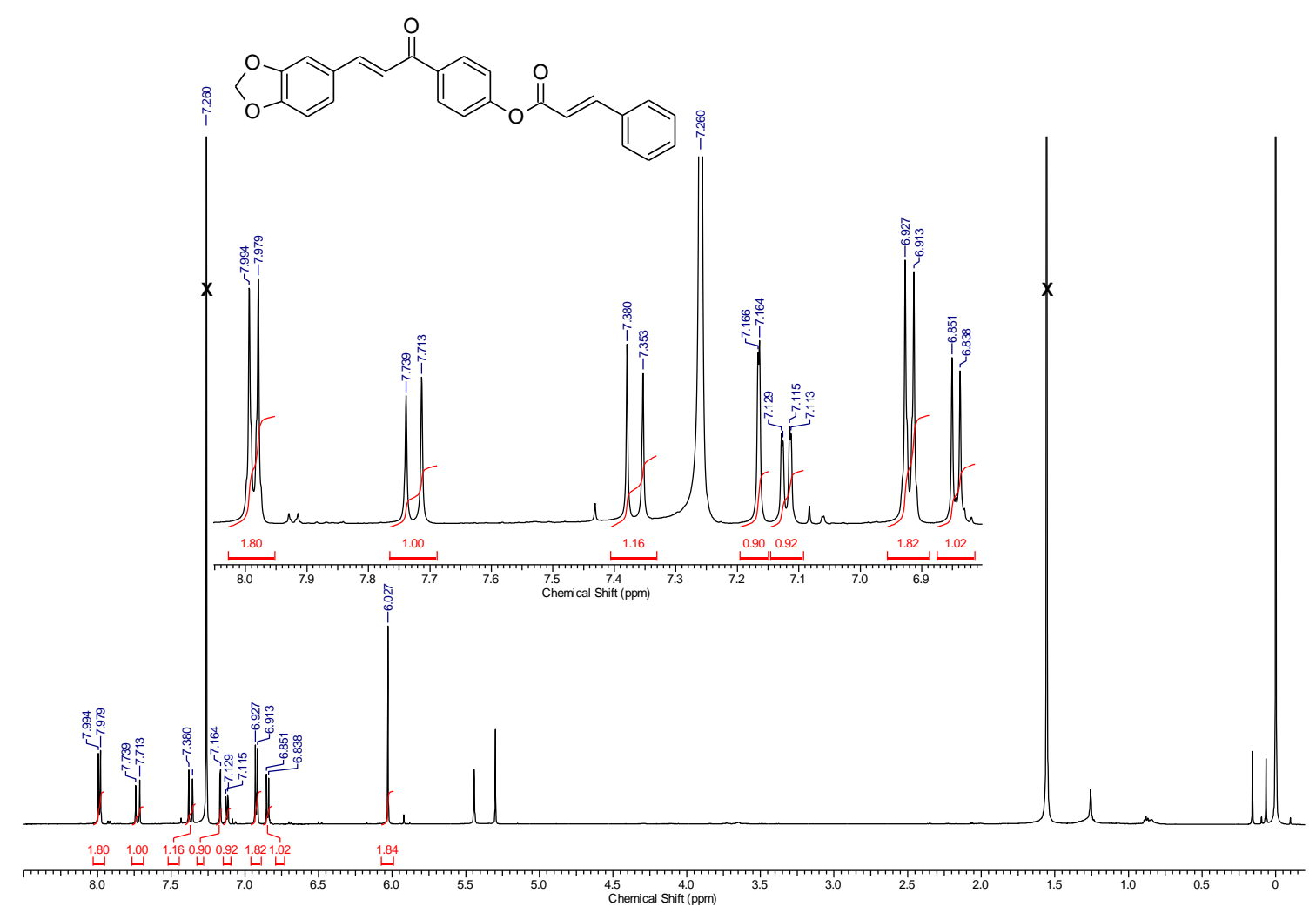

Figura 27. Espectro e expansão da região aromática do primeiro análogo de bis-chalcona obtido através de análise de $\mathrm{RMN}-{ }^{1} \mathrm{H}\left(\mathrm{CDCl}_{3}, 600 \mathrm{MHz}\right)$. 
Novas tentativas foram realizadas, utilizando-se a base volumosa t-butóxido de sódio formado in situ e em maior tempo reacional.

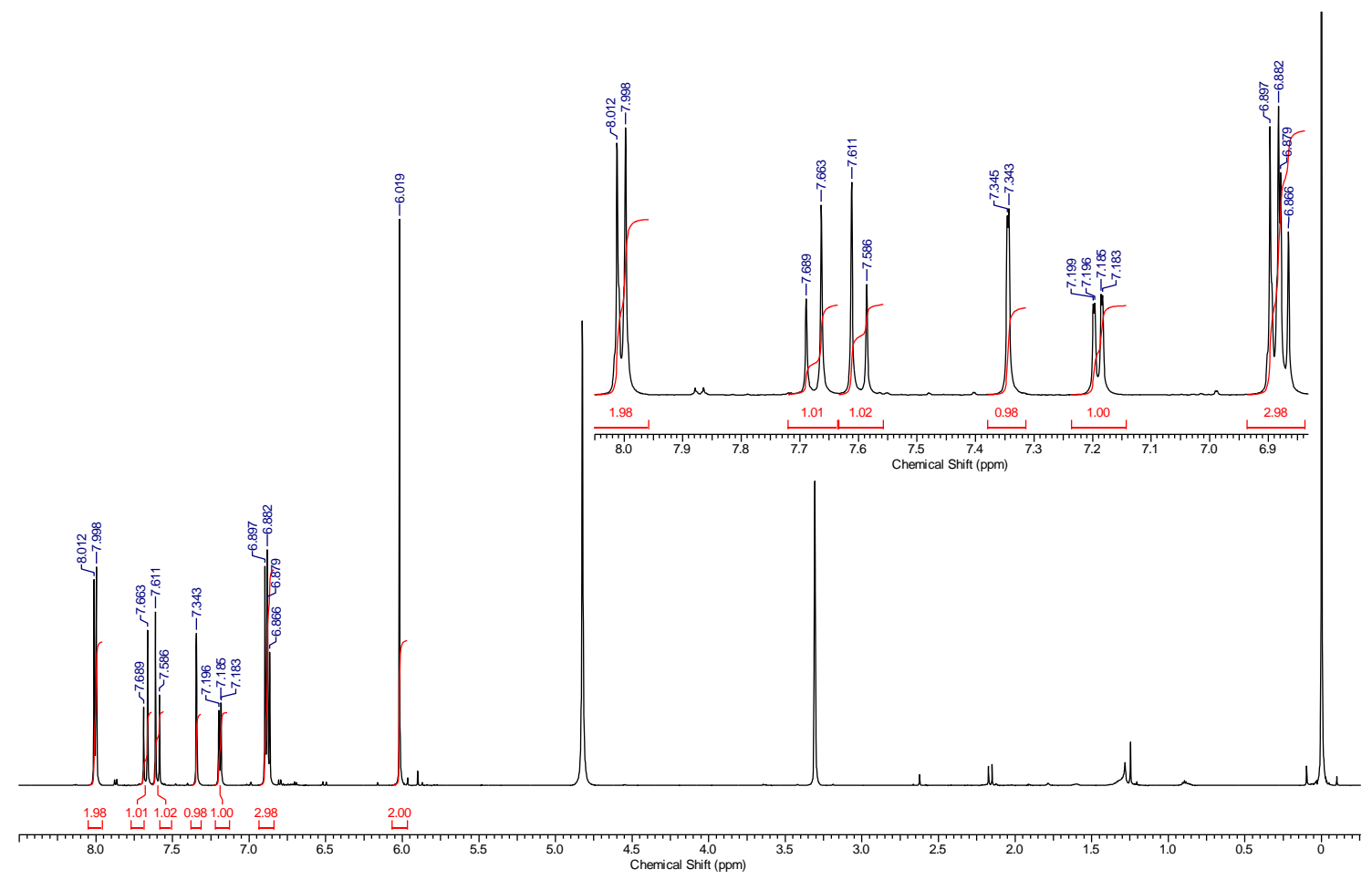

Figura 28. Espectro e expansão da região aromática do primeiro análogo de bis-chalcona obtido através de análise de $\mathrm{RMN}-{ }^{1} \mathrm{H}(\mathrm{CDCl} 3,600 \mathrm{MHz})$.

O que pode explicar a não obtenção do produto é o fato de que, durante o

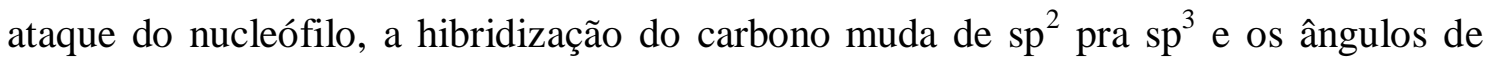
valência diminuem. Isso cria um maior impedimento estéreo para ésteres, tornando-os menos reativos. Um fator que poderia ter levado ao sucesso da reação seria o uso de uma base mais forte e volumosa, como o LDA por exemplo.

\subsubsection{Síntese de Análogos de Bis-Chalcona via Esterificação com Cloreto de Ácido (MÉTODO B)}

Tendo em vista as possíveis falhas da síntese, fez-se uma nova busca na literatura de modo a encontrar algum método que permitisse a síntese dos análogos de bis-chalconas. O trabalho de Chen et. al., ${ }^{49}$ a respeito da síntese de híbridos de cumarina mostrou-se como grande suporte para a síntese idealizada neste trabalho. A Figura 20 traz a estrutura do produto final obtido a partir da reação entre o ácido transcinâmico e a escopoletina (6-metoxi-7-hidroxi-cumarina) que se assemelha muito aos compostos almejados neste trabalho. 
O ácido cinâmico é um ácido graxo aromático de ocorrência natural, composto por um fenil substituído com um fragmento de ácido acrílico comumente encontrado em conformação $Z$. O ácido cinâmico apresenta baixa toxicidade, característica que confere diversas propriedades biológicas. No trabalho de Chen foi relatado que muitos compostos naturais e sintéticos teriam aumento na atividade anticâncer se um fragmento cinamoila fosse introduzido na forma de amidas ou ésteres. Adicionalmente, a presença da cetona $\alpha, \beta$-insaturada pode ser aplicada no design de fármacos com ação antitumoral. ${ }^{49}$

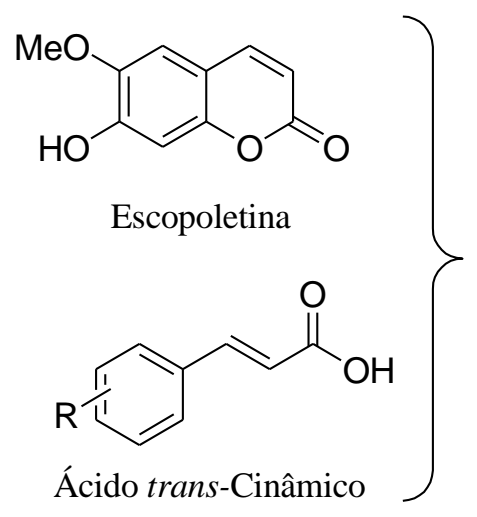<smiles></smiles>

Figura 19. Design de híbrido escopoletina-ácido cinâmico (adaptado da referência 49).

A reação entre a escopoletina e o ácido trans-cinâmico se baseia na reação de esterificação de álcoois. Conforme a literatura, ${ }^{23}$ a reação entre um haleto de acila e um álcool ou fenol é o melhor método geral para a preparação de ésteres carboxílicos. O Esquema 13 mostra a reação entre o cloreto de cinamoila derivado do ácido transcinâmico reagiu com a piridina presente como solvente, gerando um intermediário iônico instável, que reage com o fenol da chalcona sofre eliminação. 


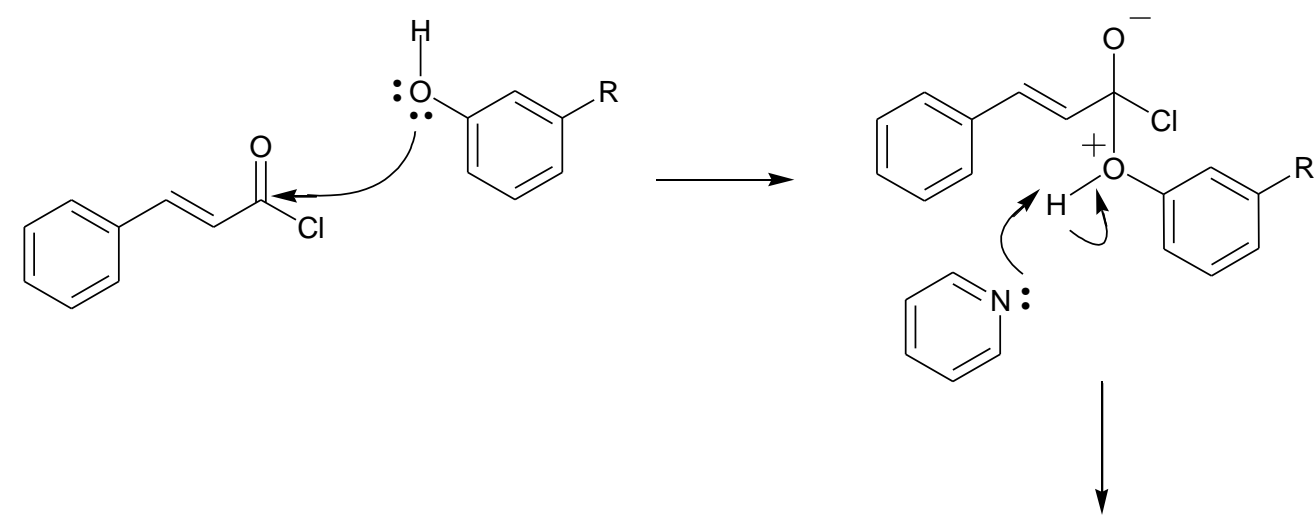<smiles>[R]c1cccc(OCC(O)(Cl)C(Cl)(Cl)CCC)c1</smiles><smiles>CCC(C)C(C)C</smiles><smiles>[R]c1ccc(OC(=O)/C=C/c2ccccc2)cc1</smiles>

Esquema 24. Reação de esterificação de um fenol.

Outro trabalho a respeito da introdução de um fragmento cinamoila a um fenol foi relatado por Dimmock et. al., ${ }^{50}$ o qual relata a a atividade citotóxica de chalconas como bases de Mannich e análogos. Sabe-se que uma variedade de cetonas $\alpha, \beta$ insaturadas demonstra reatividade preferencial com grupos tiol em contraste a grupos amino ou hidróxi. ${ }^{10,51}$

A metodologia de síntese de Chen consiste na dissolução de 1,2 equivalentes de ácido cinâmico em 5 equivalentes de cloreto de tionila $\left(\mathrm{SOCl}_{2}\right)$ com a adição de uma quantidade catalítica de dimetilformamida (DMF). A reação é mantida em refluxo durante 4 horas, seguida pela evaporação de ácido sob pressão reduzida. O produto bruto é coletado e adicionado diretamente e solução de 1 equivalente de cumarina e piridina $(200 \mathrm{mg} / \mathrm{mL})$ em banho de gelo. Após a adição, a mistura é aquecida à

\footnotetext{
${ }^{50}$ Dimmock, J. R.; Kandepu, N. M.; Hetherington, M.; Quail, J. W.; Pugazhenthi, U.; Sudom, A. M.; Chamankhah, M.; Rose, P.; Pass, E.; Allen, T. M.; Halleran, S.; Szydlowski, J.; Mutus, B.; Tannous, M.; Manavathu, E. K.; Myers, T. G.; De Clercq, E.; Balzarini, J. J. Med. Chem. 1998, 41, 1014-1026
} 
temperatura ambiente e agitada durante 2 horas. Por fim, adiciona-se água e filtra-se o sólido formado. ${ }^{49}$

Na metodologia de Dimmock a reação acontece de 1:1. O cloreto de cinamoila $(0,025 \mathrm{~mol})$ é adicionado a uma solução de hidroxichalcona $(0,025 \mathrm{~mol})$ e piridina (3 $\mathrm{mL}$ ) e a reação é mantida em refluxo durante 3-4 horas. Diferente da metodologia de Chen, a mistura reacional é adicionada a uma solução aquosa de ácido clorídrico (10\% $\mathrm{m} / \mathrm{v}$ ). O precipitado é filtrado e lavado com metanol. ${ }^{51}$

Deste modo, foi realizada a síntese dos análogos de bis-chalconas por meio da esterificação do fenol no anel A das chalconas utilizando-se o cloreto de cinamoila obtido em laboratório. No total foram sintetizados 8 derivados de bis-chalcona com rendimentos entre $4 \%$ a $36 \%$, sendo 5 destes inéditos $(\mathbf{1 1}, \mathbf{1 2}, \mathbf{1 4}, \mathbf{1 6}, \mathbf{1 7})$.

As duas metodologias foram utilizadas, porém a metodologia descrita por Dimmock mostrou-se mais efetiva para a obtenção das bis-chalconas. Contudo, deve-se fazer uma ressalva: 1) o cloreto de cinamoila foi sintetizado em laboratório segundo a descrição na metodologia de Chen; 2) a adição do cloreto de ácido foi realizada em um balão bitubulado em banho de gelo, pois se trata uma reação muito exotérmica; 3) O work up foi realizado com ácido clorídrico $(10 \% \mathrm{~m} / \mathrm{v})$, uma vez que a adição de água à mistura formou um sobrenadante de cor marrom difícil de filtrar. A Tabela 3 traz a relação das bis-chalconas sintetizadas e compara os rendimentos obtidos com a literatura.

Tabela 7. Síntese de análogos de bis-chalconas, seguindo a metodologia de Chen e Dimmock 49,51

Rendimento na literatura
$(\%)^{51}$


<smiles>O=C(/C=C/c1ccccc1)Oc1ccc(C(=O)/C=C/c2ccc(Cl)cc2)cc1</smiles>

13<smiles>O=C(/C=C/c1ccccc1)Oc1ccc(C(=O)/C=C/c2ccc(Br)cc2)cc1</smiles>

14<smiles>COc1ccccc1/C=C/C(=O)c1cccc(OC(=O)/C=C/c2ccccc2)c1</smiles>

15<smiles>CN(C)c1ccc(/C=C/C(=O)c2ccc(OC(=O)/C=C/c3ccccc3)cc2)cc1</smiles>

16<smiles>CN(C)c1ccc(/C=C/C(=O)c2cccc(OC(=O)/C=C/c3ccccc3)c2)cc1</smiles>

17<smiles>O=C(/C=C/c1ccccc1)Oc1ccc(C(=O)/C=C/c2ccccc2)cc1</smiles>

18
15

94

25

36

76

4

10

27

50

*As reações foram feitas uma única vez, excetuando-se o composto $\mathbf{1 2}$ que foi obtido segundo ambas as metodologias, porém não foi possível calcular o rendimento de acordo com a metodologia de Chen.

Os rendimentos obtidos são inferiores aos rendimentos na literatura. Tal fato pode ser justificado pela diferença nas condições ou até mesmo a condição dos reagentes, visto que não foi realizada purificação prévia dos aldeídos sólidos e da piridina.

A principal evidência da formação dos análogos de bis-chalconas foi observada no espectro RMN ${ }^{-1} \mathrm{H}(600 \mathrm{MHz})$, onde é possível verificar dois pares de dupletos na região entre 6 e 8 ppm, com ${ }^{3} J_{\mathrm{H}, \mathrm{H}}=16,1 \mathrm{~Hz}$ referentes aos hidrogênios $\mathrm{H} \alpha$ e $\mathrm{H} \beta$ 
próximos aos grupos carbonílicos. Para fins de exemplificação, dispõem-se abaixo, na Figura 21, os picos referentes aos hidrogênios do composto 18.

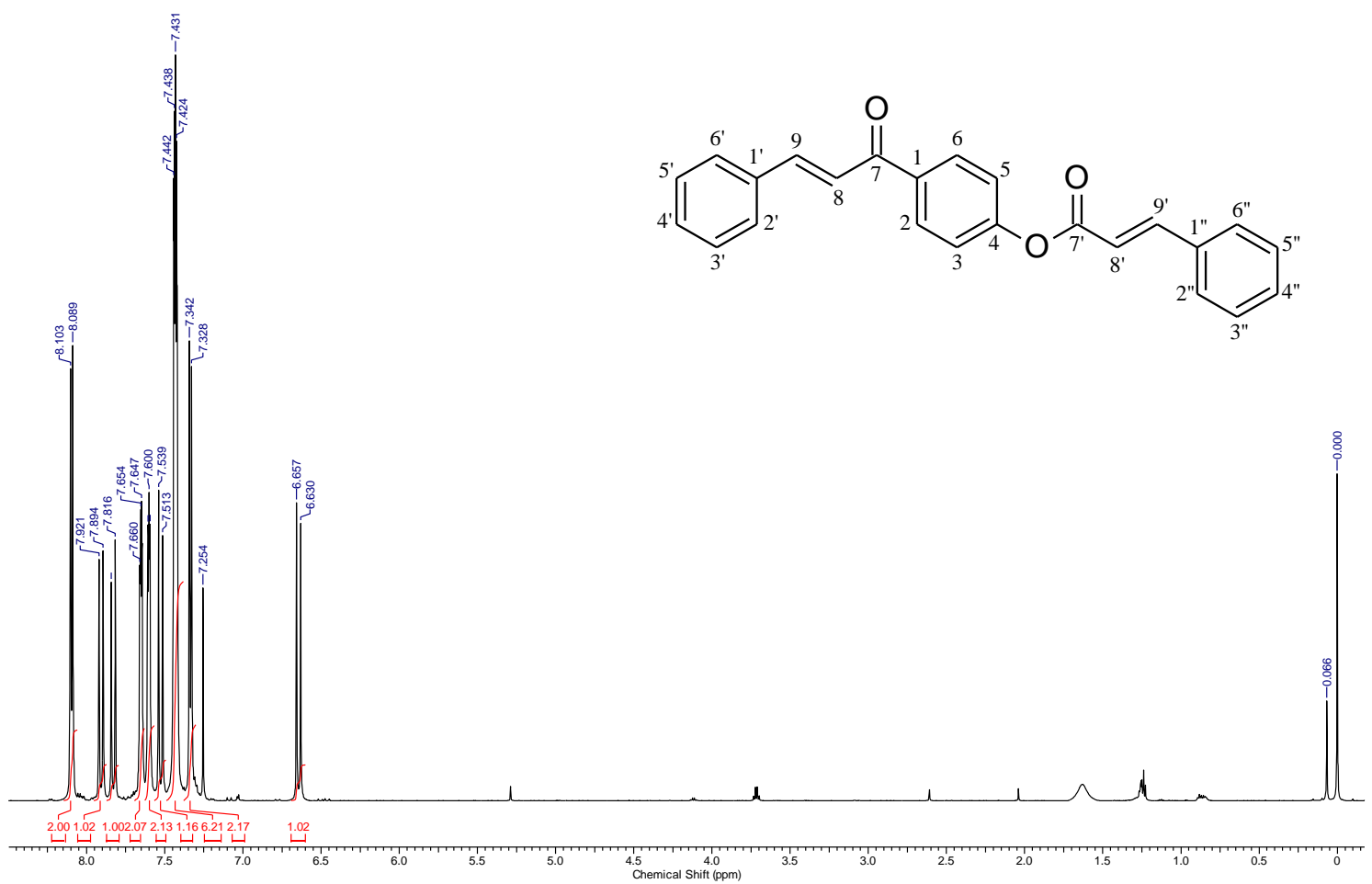

Figura 29. Espectro do composto 18 obtido através de análise de $\mathrm{RMN}-{ }^{1} \mathrm{H}\left(\mathrm{CDCl}_{3}, 600 \mathrm{MHz}\right)$.

A Figura 22 traz a expansão da região aromática do composto 18, onde é possível distinguir os pares de dupletos referentes aos hidrogênios olefínicos H8'-H9' $\left(J_{\text {trans }}=16,1 \mathrm{~Hz}\right)$ e H8-H9 $\left(J_{\text {trans }}=15,6 \mathrm{~Hz}\right)$. 


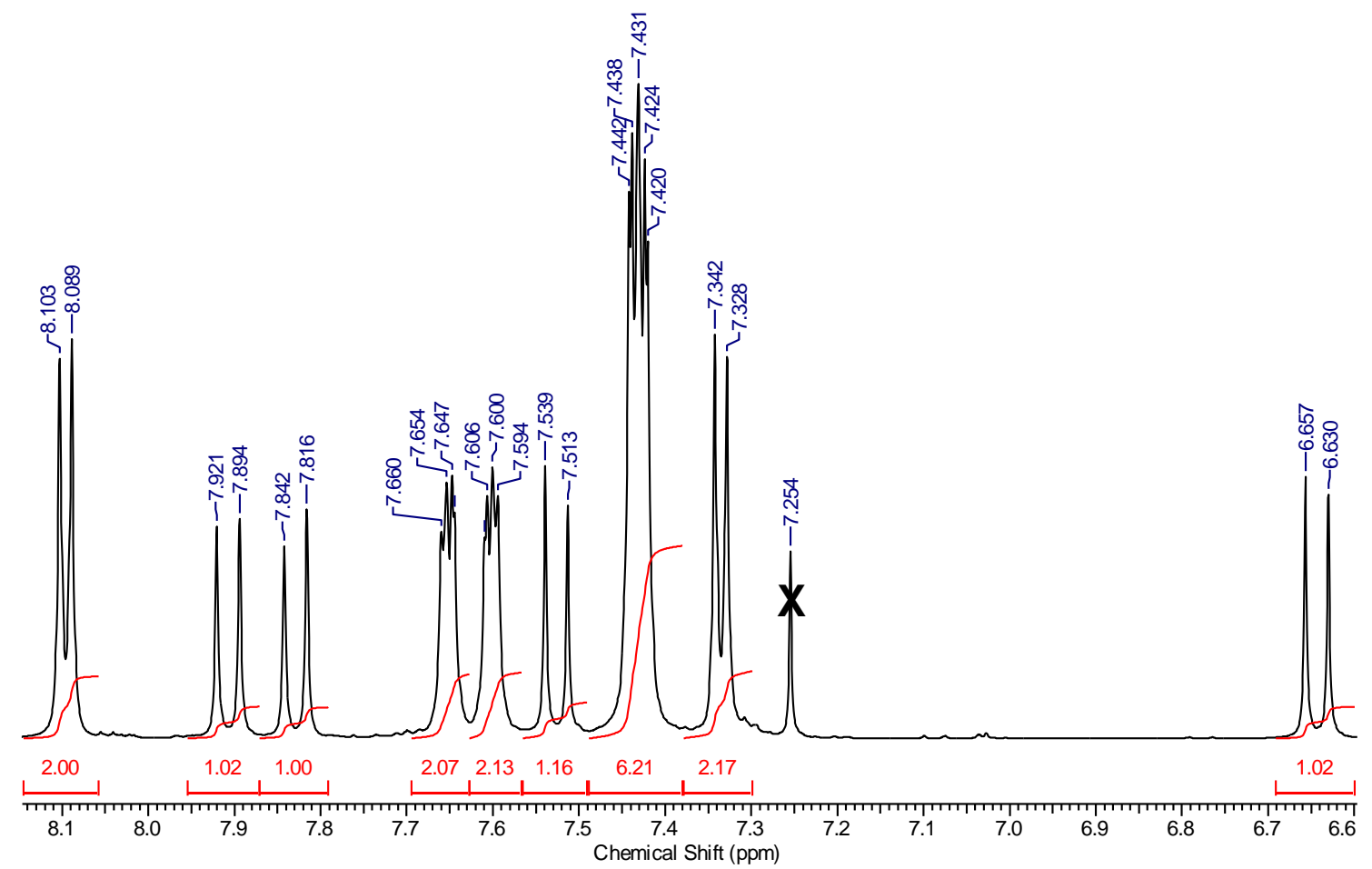

Figura 30. Expansão da região aromática do composto 18.

Para confirmar os picos referentes aos hidrogênios olefínicos supracitados, foi realizado um experimento 2D COSY (homonuclear COrrelation SpectroscopY) que estabelece as correlações entre os hidrogênios acoplados por ${ }^{2-3} J_{\mathrm{H}, \mathrm{H}}$ (Figura 23).

A Figura 24 trás a ampliação do COSY do composto 18 onde é possível correlacionar os pares de dupletos em $\delta 6,64$ ppm e $\delta 7,91$ ppm aos hidrogênios H8' e H9' do fragmento cinamoila $\left({ }^{3} J_{\mathrm{H}, \mathrm{H}}=16.1 \mathrm{~Hz}\right)$. O outro par em $\delta 7,53 \mathrm{ppm}$ e $\delta 7,83$ ppm, refere-se aos hidrogênios H8 e H9 do fragmento chalcona $\left({ }^{3} J_{\mathrm{H}, \mathrm{H}}=15.7 \mathrm{~Hz}\right)$.

Por meio dos experimentos realizados, pode-se assumir que o par em $\delta 8,05$ e $\delta$ 7,33 ppm $\left({ }^{3} J_{\mathrm{H}, \mathrm{H}}=8,2 \mathrm{~Hz}\right)$, referem-se a prótons no anel central devido a blindagem provida pelo fenil éster.

O deslocamento do dupleto em $\delta 6,65$ ppm está associado à blindagem provida pelo fragmento fenil éster devido a densidade eletrônica volumosa próxima ao hidrogênio $\alpha$ carbonila no fragmento cinamoila. 


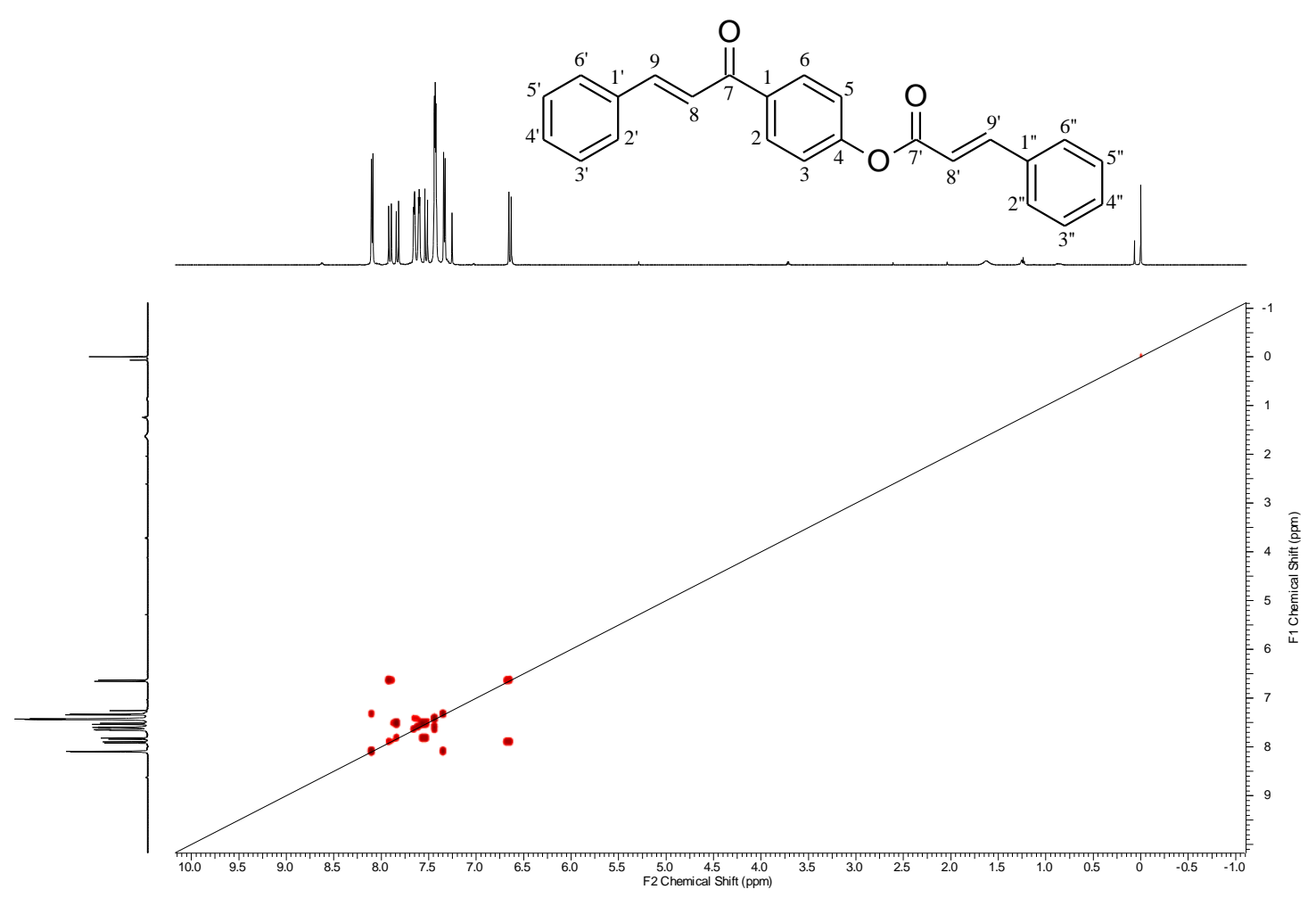

Figura 31. $\mathrm{COSY}\left(\mathrm{CHCl}_{3}\right)$ do composto 18.

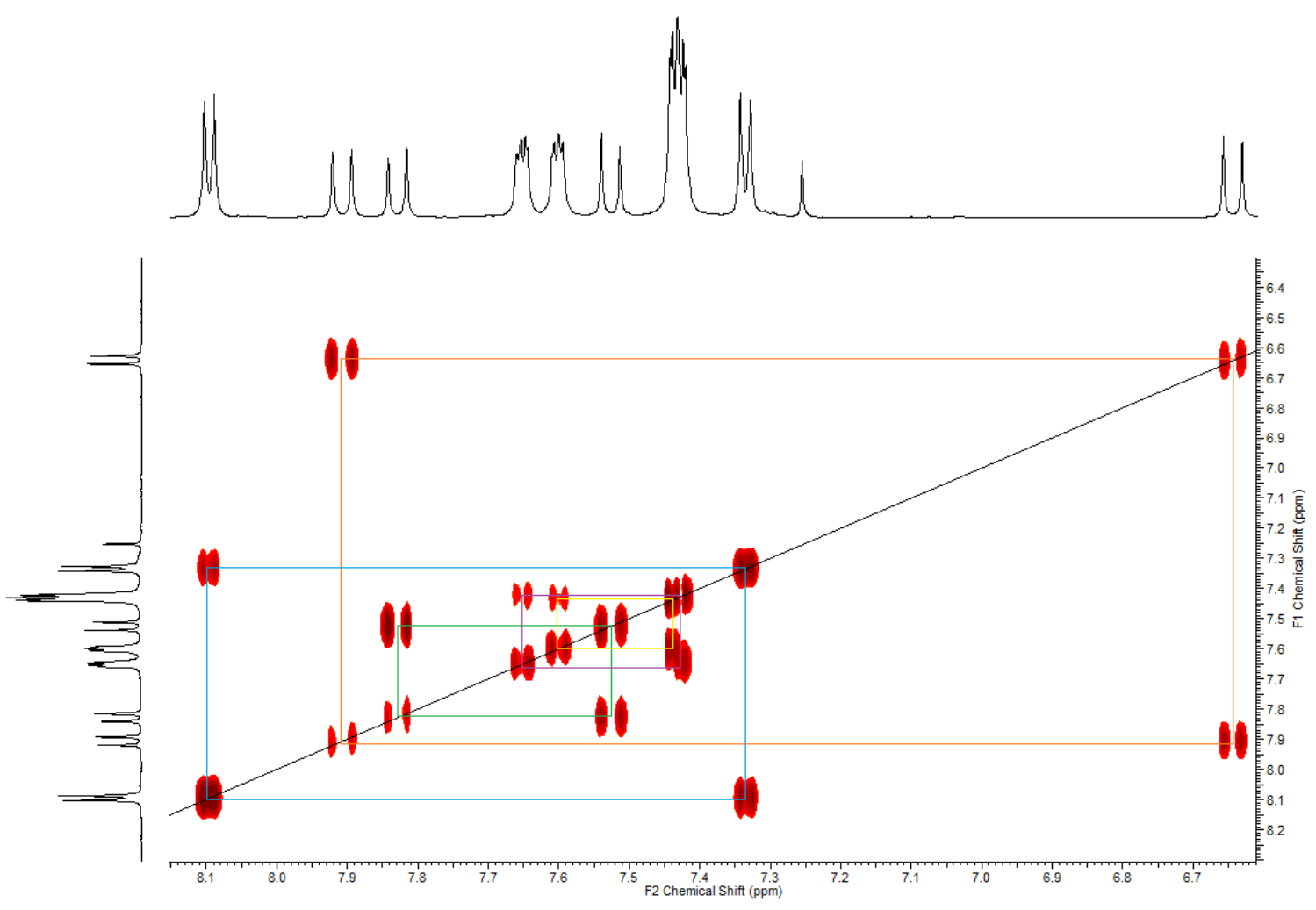

Figura 32. $\mathrm{COSY}\left(\mathrm{CHCl}_{3}\right)$ expandido do composto 18.

A seguir foi realizado o experimento HSQC-ED (Heteronuclear Single Quantum Coherence - Editing) no qual é possível correlacionar os acoplamentos ${ }^{1} J_{\mathrm{C}, \mathrm{H}}$ 
presentes na estrutura do composto 18 (Figura 25). A Figura 26 mostra a expansão do espectro HSQC, onde se pode notar as correlações H8-C8( $\delta$ 7,54 ppm, 121,8 ppm), H9C9 ( $\delta$ 7,83 ppm, 145,03 ppm), H8'-C8' ( $\delta 6,65$ ppm, 116,7 ppm) e H9'-C9' ( $\delta$ 7,90 ppm, 147,3 ppm).

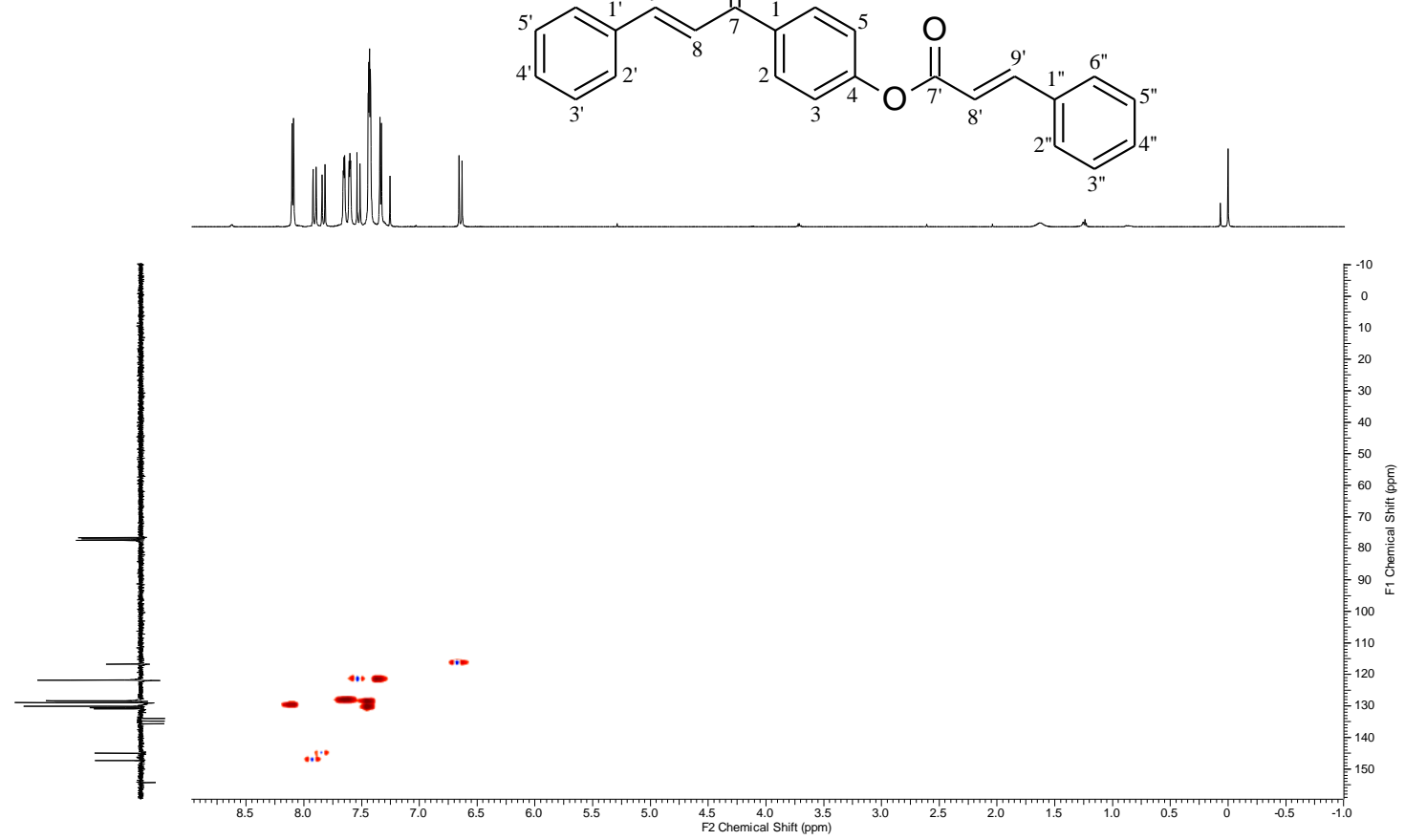

Figura 33. HSQC-ED $\left(\mathrm{CHCl}_{3}\right)$ do composto 18.

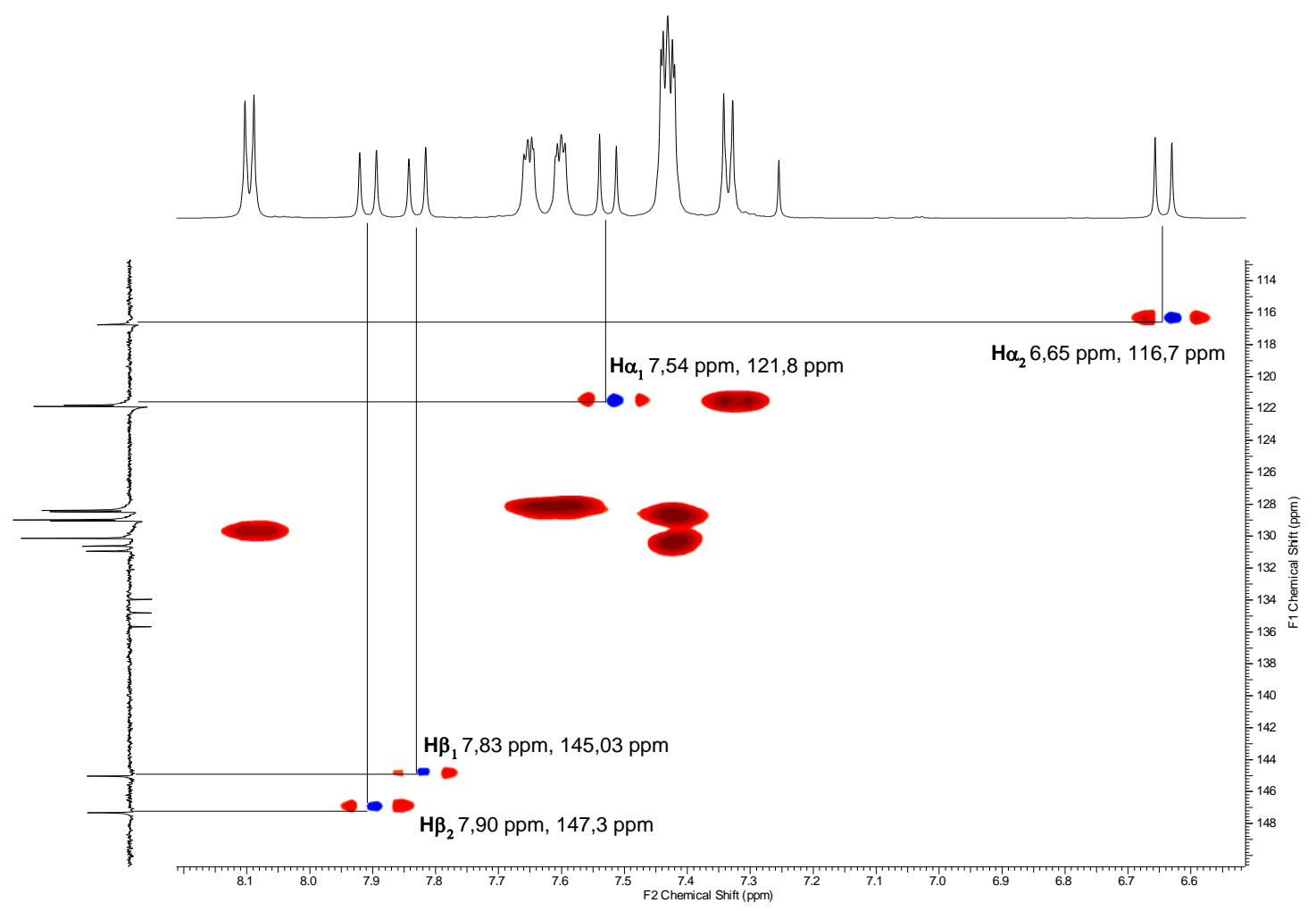

Figura 34. HSQC-ED $\left(\mathrm{CHCl}_{3}\right)$ expandido do composto 18. 


\subsection{Fotofísica}

A avaliação fotofísica dos análogos de bis-chalconas foi realizada mediante a análise de absorção e emissão dos mesmos. O composto 16 não foi utilizado nesse experimento devido a pouca quantidade de material isolado na síntese. Foram realizadas análises de espectrofotometria e espectrofluorimetria com o restante dos compostos isolados em diferentes solventes: diclorometano, acetonitrila e etanol.

Nessa etapa do estudo fotofísico, os análogos de bis-chalconas foram analisados em soluções nos respectivos solventes em concentrações de $10 \mu \mathrm{M}$. A Figura 27 apresenta os solvatogramas obtidos para a análise de absorção e emissão para a bischalcona 13. Os demais espectros de todos os derivados, excetuando-se o 16, encontram0se nos anexos (Seção 7.2)
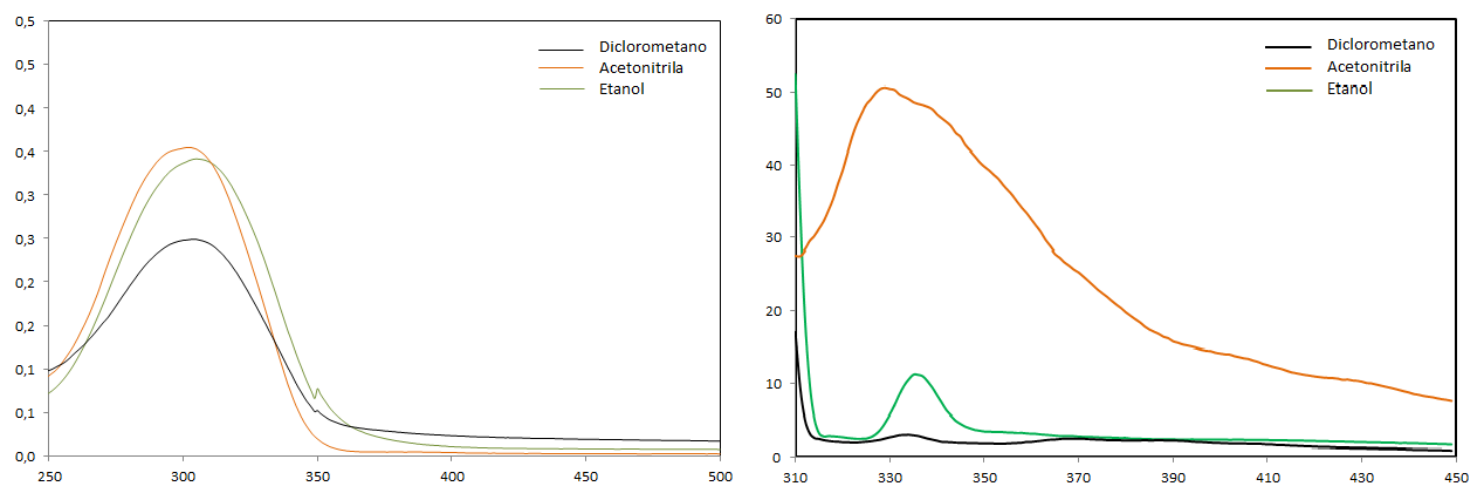

Figura 35. Espectros de absorção e emissão UV/Vis do composto 13.

A maioria das estruturas apesentou maior intensidade de absorbância em acetonitrila $(13,14,17,15$ e 18). As maiores intensidades de fluorescência firam evidenciadas em acetonitrila $(13,17,18)$ e diclorometano $(11,12,14)$.

Em geral, observa-se que o aumento da polaridade do solvente favorece o deslocamento para maiores comprimentos de onda (red shift), além de conferir maior estabilidade às moléculas no estado excitado devido às interações entre o hidrogênio e o oxigênio carbonílico. ${ }^{29}$ Quando esse comportamento é observado no espectro de absorção para solventes polares próticos (etanol), fica indicado que a transição é permitida $\left(\pi \rightarrow \pi^{*}\right)$. A maioria das bis-chalconas apresentam esse comportamento na absorção quando comparados diclorometado e etanol. Entretanto as bis-chalconas 11, 12 e 15 apresentam efeito oposto por possuírem maior $\lambda_{\text {máx }}$ em diclorometano. ${ }^{51}$

$\mathrm{Na}$ Tabela 4 estão dispostos os resultados obtidos pelo estudo UV-vis (absorção e emissão) de 7 análogos de bis-chalconas do acervo, com os comprimentos de onda na absorção e na emissão $\left(\lambda_{\text {máx }}\right)$ e coeficiente de absortividade molar $(\varepsilon)$.

\footnotetext{
${ }^{51}$ Reichardt, C.; Chem. Rev. 1994, 94, 2319-2358.
} 
O deslocamento de Stokes é um parâmetro importante extraído do estudo UVVis e é obtido pela diferença entre os comprimentos de onda máximos observados para absorção e emissão em um mesmo solvente. Esse parâmetro proporciona informações importantes sobre o estado de excitação de uma molécula. Quanto maior for o valor do deslocamento de Stokes, indica-se que o primeiro estado excitado $\left(S_{1}\right)$ é o mais estabilizado e maiores comprimentos de onda são atingidos. ${ }^{52}$ De modo geral, as bischalconas estudadas apresentam baixo valor de deslocamento de Stokes, variando entre 28-34 $\mathrm{nm}$ em acetonitrila, 14-40 $\mathrm{nm}$ em etanol e 16-53 nm em diclorometano.

Moléculas que possuem o grupo $\mathrm{N}, \mathrm{N}$ - dimetilamino em suas estruturas usualmente são descritas por outro mecanismo de transferência interna de carga (TIC), sendo este a transferência de carga na estrutura torcida (TICT). ${ }^{45,47,48}$ Contudo, esse comportamento não é observado na bis-chalcona 17 , talvez pelo fato desta não possuir outro grupo aceptor no anel aromático do fragmento cinamoila. ${ }^{28}$ Observa-se uma diferença pequena no deslocamento de Stokes na bis-chalcona 17 quando se comparam as emissões entre acetonitrila $(30 \mathrm{~nm})$, etanol $(20 \mathrm{~nm})$ e diclorometano $(25 \mathrm{~nm})$ e baixos valores de absortividade molar $\left(\varepsilon=26080 \mathrm{M}^{-1} \mathrm{~cm}^{-1}, 16590 \mathrm{M}^{-1} \mathrm{~cm}^{-1}\right.$ e $15850 \mathrm{M}^{-1} \mathrm{~cm}^{-1}$, respectivamente).

Tabela 8. Resultados obtidos a partir do estudo fotofísico dos sete análogos de bischalconas em concentração $10 \mu \mathrm{M}$.

\begin{tabular}{|c|c|c|c|c|c|}
\hline Análogo & Solvente & $\begin{array}{c}\lambda_{\text {máx }}(\mathbf{a b s}) \\
(\mathbf{n m})\end{array}$ & $\log \varepsilon(\varepsilon)$ & $\begin{array}{c}\lambda_{\text {máx }}(\mathbf{e m}) \\
(\mathbf{n m})\end{array}$ & $\begin{array}{c}\text { Deslocamento } \\
\text { de Stokes } \\
(\mathbf{n m})\end{array}$ \\
\hline \multirow{3}{*}{11} & $\mathrm{CH}_{3} \mathrm{CN}$ & 269 & $4,28(19170)$ & 301 & 32 \\
\hline & $\mathrm{EtOH}$ & 276 & $4,19(15690)$ & 290 & 14 \\
\hline & $\mathrm{CH}_{2} \mathrm{Cl}_{2}$ & 293 & $4,70(54300)$ & 322 & 29 \\
\hline \multirow{3}{*}{12} & $\mathrm{CH}_{3} \mathrm{CN}$ & 285 & $4,26(18560)$ & 316 & 31 \\
\hline & EtOH & 289 & $4,18(15420)$ & 314 & 25 \\
\hline & $\mathrm{CH}_{2} \mathrm{Cl}_{2}$ & 290 & $4,42(26550)$ & 332 & 42 \\
\hline \multirow{3}{*}{13} & $\mathrm{CH}_{3} \mathrm{CN}$ & 302 & $4,55(35490)$ & 336 & 34 \\
\hline & EtOH & 305 & $4,53(34160)$ & 329 & 24 \\
\hline & $\mathrm{CH}_{2} \mathrm{Cl}_{2}$ & 304 & $4,39(24900)$ & 334 & 30 \\
\hline \multirow{2}{*}{14} & $\mathrm{CH}_{3} \mathrm{CN}$ & 302 & $4,45(28250)$ & 330 & 28 \\
\hline & $\mathrm{EtOH}$ & 306 & $4,39(24690)$ & 329 & 23 \\
\hline
\end{tabular}




\begin{tabular}{|c|c|c|c|c|c|}
\hline & $\mathrm{CH}_{2} \mathrm{Cl}_{2}$ & 305 & $4,28(19090)$ & 358 & 53 \\
\hline \multirow{4}{*}{$\mathbf{1 5}$} & $\mathrm{CH}_{3} \mathrm{CN}$ & 286 & $4,49(31520)$ & 317 & 31 \\
\cline { 2 - 6 } & $\mathrm{EtOH}$ & 288 & $4,21(16590)$ & 328 & 40 \\
\cline { 2 - 6 } & $\mathrm{CH}_{2} \mathrm{Cl}_{2}$ & 289 & $4,20(16030)$ & 305 & 16 \\
\hline \multirow{4}{*}{$\mathbf{1 7}$} & $\mathrm{CH}_{3} \mathrm{CN}$ & 284 & $4,41(26080)$ & 314 & 30 \\
\cline { 2 - 6 } & $\mathrm{EtOH}$ & 288 & $4,21(16590)$ & 308 & 20 \\
\cline { 2 - 6 } & $\mathrm{CH}_{2} \mathrm{Cl}$ & 287 & $4,20(15850)$ & 312 & 25 \\
\hline \multirow{3}{*}{$\mathbf{1 8}$} & $\mathrm{CH}_{3} \mathrm{CN}$ & 301 & $4,74(55710)$ & 334 & 33 \\
\cline { 2 - 6 } & $\mathrm{EtOH}$ & 304 & $4,49(31360)$ & 331 & 27 \\
\cline { 2 - 6 } & $\mathrm{CH}_{2} \mathrm{Cl}$ & 303 & $4,40(25600)$ & 333 & 30 \\
\hline
\end{tabular}

Na Tabela 4, observa-se que maiores valores de deslocamento de Stokes são encontrados em diclorometano nas bis-chalconas $12(42 \mathrm{~nm}) \mathbf{1 4}(53 \mathrm{~nm})$. Seguido de 11 $(40 \mathrm{~nm})$ em etanol e $\mathbf{1 1}(32 \mathrm{~nm}), \mathbf{1 3}(34 \mathrm{~nm}), \mathbf{1 7}(30 \mathrm{~nm})$ e $\mathbf{1 8}(33 \mathrm{~nm})$ em acetonitrila. Quando se compara todos os valores de deslocamento de Stokes dos compostos obtidos nos três solventes, observa-se que esses valores são relativamente baixos, que pode indicar que os compostos sofram rápido decaimento do estado excitado $\left(\mathrm{S}_{1}\right)$ para o estado fundamental $\left(\mathrm{S}_{0}\right)$.

Com relação aos coeficientes de extinção molar em cada solvente, tem-se que os maiores valores estão relacionados às estruturas $12\left(\varepsilon_{\text {Acetonitrila }}=55710 \mathrm{M}^{-1} \mathrm{~cm}^{-1}\right), \mathbf{1 3}$ $\left(\varepsilon_{\text {Etanol }}=34160 \mathrm{M}^{-1} \mathrm{~cm}^{-1}\right)$ e $11\left(\varepsilon_{\text {Diclorometano }}=54300 \mathrm{M}^{-1} \mathrm{~cm}^{-1}\right)$. Isso indica que esses compostos apresentam alta emissão e rápido decaimento nos respectivos solventes. ${ }^{44}$ Com estudos mais aprofundados, estes compostos podem servir de modelos no desenvolvimento de fluoróforos com propriedades de emissão comutável. ${ }^{42}$ 


\section{Conclusão e Perspectivas}

De modo geral, o objetivo deste trabalho foi alcançado, pois foram obtidos 8 análogos de bis-chalconas contendo um fragmento fenil éster, sendo 5 análogos inéditos na literatura. O método A proposto inicialmente mostrou-se ineficiente quanto à obtenção de análogos de bis-chalconas, sendo necessário novo estudo metodológico a fim de se conseguir melhores condições que fornecessem os resultados esperados em bons rendimentos.

Com os experimentos 2D da espectroscopia de Ressonância Magnética Nuclear foi possível correlacionar os dados obtidos para uma melhor caracterização dos produtos obtidos a partir das técnicas $1 \mathrm{D} \mathrm{RMN}-{ }^{1} \mathrm{H}$ e $\mathrm{RMN}-{ }^{13} \mathrm{C}$ para compreender os acoplamentos ${ }^{3} J_{\mathrm{H}, \mathrm{H}}$ e ${ }^{1} J_{\mathrm{C}, \mathrm{H}}$.

Apesar das observações realizadas nos ensaios fotofísicos, não há esclarecimento com relação ao processo de transferência interna de carga. Desta forma, será necessário um estudo mais criterioso, com maior variação de solventes, para possibilitar a obtenção de dados como Lippert-Mataga e rendimento quântico.

Uma perspectiva que pode ser explorada para esses análogos de bis-chalconas, refere-se à possível aplicação biológica, uma vez que esta ainda é uma área pouco explorada na literatura. Exemplo disso tem-se o análogo no trabalho de Dimmock et. al. (13 neste trabalho) que se apresentou promissor em testes biológicos. 


\section{Parte Experimental}

\subsection{Métodos Analíticos}

\subsubsection{Ressonância Magnética Nuclear}

Os espectros de ressonância magnética nuclear de hidrogênio (300 MHz) e carbono $(75$ $\mathrm{MHz}$ ) foram obtidos em aparelho Varian Mercury Plus $300 \mathrm{MHz}, 7,05 \mathrm{~T}$. á a ressonância magnética nuclear de hidrogênio $(600 \mathrm{MHz})$ e carbono $(150 \mathrm{MHz})$ foram obtidos em aparelho Bruker Avance III HD 600 MHz, 14,1 T. Todas as chalconas e bischalconas obtidas foram solubilizadas em $\mathrm{CDCl}_{3}$, já os adutos de chalcona foram solubilizados em DMSO. Os deslocamentos químicos $(\delta)$ expressados em ppm (parte por milhão), assumindo como referência interna o TMS. Os dados espectroscópicos referentes aos espectros de RMN ${ }^{1} \mathrm{H}$ estão organizados segundo a convenção: $\delta$ deslocamento químico [número de hidrogênios, multiplicidade, constante de acoplamento em Hz]. As abreviações das multiplicidades dos sinais nos espectros de RMN ${ }^{1} \mathrm{H}$ foram utilizados segundo a convenção: s (simpleto), $\mathrm{d}$ (dupleto), $\mathrm{t}$ (tripleto), $\mathrm{q}$ (quadrupleto), qt (quintupleto), st (sextupleto), m (multipleto) e dd (duplodupleto).

\subsubsection{Estudo Fotofísico}

Para as leituras de absorção e emissão, partiu-se de soluções estoque das bis-chalconas a concentração de $10^{-3} \mathrm{~mol} \mathrm{~L}^{-1}$ em acetonitrila, etanol e diclorometano, as quais foram diluídas até a concentração de $10^{-6} \mathrm{~mol} \mathrm{~L}^{-1}$. Para a absorção, as análises foram feitas no aparelho Varian Cary 50- Bio UV visible Spectrophotometer e as medidas de emissão foram realizadas no aparelho Fluorolog Horiba com leitura a cada $1 \mathrm{~nm}$ e fenda de 5,0.

\subsection{Síntese de Chalcona}

\section{Procedimento geral para síntese de chalcona}

A cetona (1 mmol) foi adicionada a uma solução de $\mathrm{NaOH}(30 \% \mathrm{~m} / \mathrm{v})$ e etanol $(3 \mathrm{~mL})$. A mistura foi agitada durante 20 minutos em banho de gelo. Em seguida, o aldeído (1 mmol) foi adicionado e a mistura foi agitada durante 12 a 24 horas em temperatura ambiente. A mistura reacional foi acidificada com $\mathrm{HCl} 1 \mathrm{M}$. O precipitado foi coletado, lavado com água, seco e purificado por recristalização com EtOH. 
<smiles>O=C(/C=C/c1ccc2c(c1)OCO2)c1cccc(O)c1</smiles>

O produto foi obtido a partir de 3,00 g da 1-(3-Hydroxyphenyl)-ethanone, 2,72 g de Benzo[1,3]dioxole-5-carbaldehyde, e 30\% $\mathrm{NaOH}$ em 32 $\mathrm{mL}$ de $\mathrm{MeOH}$. O composto foi obtido como sólido amarelo, com rendimento de $82 \%$ após recristalização em EtOH. $\mathrm{RMN}{ }^{1} \mathrm{H}\left(300 \mathrm{MHz}, \mathrm{CDCl}_{3} / \mathrm{DMSO}\right) \delta:$ 7,95 (d, $J=8,79$ $\mathrm{Hz}, 2 \mathrm{H}) ; 7,70(\mathrm{~d}, J=15,5 \mathrm{~Hz}, 1 \mathrm{H}) ; 7,39$ (d, $J=15,5 \mathrm{~Hz}, 1 \mathrm{H}) ; 7,17$ (d, $J=0,8 \mathrm{~Hz}, 2 \mathrm{H})$; $7,12(\mathrm{~d}, J=8,2 \mathrm{~Hz}, 2 \mathrm{H}) ; 6,93(\mathrm{~d}, J=8,7 \mathrm{~Hz}, 2 \mathrm{H}) ; 6,84(\mathrm{~d}, J=8,2 \mathrm{~Hz}, 1 \mathrm{H}) ; 6,03$ (s, 1H). $\mathrm{RMN}{ }^{13} \mathrm{C}\left(75 \mathrm{MHz}, \mathrm{CDCl}_{3} / \mathrm{DMSO}\right) \delta: 188,5 ; 161,9 ; 149,5 ; 148,2 ; 143,3 ; 130,8$; 129,$9 ; 129,5 ; 124,8 ; 120,0 ; 115,5 ; 108,5 ; 106,5 ; 101,5$.

\subsubsection{3-Benzo[1,3]dioxol-5-yl-1-(4-hydroxy-phenyl)-propenone}

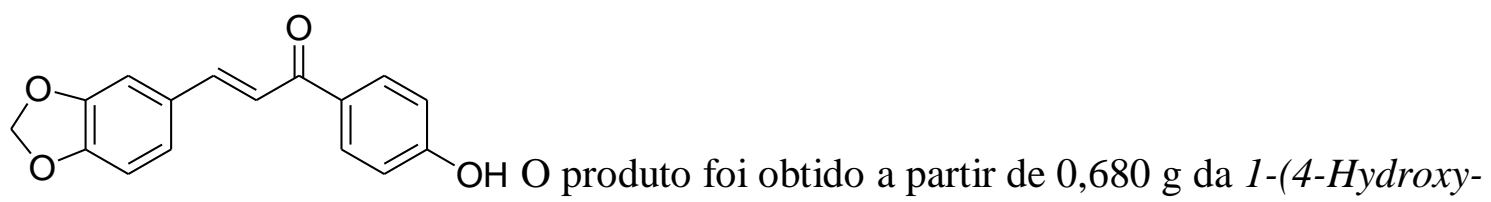
phenyl)-ethanone, 0,750 g de Benzo[1,3]dioxole-4-carbaldehyde, e 30\% $\mathrm{NaOH}$ em 10 $\mathrm{mL}$ de EtOH. O composto foi obtido como sólido amarelo, com rendimento de 43,4\% após recristalização em EtOH. $\mathrm{RMN}{ }^{1} \mathrm{H}\left(300 \mathrm{MHz}, \mathrm{CDCl}_{3} / \mathrm{DMSO}\right) \delta:$ 7,95 (d, $J=8,79$ $\mathrm{Hz}, 2 \mathrm{H}) ; 7,70(\mathrm{~d}, J=15,5 \mathrm{~Hz}, 1 \mathrm{H}) ; 7,39$ (d, $J=15,5 \mathrm{~Hz}, 1 \mathrm{H}) ; 7,17$ (d, $J=0,8 \mathrm{~Hz}, 2 \mathrm{H})$; $7,12(\mathrm{~d}, J=8,2 \mathrm{~Hz}, 2 \mathrm{H}) ; 6,93$ (d, $J=8,7 \mathrm{~Hz}, 2 \mathrm{H}) ; 6,84(\mathrm{~d}, J=8,2 \mathrm{~Hz}, 1 \mathrm{H}) ; 6,03$ (s, 1H). $\mathrm{RMN}{ }^{13} \mathrm{C}\left(75 \mathrm{MHz}, \mathrm{CDCl}_{3} / \mathrm{DMSO}\right) \delta: 188,5 ; 161,9 ; 149,5 ; 148,2 ; 143,3 ; 130,8$; 129,$9 ; 129,5 ; 124,8 ; 120,0 ; 115,5 ; 108,5 ; 106,5 ; 101,5$.

5.2.3. 3-(4-Bromo-phenyl)-1-(4-hydroxy-phenyl)-propenone<smiles>O=C(/C=C/c1ccc(Br)cc1)c1ccc(OO[18OH])cc1</smiles>
phenyl)-ethanone, 0,925 g de 4-Bromo-benzaldehyde, e $30 \% \mathrm{NaOH}$ em $10 \mathrm{~mL}$ de EtOH. O composto foi obtido como sólido amarelo, com rendimento de $60 \%$ após recristalização em EtOH. $\mathrm{RMN}{ }^{1} \mathrm{H}\left(600 \mathrm{MHz}, \mathrm{CDCl}_{3}\right) \delta: 7,99(\mathrm{~d}, J=8,4 \mathrm{~Hz}, 2 \mathrm{H}) ; 7,95$ $(\mathrm{d}, J=8,4,1 \mathrm{~Hz}, 1 \mathrm{H}) ; 7,73(\mathrm{~d}, J=15,7 \mathrm{~Hz}, 1 \mathrm{H}) ; 7,62(\mathrm{~d}, J=8,0 \mathrm{~Hz}, 1 \mathrm{H}) ; 7,57-7,52$ (t, $3 \mathrm{H}) ; 6,93(\mathrm{~d}, J=8,4 \mathrm{~Hz}, 2 \mathrm{H}) . \mathrm{RMN}{ }^{13} \mathrm{C}\left(150 \mathrm{MHz}, \mathrm{CDCl}_{3}\right) \delta: 179,2 ; 142,7 ; 139,7$; 133,$9 ; 132,1 ; 131,9 ; 131,6 ; 131,8 ; 129,7 ; 128,6 ; 122,3 ; 121,4 ; 115,5$. 
<smiles>COc1ccccc1/C=C/C(=O)c1cccc(O)c1</smiles>

O produto foi obtido a partir de 0,680 g da 1-(3-Hydroxyphenyl)-ethanone, 0,680 g de 2-Methoxy-benzaldehyde, e $30 \% \mathrm{NaOH}$ em $10 \mathrm{~mL}$ de EtOH. O composto foi obtido como sólido laranja, com rendimento de $76 \%$ após recristalização em EtOH. RMN ${ }^{1} \mathrm{H}\left(600 \mathrm{MHz}, \mathrm{CDCl}_{3}\right) \delta: 8,11(\mathrm{~d}, J=16,2 \mathrm{~Hz}, 1 \mathrm{H})$; 7,65-7,56 (m, 3H); 7,58 (d, $J=16,2 \mathrm{~Hz}, 1 \mathrm{H}) ; 7,54(\mathrm{~d}, J=7,70 \mathrm{~Hz}, 1 \mathrm{H}) ; 7,41-7,30$ (m, 2H); 7,14-7,08 (m, 1H); 7,00-6,94 (t, $J=7,34 \mathrm{~Hz}, 1 \mathrm{H}) ; 6,92(\mathrm{~d}, J=8,4 \mathrm{~Hz}, 1 \mathrm{H}) ; 3,88$ $(\mathrm{s}, 3 \mathrm{H})$.

5.2.5. 1-(4-Hydroxy-phenyl)-3-phenyl-propenone<smiles>O=C(/C=C/c1ccccc1)c1ccc(O)cc1</smiles>
phenyl)-ethanone, 0,530 g de Benzaldehyde, e 30\% NaOH em $10 \mathrm{~mL}$ de EtOH. O composto foi obtido como sólido amarelo, com rendimento de $65 \%$ após recristalização em EtOH. RMN ${ }^{1} \mathrm{H}\left(600 \mathrm{MHz}, \mathrm{CDCl}_{3}\right) \delta: 8,00(\mathrm{~d}, J=8,8 \mathrm{~Hz}, 2 \mathrm{H}) ; 7,81(\mathrm{~d}, J=15,7$ $\mathrm{Hz}, 1 \mathrm{H}) ; 7,68-7,59$ (dd, $J=6,6-2,9 \mathrm{~Hz}, 2 \mathrm{H}) ; 7,55$ (d, $J=15,7 \mathrm{~Hz}, 1 \mathrm{H}) ; 7,45-7,37$ (m, $3 \mathrm{H}) ; 6,99(\mathrm{~d}, J=8,8 \mathrm{~Hz}, 2 \mathrm{H}) . \mathrm{RMN}{ }^{13} \mathrm{C}\left(75 \mathrm{MHz}, \mathrm{CDCl}_{3}\right) \delta: 188,9 ; 160,3 ; 144,2$; 135,$0 ; 131,1 ; 130,4 ; 128,9 ; 128,4 ; 121,9 ; 115,5$.

5.2.6. 3-(4-Dimethylamino-phenyl)-1-(4-hydroxy-phenyl)-propenone<smiles>CN(C)c1ccc(/C=C/C(=O)c2ccc(O)cc2)cc1</smiles>

O produto foi obtido a partir de $0,680 \mathrm{~g}$ da $1-(4-$ Hydroxy-phenyl)-ethanone, 0,746 g de 4-Dimethylamino-benzaldehyde, e 30\% $\mathrm{NaOH}$ em $10 \mathrm{~mL}$ de EtOH. O composto foi obtido como sólido laranja, com rendimento de $46 \%$ após recristalização em EtOH. RMN ${ }^{1} \mathrm{H}\left(300 \mathrm{MHz}, \mathrm{CDCl}_{3}\right) \delta: 7,81(\mathrm{~d}, J=15,2$ $\mathrm{Hz}, 1 \mathrm{H}) ; 7,56(\mathrm{~s}, 1 \mathrm{H}) ; 7,61-7,48(\mathrm{~m}, 3 \mathrm{H}) ; 7,42-7,28(\mathrm{~m}, 1 \mathrm{H}) ; 7,31(\mathrm{~d}, J=15,2 \mathrm{~Hz}, 1 \mathrm{H})$; 7,14-7,04 (dd, $J=8,21,1,7 \mathrm{~Hz}, 1 \mathrm{H}) ; 6,68(\mathrm{~d}, J=8,792 \mathrm{H}) ; 7,05(\mathrm{~s}, 6 \mathrm{H}) . \mathrm{RMN}{ }^{13} \mathrm{C}(75$ $\left.\mathrm{MHz}, \mathrm{CDCl}_{3}\right) \delta: 190,72 ; 156,37 ; 152,14 ; 146,47 ; 140,38 ; 130,59 ; 129,66 ; 122,52 ;$ 120,$64 ; 119,72 ; 116,63 ; 115,16 ; 111,80 ; 40,12$. 
<smiles>CN(C)c1ccc(/C=C/C(=O)c2cccc(O)c2)cc1</smiles>

O produto foi obtido a partir de $0,680 \mathrm{~g}$ da $1-(3-$ Hydroxy-phenyl)-ethanone, 0,746 g de 4-Dimethylamino-benzaldehyde, e 30\% $\mathrm{NaOH}$ em $10 \mathrm{~mL}$ de EtOH. O composto foi obtido como sólido laranja, com rendimento de $74 \%$ após recristalização em EtOH. RMN ${ }^{1} \mathrm{H}\left(300 \mathrm{MHz}, \mathrm{CDCl}_{3}\right) \delta: 7,81(\mathrm{~d}, J=15,2$ $\mathrm{Hz}, 1 \mathrm{H}) ; 7,56(\mathrm{~s}, 1 \mathrm{H}) ; 7,61-7,48(\mathrm{~m}, 3 \mathrm{H}) ; 7,42-7,28(\mathrm{~m}, 1 \mathrm{H}) ; 7,31(\mathrm{~d}, J=15,2 \mathrm{~Hz}, 1 \mathrm{H})$; 7,14-7,04 (dd, $J=8,21,1,7 \mathrm{~Hz}, 1 \mathrm{H}) ; 6,68(\mathrm{~d}, J=8,792 \mathrm{H}) ; 7,05(\mathrm{~s}, 6 \mathrm{H}) . \mathrm{RMN}{ }^{13} \mathrm{C}(75$ $\left.\mathrm{MHz}, \mathrm{CDCl}_{3}\right) \delta: 190,7 ; 156,3 ; 152,1 ; 146,4 ; 140,3 ; 130,5 ; 129,6 ; 122,5 ; 120,6 ; 119,7$; 116,$6 ; 115,1 ; 111,8 ; 40,1$.

5.2.8. Acetic acid 3-(3-benzo[1,3]dioxol-5-yl-acryloyl)-phenyl ester<smiles>CC(=O)Oc1cccc(C(=O)/C=C/c2ccc3c(c2)OCO3)c1</smiles>

O produto foi obtido a partir de 4,00 g da 1-(3Hydroxy-phenyl)-ethanone, excesso de Anidrido Acético, e 30\% $\mathrm{NaOH}$ em EtOH suficiente para solubilizar o produto de partida. O composto foi obtido como sólido amarelo, com rendimento de $98 \%$ após recristalização em purificação por coluna cromatográfica (diclorometano). R.f. 0,42. RMN ${ }^{1} \mathrm{H}(600 \mathrm{MHz}, \mathrm{DMSO}) \delta: 8,06$ (d, $J=$ 7,70 Hz, 1H); 7,90 (s, 1H); 7,81 (d, $J=15,6 \mathrm{~Hz}, 1 \mathrm{H}) ; 7,71(\mathrm{~d}, J=15,6 \mathrm{~Hz}, 1 \mathrm{H})$ 7,68 (d, $J=1,10 \mathrm{~Hz}, 1 \mathrm{H}) ; 7,62(\mathrm{t}, 1 \mathrm{H}) ; 7,44(\mathrm{dd}, 1 \mathrm{H}) ; 7,35(\mathrm{dd}, 1 \mathrm{H}) ; 7,00(\mathrm{~d}, J=8,2 \mathrm{~Hz}, 1 \mathrm{H})$; $6,12(\mathrm{~s}, 1 \mathrm{H}) ; 2,32$ (s, 2H). RMN ${ }^{13} \mathrm{C}\left(75 \mathrm{MHz}, \mathrm{CDCl}_{3} / \mathrm{DMSO}\right) \delta: 188,4 ; 169,6 ; 151,3$; 150,$2 ; 148,6 ; 145,0 ; 139,6 ; 130,4 ; 129,6 ; 127,0 ; 126,6 ; 126,3 ; 122,2 ; 120,1 ; 109,0$; 107,$5 ; 102,1 ; 21,3$.

\subsection{Síntese do Cloreto de Cinamoila}

Procedimento geral para síntese do cloreto de cinamila

Ao balão contendo $0,74 \mathrm{~g}$ (5 mmol) de ácido trans-cinâmico são adicionados $1,8 \mathrm{~mL}$ (25 mmol) de cloreto de tionila recém destilado. A mistura é inicialmente agitada em refluxo até que a temperatura do banho atinja $50{ }^{\circ} \mathrm{C}$ e, em seguida, a agitação permanece durante mais 2 horas à temperatura de $80^{\circ} \mathrm{C}$. 


\subsection{Síntese de Produto Final}

Procedimento geral para síntese de bis-chalcona

O cloreto de cinamila $(5 \mathrm{mmol})$ foi adicionado em um balão $(50 \mathrm{~mL})$ contendo a chalcona $(5 \mathrm{mmol})$ e a piridina $(3 \mathrm{~mL})$. A mistura foi aquecida sob refluxo durante 3 horas. Após resfriada, a mistura reacional foi adicionada em ácido clorídrico (1 M), e o precipitado foi coletado, lavado com metanol e secado.

5.4.1. 3-Phenyl-acrylic acid 4-(3-benzo[1,3]dioxol-5-yl-acryloyl)-phenyl ester

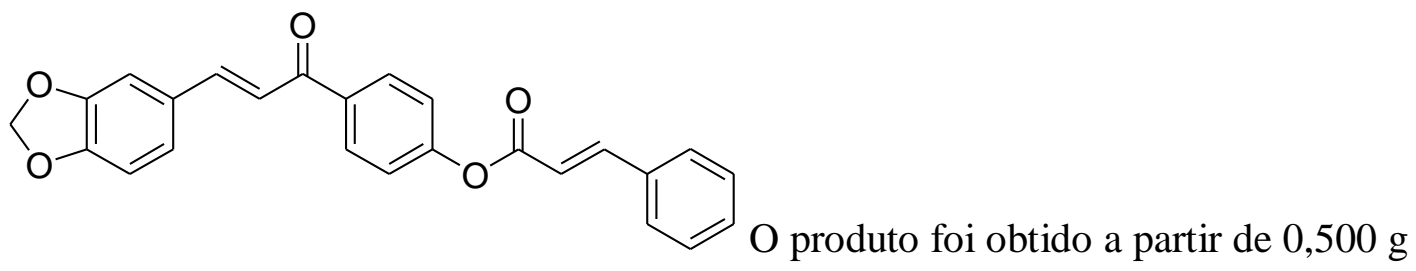
da chalcona 2, 1,67 g do cloreto de cinamila em $3 \mathrm{~mL}$ de piridina. $\mathrm{O}$ composto foi obtido como sólido amarelo, com rendimento de $20 \%$, sem purificação. RMN ${ }^{1} \mathrm{H}$ $\left(600 \mathrm{MHz}, \mathrm{CDCl}_{3}\right) \delta: 7,90(\mathrm{~m}, 2 \mathrm{H}) ; 7,80(\mathrm{~s}, 1 \mathrm{H}) ; 7,76(\mathrm{~d}, J=15,4 \mathrm{~Hz}, 1 \mathrm{H}) ; 7,60$ $(\mathrm{s}, 2 \mathrm{H}) ; 7,54(\mathrm{t}, 1 \mathrm{H}) ; 7,44(\mathrm{~s}, 3 \mathrm{H}) ; 7,41(\mathrm{~d}, J=8,0 \mathrm{~Hz}, 1 \mathrm{H}) ; 7,33(\mathrm{~d}, J=15,4 \mathrm{~Hz}$, $1 \mathrm{H}) ; 7,17(\mathrm{~s}, 1 \mathrm{H}) ; 7,13(\mathrm{~d}, J=8,0 \mathrm{~Hz}, 1 \mathrm{H}) ; 6,84(\mathrm{~d}, J=7,7 \mathrm{~Hz}, 1 \mathrm{H}) ; 6,65(\mathrm{~d}, J=$ $16,4 \mathrm{~Hz}, 1 \mathrm{H}) ; 6,02(\mathrm{~s}, 2 \mathrm{H}) . \mathrm{RMN}{ }^{13} \mathrm{C}\left(150 \mathrm{MHz}, \mathrm{CDCl}_{3}\right) \delta: 189,3 ; 165,2 ; 151,0 ;$ 150,$0 ; 148,4 ; 147,1 ; 145,2 ; 139,8 ; 134,1 ; 130,8 ; 129,6 ; 129,2 ; 129,0 ; 128,3 ; 125,9$; 125,$7 ; 125,4 ; 121,7 ; 119,8 ; 116,9 ; 108,7 ; 106,7 ; 101,6$.

5.4.2. 3-Phenyl-acrylic acid 3-(3-benzo[1,3]dioxol-5-yl-acryloyl)-phenyl ester (12)<smiles>O=C(/C=C/c1ccccc1)Oc1cccc(C(=O)/C=C/c2ccc3c(c2)OCO3)c1</smiles>

O produto foi obtido a partir de 0,500 $\mathrm{g}$ da chalcona 2, 1,67 $\mathrm{g}$ do cloreto de cinamila em $3 \mathrm{~mL}$ de piridina. $\mathrm{O}$ composto foi obtido como sólido amarelo, com rendimento de $10 \%$, sem purificação. RMN ${ }^{1} \mathrm{H}$ $\left(600 \mathrm{MHz}, \mathrm{CDCl}_{3}\right) \delta: 7,90(\mathrm{~m}, 2 \mathrm{H}) ; 7,80(\mathrm{~s}, 1 \mathrm{H}) ; 7,76(\mathrm{~d}, J=15,4 \mathrm{~Hz}, 1 \mathrm{H}) ; 7,60$ $(\mathrm{s}, 2 \mathrm{H}) ; 7,54(\mathrm{t}, 1 \mathrm{H}) ; 7,44(\mathrm{~s}, 3 \mathrm{H}) ; 7,41(\mathrm{~d}, J=8,0 \mathrm{~Hz}, 1 \mathrm{H}) ; 7,33(\mathrm{~d}, J=15,4 \mathrm{~Hz}$, $1 \mathrm{H}) ; 7,17(\mathrm{~s}, 1 \mathrm{H}) ; 7,13(\mathrm{~d}, J=8,0 \mathrm{~Hz}, 1 \mathrm{H}) ; 6,84(\mathrm{~d}, J=7,7 \mathrm{~Hz}, 1 \mathrm{H}) ; 6,65(\mathrm{~d}, J=$ $16,4 \mathrm{~Hz}, 1 \mathrm{H}) ; 6,02$ (s, 2H). $\mathrm{RMN}{ }^{13} \mathrm{C}\left(150 \mathrm{MHz}, \mathrm{CDCl}_{3}\right) \delta: 189,3 ; 165,2 ; 151,0$; 150,$0 ; 148,4 ; 147,1 ; 145,2 ; 139,8 ; 134,1 ; 130,8 ; 129,6 ; 129,2 ; 129,0 ; 128,3 ; 125,9$; 125,$7 ; 125,4 ; 121,7 ; 119,8 ; 116,9 ; 108,7 ; 106,7 ; 101,6$. 


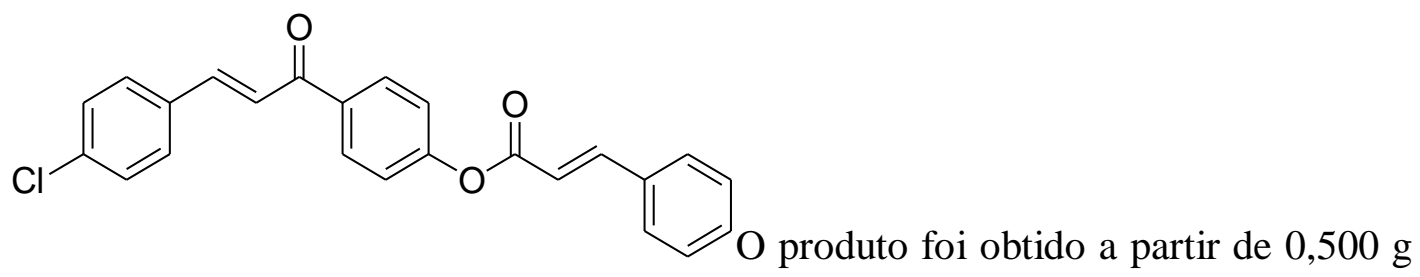
da chalcona $3,1,67 \mathrm{~g}$ do cloreto de cinamila em $3 \mathrm{~mL}$ de piridina. $\mathrm{O}$ composto foi obtido como sólido branco, com rendimento de $15 \%$, sem purificação. RMN ${ }^{1} \mathrm{H}$ $\left(600 \mathrm{MHz}, \mathrm{CDCl}_{3}\right) \delta: 8,09(\mathrm{~d}, J=8,8 \mathrm{~Hz}, 2 \mathrm{H}) ; 7,91(\mathrm{~d}, J=16,2 \mathrm{~Hz}, 1 \mathrm{H}) ; 7,77(\mathrm{~d}$, $J=15,6 \mathrm{~Hz}, 1 \mathrm{H}) ; 7,63-7,59(\mathrm{~m}, 2 \mathrm{H}) ; 7,59-7,55(\mathrm{~m}, 2 \mathrm{H}) ; 7,49(\mathrm{~d}, J=15,0 \mathrm{~Hz}, 1 \mathrm{H})$; 7,46-7,42 (m, 3H); 7,40 (d, $J=8,4 \mathrm{~Hz}, 2 \mathrm{H}) ; 7,34$ (d, $J=8,8,2 \mathrm{H}) ; 6,64$ (d, $J=15,6$ $\mathrm{Hz}, 1 \mathrm{H}) . \mathrm{RMN}{ }^{13} \mathrm{C}\left(150 \mathrm{MHz}, \mathrm{CDCl}_{3}\right) \delta: 189,0 ; 164,8 ; 154,5 ; 147,3 ; 143,5 ; 135,5$; 134,$0 ; 133,7 ; 132,2 ; 130,9 ; 130,1 ; 129,8 ; 129,0 ; 128,4 ; 128,4 ; 124,9 ; 122,3 ; 121,9$; 116,7 .

5.4.4. 3-Phenyl-acrylic acid 4-[3-(4-bromo-phenyl)-acryloyl]-phenyl ester (14)

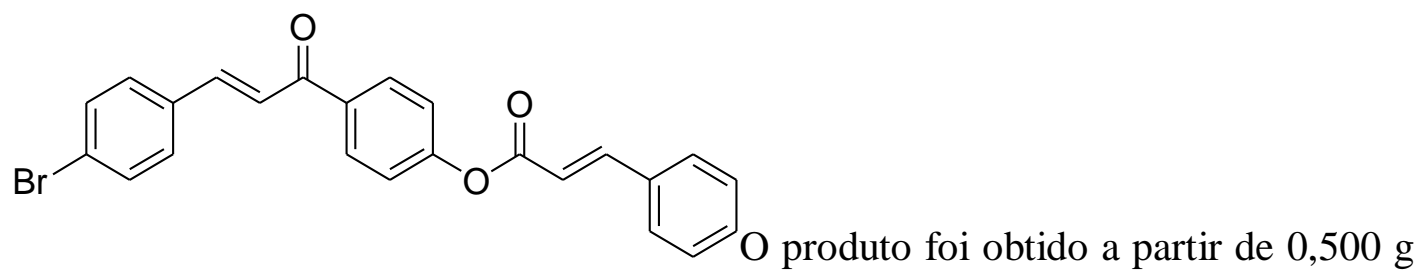
da chalcona $\mathbf{x}, 1,67 \mathrm{~g}$ do cloreto de cinamila em $3 \mathrm{~mL}$ de piridina. $\mathrm{O}$ composto foi obtido como sólido branco, com rendimento de $25 \%$, sem purificação. RMN ${ }^{1} \mathrm{H}$ $\left(600 \mathrm{MHz}, \mathrm{CDCl}_{3}\right) \delta: 8,09(\mathrm{~d}, J=8,4 \mathrm{~Hz}, 2 \mathrm{H}) ; 7,91(\mathrm{~d}, J=16,1 \mathrm{~Hz}, 1 \mathrm{H}) ; 7,75(\mathrm{~d}, J$ $=15,7 \mathrm{~Hz}, 1 \mathrm{H}) ; 7,65-7,58(\mathrm{~m}, 2 \mathrm{H}) ; 7,58-7,54(\mathrm{~m}, 3 \mathrm{H}) ; 7,44(\mathrm{~d} J=3,3 \mathrm{~Hz}, 3 \mathrm{H})$; $7,34(\mathrm{~d}, J=8,4 \mathrm{~Hz}, 2 \mathrm{H}) ; 6,64(\mathrm{~d}, J=16,1,1 \mathrm{H}) . \mathrm{RMN}{ }^{13} \mathrm{C}\left(150 \mathrm{MHz}, \mathrm{CDCl}_{3}\right) \delta$ : 189,$0 ; 164,8 ; 154,5 ; 147,3 ; 143,5 ; 135,5 ; 134,0 ; 133,7 ; 132,2 ; 130,9 ; 130,1 ; 129,8$; 129,$0 ; 128,4 ; 124,9 ; 122,3 ; 121,9 ; 116,7$.

5.4.5. 3-Phenyl-acrylic acid 4-[3-(2-methoxy-phenyl)-acryloyl]-phenyl ester

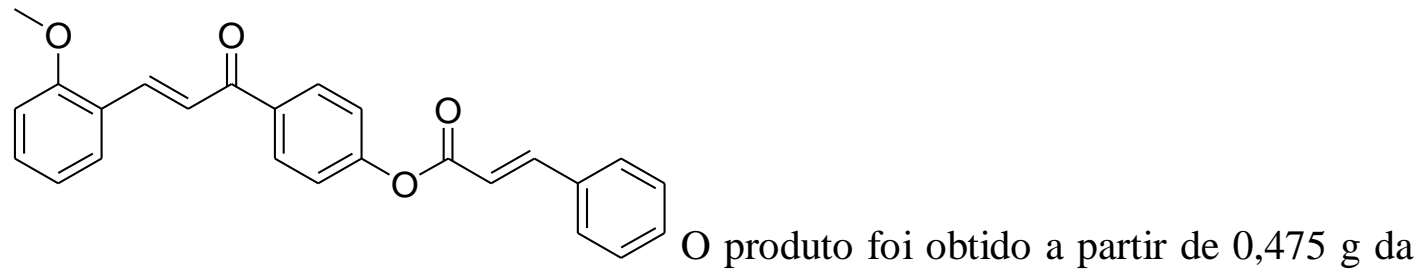
chalcona 11, 1,67 g do cloreto de cinamila em $3 \mathrm{~mL}$ de piridina. $\mathrm{O}$ composto foi obtido como óleo marrom, purificado por coluna cromatográfica (AcOEt/Hexano $10 \%$, com rendimento de $36 \% . \mathrm{R}_{\mathrm{f} .} 0,53 . \mathrm{RMN}{ }^{1} \mathrm{H}\left(600 \mathrm{MHz}, \mathrm{CDCl}_{3}\right) \delta: 8,14$ (d, $J$ 
$=15,7 \mathrm{~Hz}, 1 \mathrm{H}) ; 7,91(\mathrm{~m}, 2 \mathrm{H}) ; 7,82(\mathrm{~s}, 1 \mathrm{H}) ; 7,64(\mathrm{~d}, J=7,7 \mathrm{~Hz}, 1 \mathrm{H}) ; 7,60(\mathrm{~s}, 2 \mathrm{H})$; 7,59-7,52 (m, 2H); 7,44 (s, 3H); 7,42-7,366 (m, 2H); 6,99 (t, 1H); 6,94 (d, $J=8,4$ $\mathrm{Hz}, 1 \mathrm{H}) ; 6,66(\mathrm{~d}, J=16,1 \mathrm{~Hz}, 1 \mathrm{H}) ; 3,92(\mathrm{~s}, 3 \mathrm{H}) . \mathrm{RMN}{ }^{13} \mathrm{C}\left(150 \mathrm{MHz}, \mathrm{CDCl}_{3}\right) \delta$ : 190,$0 ; 165,2 ; 158,9 ; 151,0 ; 147,0 ; 140,9 ; 140,0 ; 134,1 ; 131,9 ; 130,8 ; 129,5 ; 129,3$; 129,$0 ; 128,3 ; 125,8 ; 123,8 ; 122,2 ; 121,7 ; 120,7116,9 ; 55,5$.

5.4.6. 3-Phenyl-acrylic acid 3-[3-(4-dimethylamino-phenyl)-acryloyl]-phenyl ester<smiles>CN(C)c1ccc(/C=C/C(=O)c2cccc(OC(=O)/C=C/c3ccccc3)c2)cc1</smiles>

O produto foi obtido a partir de

$0,500 \mathrm{~g}$ da chalcona $\mathbf{X}, 1,67 \mathrm{~g}$ do cloreto de cinamila em $3 \mathrm{~mL}$ de piridina. $\mathrm{O}$ composto foi obtido como laranja, com rendimento de $10 \%$, sem purificação. RMN ${ }^{1} \mathrm{H}\left(600 \mathrm{MHz}, \mathrm{CDCl}_{3}\right) \delta: 8,07(\mathrm{~d}, J=8,4 \mathrm{~Hz}, 2 \mathrm{H}) ; 7,90(\mathrm{~d}, J=15,7 \mathrm{~Hz}, 1 \mathrm{H}) ; 7,81$ $(\mathrm{d}, J=15,4 \mathrm{~Hz}, 1 \mathrm{H}) ; 7,60(\mathrm{~d}, J=3,3 \mathrm{~Hz}, 2 \mathrm{H}) ; 7,50(\mathrm{~d}, J=8,4 \mathrm{~Hz}, 2 \mathrm{H}) ; 7,44(\mathrm{~s}$, $3 \mathrm{H}) ; 7,37-7,28(\mathrm{~m}, 3 \mathrm{H}) ; 6,70(\mathrm{~d}, J=8,4 \mathrm{~Hz}, 2 \mathrm{H}) ; 6,64(\mathrm{~d}, J=16,1 \mathrm{~Hz}, 1 \mathrm{H}) ; 3,05(\mathrm{~s}$, $6 \mathrm{H}) . \mathrm{RMN}{ }^{13} \mathrm{C}\left(150 \mathrm{MHz}, \mathrm{CDCl}_{3}\right) \delta: 189,4 ; 164,9 ; 153,8 ; 152,1 ; 147,1 ; 141,0$; 136,$6 ; 134,0 ; 130,8 ; 132,2 ; 130,9 ; 130,4 ; 129,9 ; 129,0 ; 128,3 ; 122,6 ; 121,6 ; 116,7$; 40,1 .

5.4.7. Phenyl-acrylic acid 4-(3-phenyl-acryloyl)-phenyl ester (18)<smiles>CCOCCOCCOCCOCCOCCOCCOCCOCCOCCOc1ccc(C=CC(=O)Oc2ccc(C(=O)C=Cc3ccccc3)cc2)cc1</smiles>
chalcona 12, 1,67 g do cloreto de cinamila em $3 \mathrm{~mL}$ de piridina. $\mathrm{O}$ composto foi obtido como sólido branco, com rendimento de $27 \%$, sem purificação. RMN ${ }^{1} \mathrm{H}$ $\left(600 \mathrm{MHz}, \mathrm{CDCl}_{3}\right) \delta: 8,10(\mathrm{~d}, J=8,4 \mathrm{~Hz}, 2 \mathrm{H}) ; 7,91(\mathrm{~d}, J=16,1 \mathrm{~Hz}, 1 \mathrm{H}) ; 7,83(\mathrm{~d}$, $J=15,7 \mathrm{~Hz}, 1 \mathrm{H}) ; 7,69-7,63(\mathrm{~m}, 2 \mathrm{H}) ; 7,63-7,57(\mathrm{~m}, 2 \mathrm{H}) ; 7,53(\mathrm{~d}, J=16,7 \mathrm{~Hz}, 1 \mathrm{H})$; 7,48-7,38 (m, 5H); 7,34 (d, $J=8,4 \mathrm{~Hz}, 2 \mathrm{H}) ; 6,64$ (d, $J=16,1 \mathrm{~Hz}, 1 \mathrm{H}) . \mathrm{RMN}{ }^{13} \mathrm{C}$ $\left(150 \mathrm{MHz}, \mathrm{CDCl}_{3}\right) \delta: 189,3 ; 164,8 ; 154,3 ; 147,3 ; 145,0 ; 135,7 ; 134,8 ; 134,0 ; 130,9 ;$ 130,$6 ; 130,1 ; 129,0 ; 129,0 ; 128,5 ; 128,4 ; 121,9 ; 116,8$. 


\section{Referências Bibliográficas}

${ }^{1}$ Grotewold, E. (2006). The Science of Flavonoids. New York. Springer Science + Business Media, Inc.

${ }^{2}$ Ni, L.; Meng, C. Q.; Sikorski, J. A.; Exp. Opn. 2004, 14, 1669-1691.

${ }^{3}$ Brown, D. (1995). Encyclopedia of Herbs and Their Uses. New York. Folkard C (Ed.) Dorling Kindersley Publishing, Inc.

${ }^{4}$ Haraguchi, H.; Ishikawa, H.; Mizutani, K.; Tamura, Y.; Kinoshita, T.; Bioorg. Med. Chem. 1998, 6(3), 339-347.

${ }^{5}$ Zhao, F.; Nozawa, H.; Daikonnya, A.; Kondo, K.; Kitanaka, S.; Biol. Pharm. Bull. 2003, 26(1), 61-65.

${ }^{6}$ Zhai, L.; Chen, M.; Blom, J.; Theander, T. G.; Christensen, S. B.; Kharazmi, A.; J. Antimicro. Chemother. 1999, 43, 793-803.

${ }^{7}$ Haraguchi, H.; Tanimoto, K.; Tamura, Y.; Mizutani, K.; Kinoshita, T.; Phytochem. 1998, $48(1), 125-129$.

${ }^{8}$ Chiaradia, L. D.; Martins, P. G. A.; Cordeiro, M. N. S.; Guido, R. V. C.; Ecco, G.; Andricopulo, A. D.; Yunes, R. A.; Vernal, J.; Nunes, J. R.; Terenzi, H.; J. Med. Chem. 2012, 55, 390-402.

${ }^{9}$ Nowakowska, Z.; Eur. J. Med. Chem. 2007, 42, 125-127.

${ }^{10}$ Silva, W. A.; Andrade, C. K. Z.; Napolitano, H. B.; Vencato, I.; Lariucci, C.; de Castro, M. R. C.; Camargo, A. J.; J. Braz. Chem. Soc. 2013, 24(1), 133-144.

${ }^{11}$ Dao, T. T. H.; Linhorst, H. J. M.; Verpoorte, R.; Phytocham. Ver. 2011, 10, 397.

${ }^{12}$ Schröder, J.; The Chalcone Stilbene-Synthase type Family of Condensing Enzymes. In: Comprehensive Natural Products Chemistry. Sankawa U, 1999, 749-771.

${ }^{13}$ Larsen, M.; Kromann, H.; Kharazmi, A.; Nielsen, S. F.; Bioorg. Med. Chem. Lett. 2005, 15 , 4858-4861.

${ }^{14}$ Nielsen, S. F.; Kharazmi, A.; Christensen, S. B.; Bioorg. Med. Chem. 1998, 6, 937.

${ }^{15}$ Shimokoriyama, M.; Flavanones, Chalcones and Aurones. Geissman TA, The Macmillan Company, New York, 1962: 186-313.

${ }^{16}$ Evranos Aksöz, B.; Ertan, R.; J. Pharm. Sci. 2011, 36, 223-242.

${ }^{17}$ Davey, W.; Gwilt, J. R.; J. Chem. Soc. 1957, 1008-1014.

${ }^{18}$ Saiyad, I. Z.; Nadkarni, D. R.; Wheeler, T. S.; J. Chem. Soc. 1937, 1737-1739.

${ }^{19}$ Shenoi, R. B.; Shah, R. C.; Wheeler, T. S.; J. Chem. Soc. 1940, 247-251.

${ }^{20}$ Feuestein, W.; Kostanecki, S. V.; Chem. Ber. 1898, 31, ???-???

${ }^{21}$ Mahal, H. S.; Enkataraman, K.; J. Chem. Soc. 1933, 616-617.

${ }^{22}$ Claisen, L.; Lowman, O.; Zeitschrift für Chemie. 1868, 651-654.

${ }^{23}$ Kürti, L.; Czakó, B. (2005). Strategic Application of Named Reactions in Organic Synthesis.

California, Elsevier Inc. 
${ }^{24}$ Fleming, I. (2010). Molecular Orbitals and Organix Chemical Reactions. Cambridge, John Wiley \& Sons, Ltd.

${ }^{25}$ Chiaradia, L. D.; dos Santos, R.; Vitor, C. E.; Vieira, A. A.; Leal, P. C.; Nunes, R. J.; Calixto, J. B.; Yunes, R. A.; Bioorg. Med. Chem. 2008, 16, 658-667.

${ }^{26}$ Gaber, M.; El-Daly, S. A.; Fayed, T. A.; El-Sayed, Y. S.; Optics \& Laser Tec. 2008, 40, 528537.

${ }^{27}$ Skoog, D. A.; West, D. M.; Hooler, F. J.; Stanley, R. C.; Fundamentos de Química Analítica, Tradução da $8^{\text {a }}$ ed.; Ed. Thomson: São Paulo, SP, 2008.

${ }^{28}$ Zhou, B.; Jiyang, P.; Lu, J.; Xing, C.; Arch. Pharm. Chem. Life Sci. 2016, 349, 539-552.

${ }^{29}$ Tsukerman, S. V.; Maslennikova, V. P.; Nikitchenko, V. M.; Lavroshin, V. F.; Zhurnal Prikladnoi Spektroskopii. 1970, 12(1), 91-96.

${ }^{30}$ Nurmukhmetov, R. N.; Belaits, A. L.; Shigorin, D. N.; Shner, V. F. Zh. Fiz. Khim. 1967, 41, 3107.

${ }^{31}$ Ram, V. J.; Saxena, A. S.; Srivastava, S.; Chandra, S.; Bioorg. Med. Chem. Lett. 2000, 10, 2159-2161.

${ }^{32}$ Modzelewska, A.; Pettit, C.; Achanta, G.; Davidson, N. E.; Huang, P.; Khan, S. R.; Bioorg. Med. Chem. 2006, 14, 3491-3495.

${ }^{33}$ Reddy, M. V. B.; Shen, Y.; Ohkoshi, E.; Bastow, K. F.; Qian, K.; Lee, K.; Wu, T.; Eur. J. Med. Chem. 2012, 47, 97-103.

${ }^{34}$ Husain, A.; Rashid, M.; Mishra, R.; Kumar, D.; Acta Poloniae Pharmaceutica - Drug Research. 2013, 70(3), 443-449.

${ }^{35}$ Mobinikhaledi, A.; Kalhor, M.; Jamalifar, H.; Med. Chem. Res. 2012, 21, 1811-1816.

${ }^{36}$ Domínguez, J. N.; de Domínguez, N. G.; Rodrigues, J.; Acosta, M. E.; Caraballo, N.; León, C.; J. Enzyme Inhib. Med. Chem. 2012, 28(6), 1267-1273.

${ }^{37}$ Domínguez, J. N.; León, C.; Rodrigues, J.; de Domínguez, N. G.; Gut, J.; Rosenthal, P. J.; J. Med. Chem. 2005, 48, 3654-3658.

${ }^{38}$ Winter, E.; Neuenfeldt, P. D.; Chiaradia-Delatorre, L. D.; Gauthier, C.; Yunes, R. A.; Nunes, R. J.; Creczynski-Pasa, T. B.; Di Pietro, A.; J. Med. Chem. 2014, 57, 2930-2941.

${ }^{39}$ Natarajan, K.; Xie, Y.; Baer, M. R.; Ross, D. D.; Biochemical Pharmacology. 2012, 83, $1084-$ 1103.

${ }^{40}$ Valdameri, G.; Genoux-Bastide, E.; Peres, B.; Gauthier, C.; Guitton, J.; Terreux, R.; Winnischofer, S. M. B.; Rocha, M. E. M.; Boumendjel, A.; Di Pietro, A.; J. Med. Chem. 2012, 55, 966-970.

${ }^{41}$ Asiri, A. M.; Khan, S. A.; Mat. Lett. 2011, 65, 1749-1752.

${ }^{42}$ Asiri, A. M.; Marwani, H. M.; Alamry, K. A.; Al-Amoudi, M. S.; Khan, S. A.; El-Daly, S. A.; Int. J. Electrochem. Sci. 2014, 9, 799-809.

${ }^{43}$ Siddiqui, Z. N.; Khan, T.; J. Braz. Chem. Soc. 2014, 25(6), 1002-1011.

${ }^{44}$ Lakowicz, J. R.; Principles of Fluorescence Spectroscopy. $3^{\mathrm{a}}$ ed.; Springer: Nova York, USA, 2006. 
${ }^{45}$ Alvim, H. G. O.; Fagg, E. L.; Oliveira, A. L.; Oliveira, H. C. B.; Freitas, S. M.; Xavier, M. A. E.; Soares, T. A.; Gomes, A. F.; Gozzo, F. C.; Silva, W. A.; Neto, B. A. D.; Org. Biomol. Chem. 2013, $11,4764$.

${ }^{46}$ Pavia, D. L.; Lampman, G. M.; Kriz, G. S.; Introduction To Spectroscopy. $3^{\text {a }}$ ed.; Thomson Learning, Inc.: Washington, USA, 2001.

${ }^{47}$ Yang, X.; Shen, G. Yu, R.; Microchemical Journal. 1999, 62, 394-404.

${ }^{48}$ Rurack, K.; Dekhtyar, M. L.; Bricks, J. L.; Resch-Genger, U.; Rettig, W.; J. Phys, Chem. A. 1999, 103, 9626-9635.

${ }^{49}$ Li, L.; Zhao, P.; Hu, J.; Liu, J.; Liu, Y.; Wang,; Xia, Y.; Dai, Y.; Chen, L.; Eur. J. of Med. Chem. 2015, 93, 300-307.

${ }^{51}$ Dimmock, J. R.; Kandepu, N. M.; Hetherington, M.; Quail, J. W.; Pugazhenthi, U.; Sudom, A. M.; Chamankhah, M.; Rose, P.; Pass, E.; Allen, T. M.; Halleran, S.; Szydlowski, J.; Mutus, B.; Tannous, M.; Manavathu, E. K.; Myers, T. G.; De Clercq, E.; Balzarini, J. J. Med. Chem. 1998, $41,1014-1026$

${ }^{52}$ Reichardt, C.; Chem. Rev. 1994, 94, 2319-2358.

${ }^{53}$ MELO, L. R. Síntese, Caracterização e Estudo Fotofísicos de Chalconas Fluorescentes. 2015. 93 f. Dissertação de Mestrado - Instituto de Química, Universidade de Brasília, Distrito Federal. 2015.

\section{Anexos}

\subsection{Espectros de $\mathrm{RMN}{ }^{1} \mathrm{He} \mathrm{e}^{13} \mathrm{C}$}




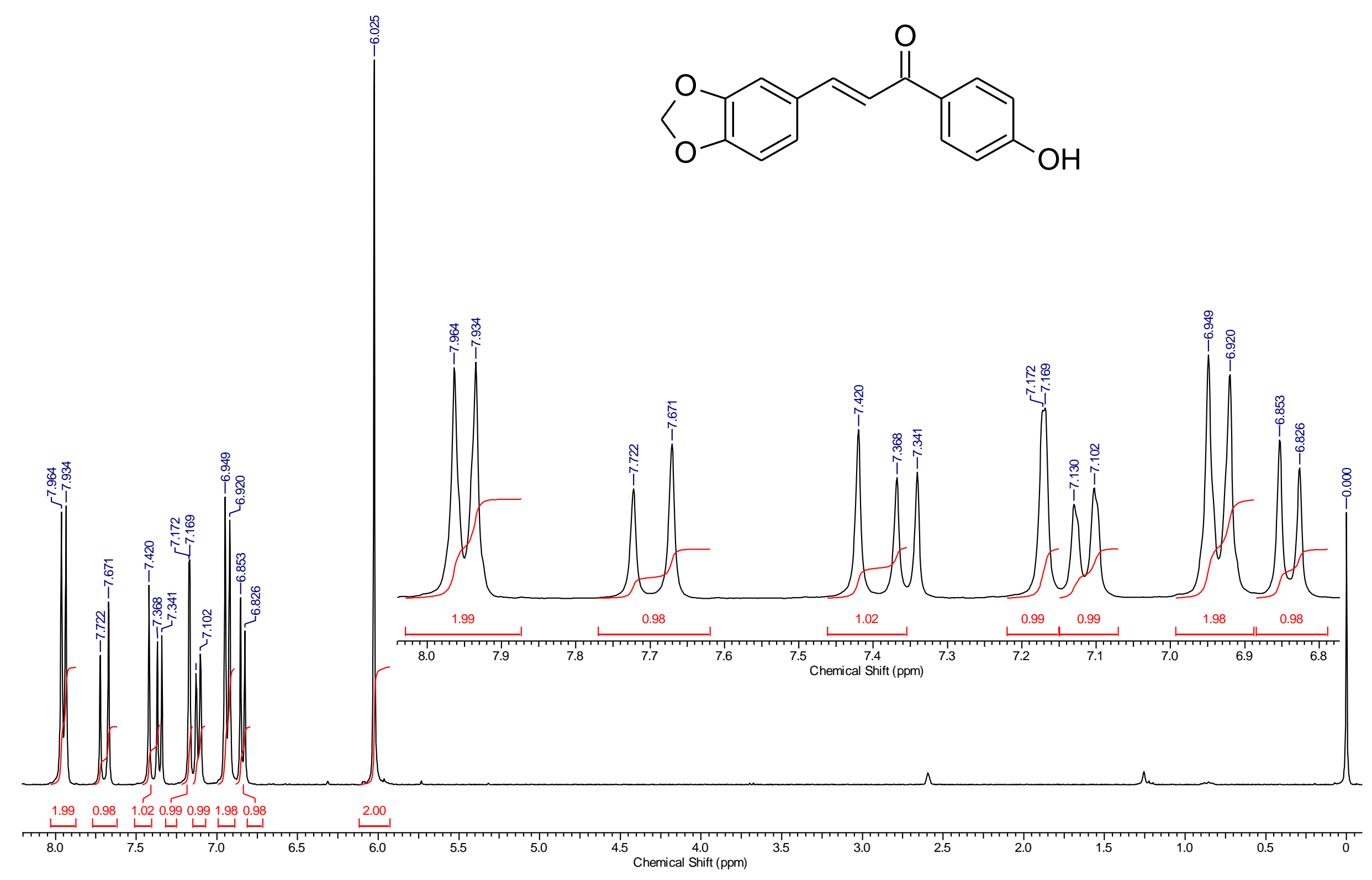

Espectro 1. RMN- ${ }^{1} \mathrm{H}\left(600 \mathrm{MHz}, \mathrm{CDCl}_{3}\right)$ do composto 1. 


$$
\text { L }
$$




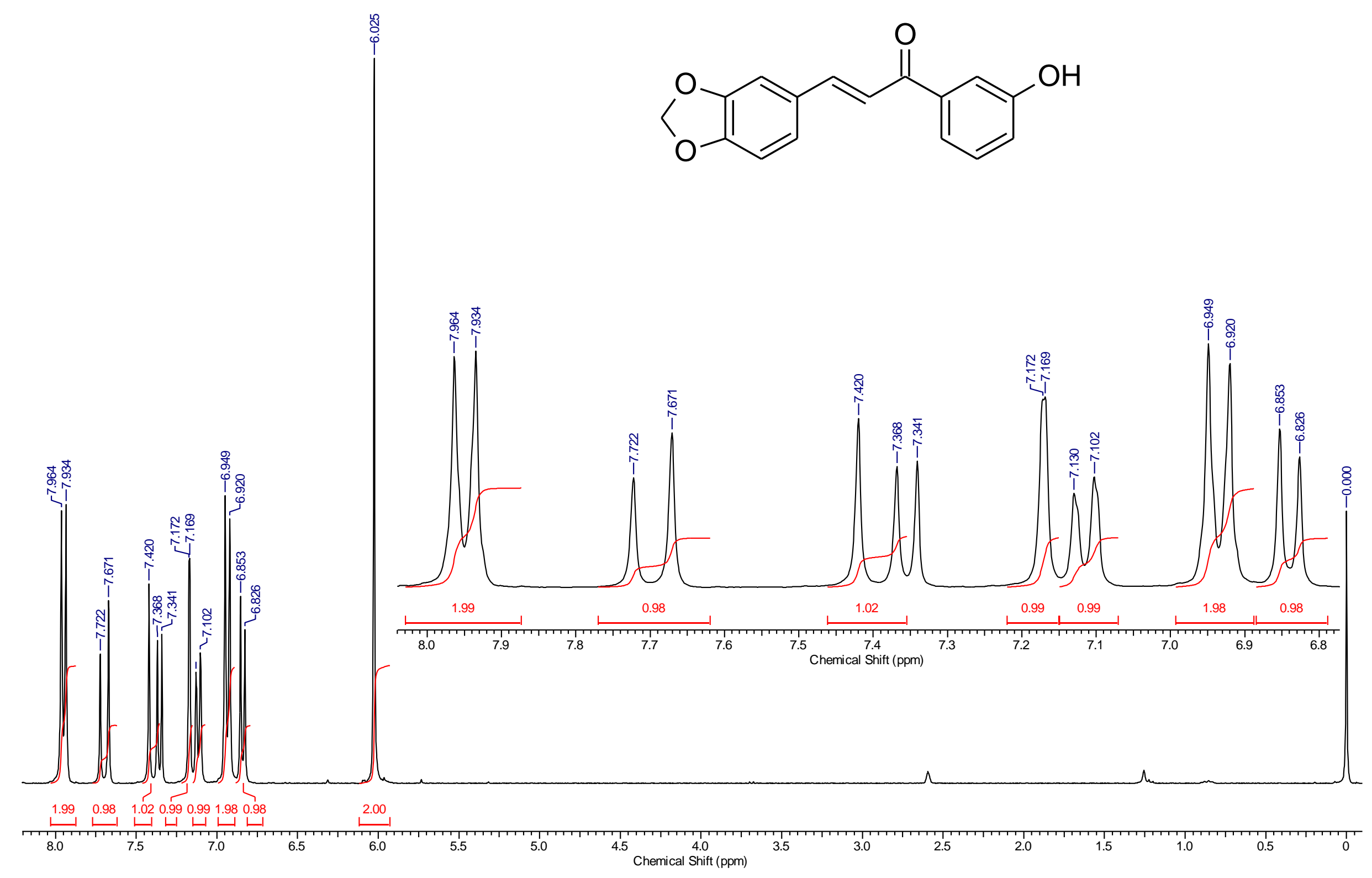

Espectro 3. RMN- ${ }^{1} \mathrm{H}\left(600 \mathrm{MHz}, \mathrm{CDCl}_{3}\right)$ do composto 2. 


$$
\text { . }
$$




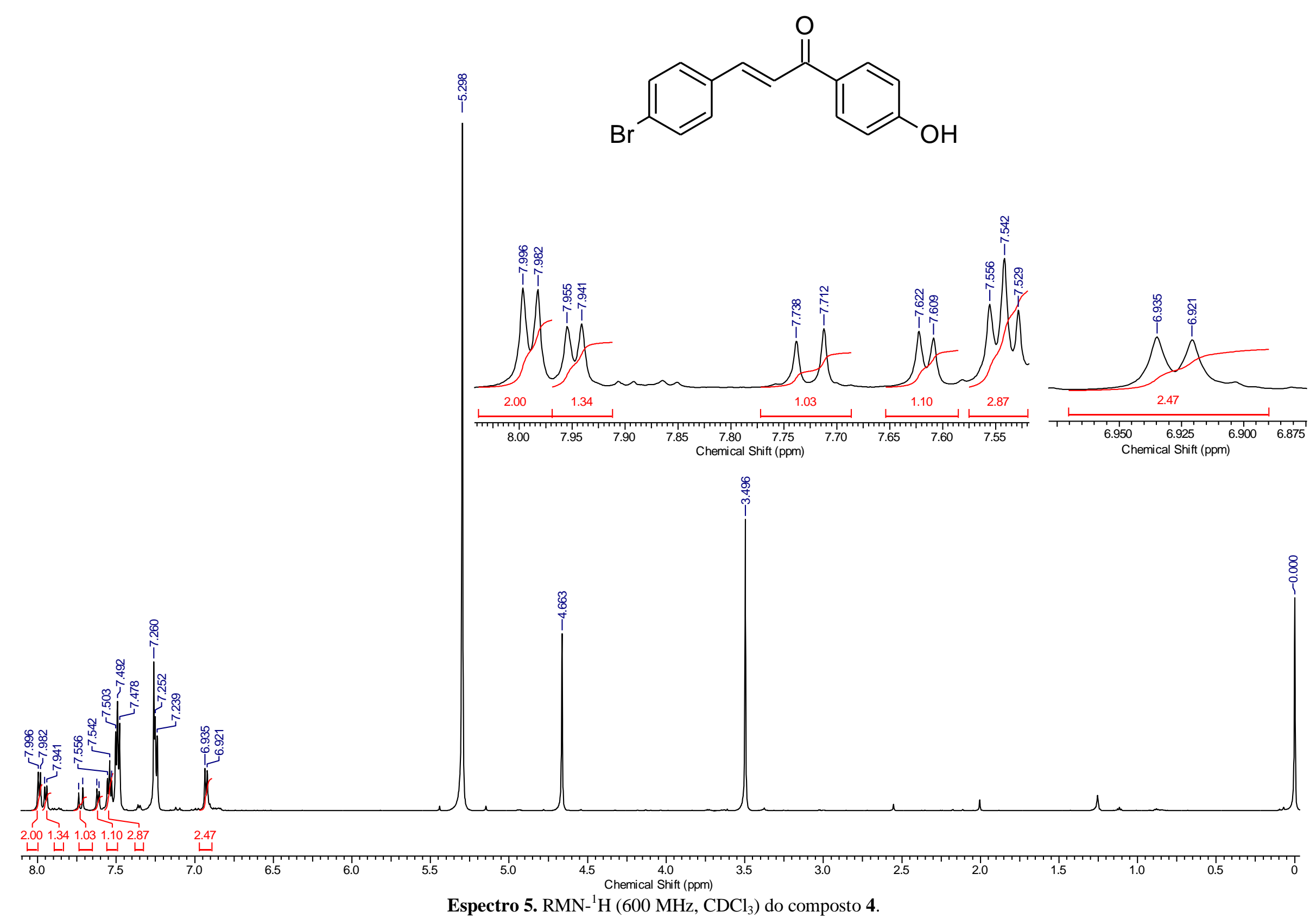




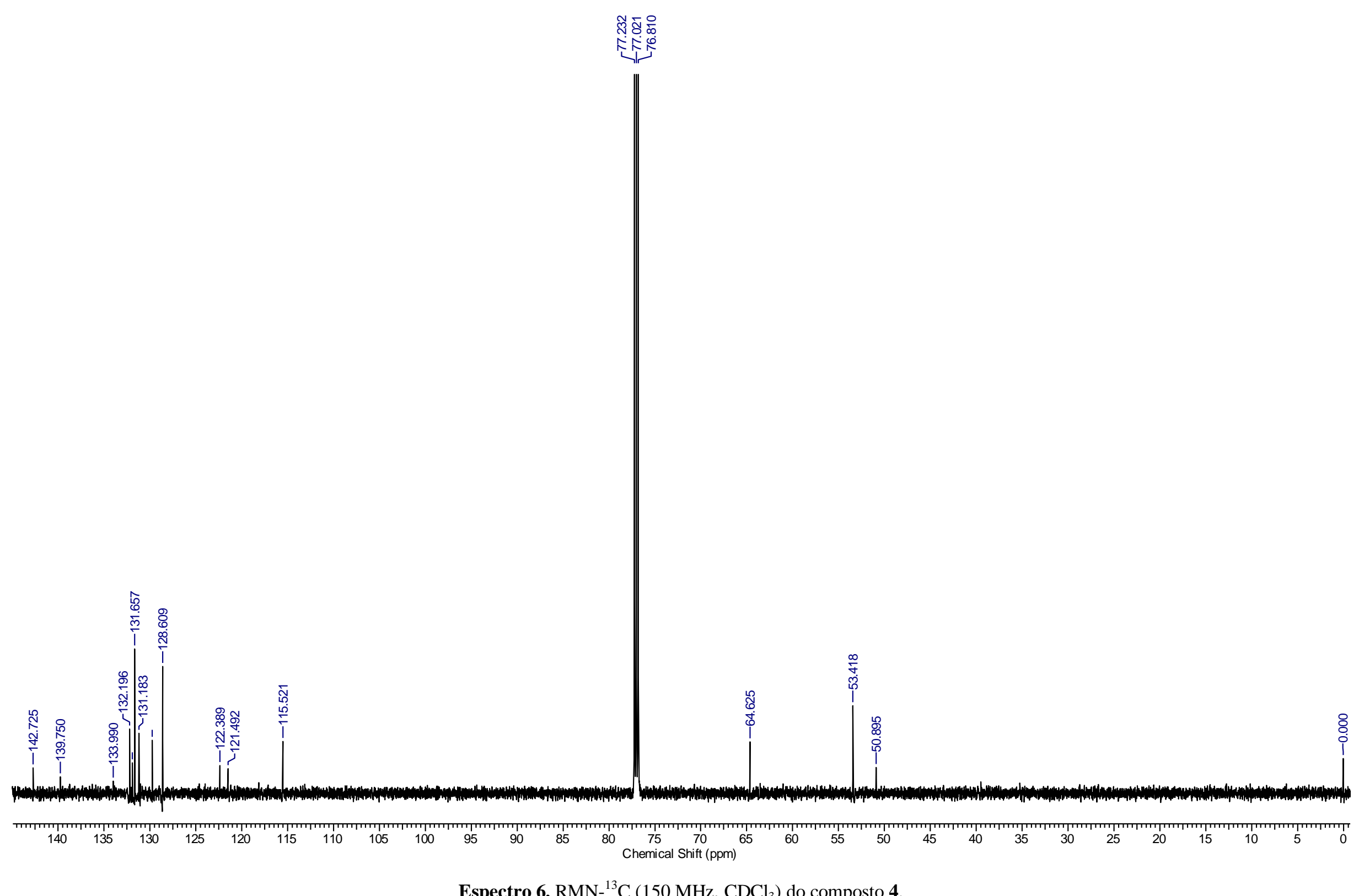

Espectro 6. $\mathrm{RMN}-{ }^{13} \mathrm{C}\left(150 \mathrm{MHz}, \mathrm{CDCl}_{3}\right)$ do composto 4. 


$$
H \|_{1}^{\infty}
$$




$$
1
$$




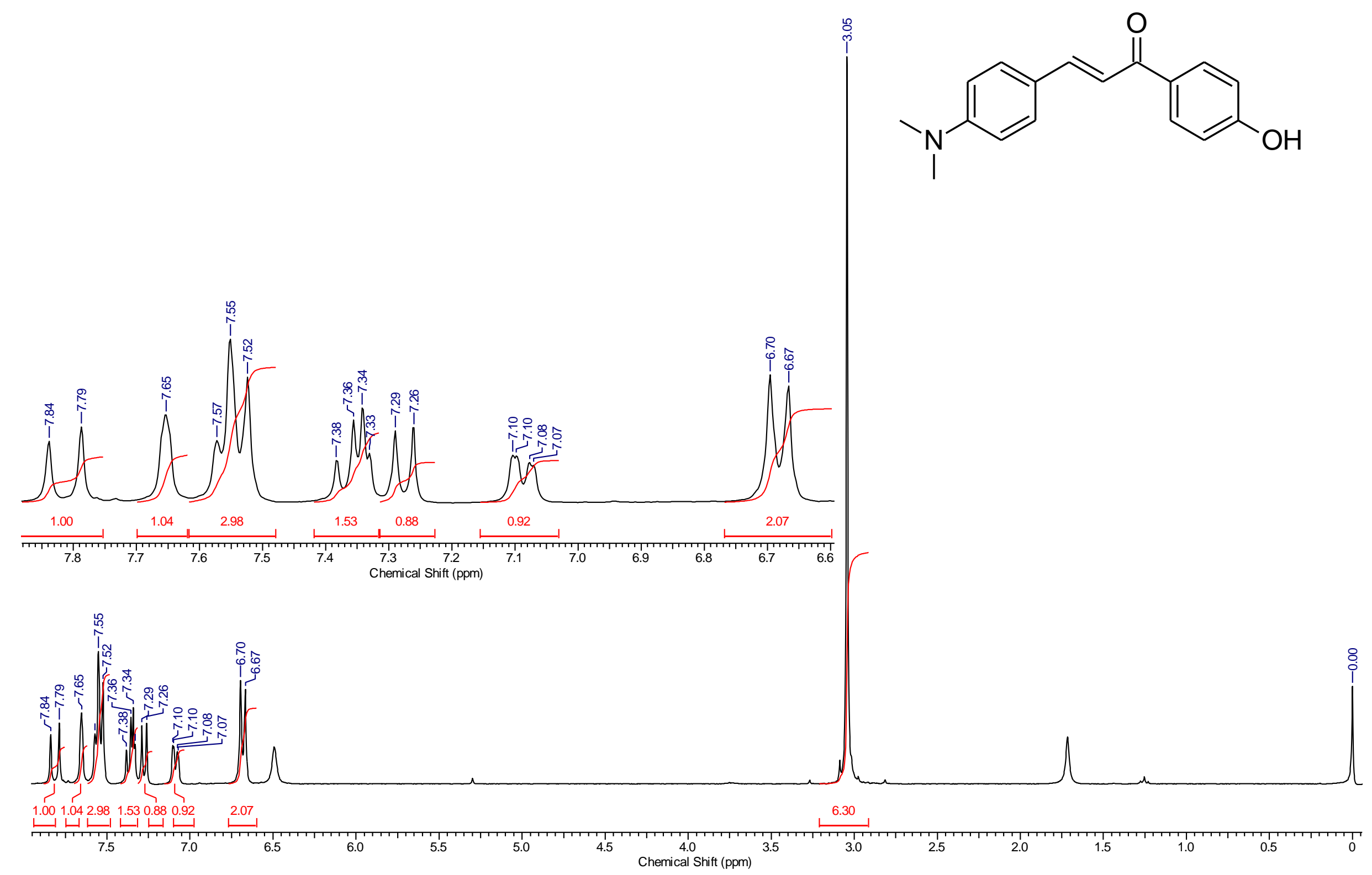

Espectro 9. RMN- ${ }^{1} \mathrm{H}\left(600 \mathrm{MHz}, \mathrm{CDCl}_{3}\right)$ do composto 7. 


$$
H
$$




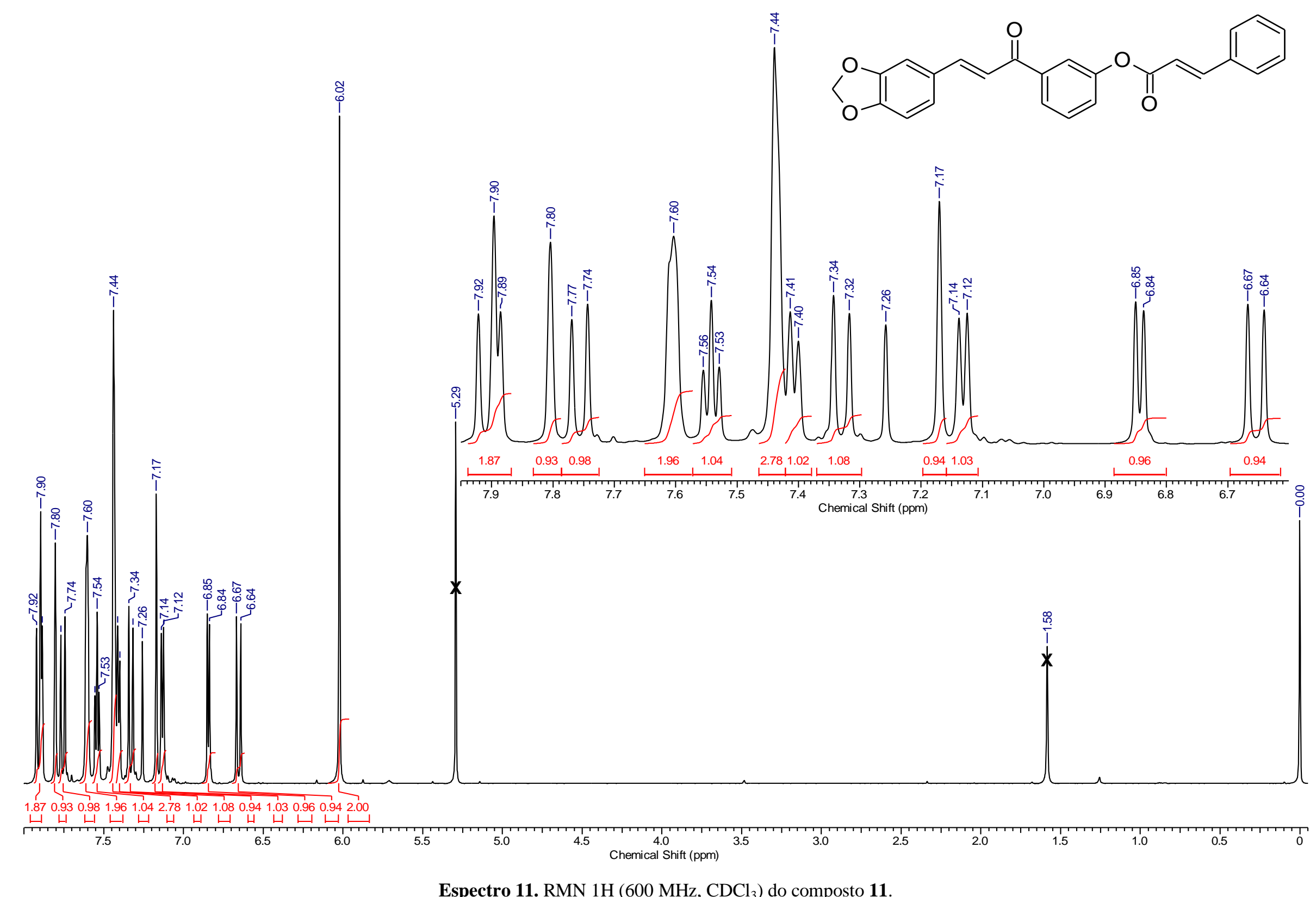




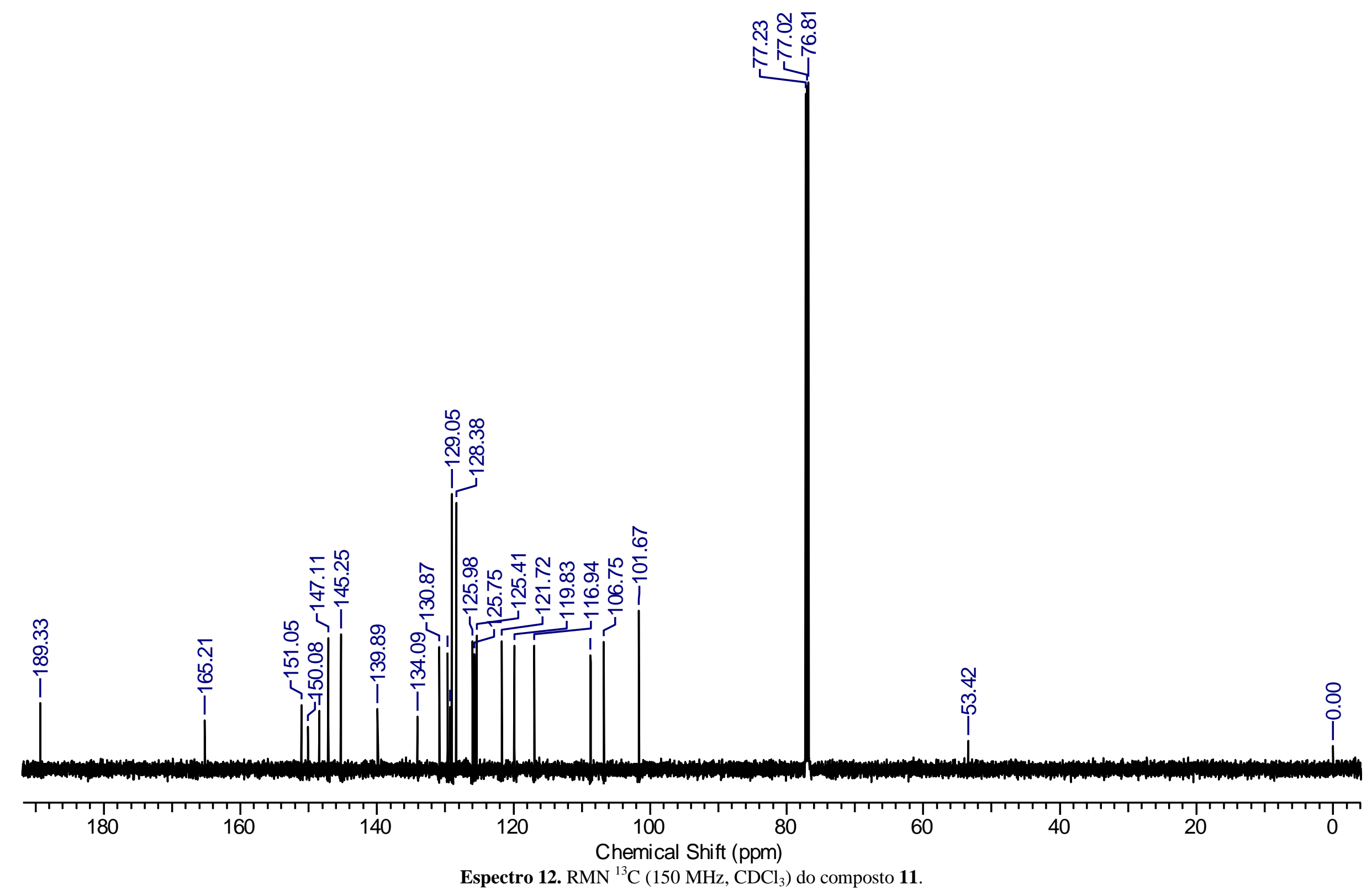




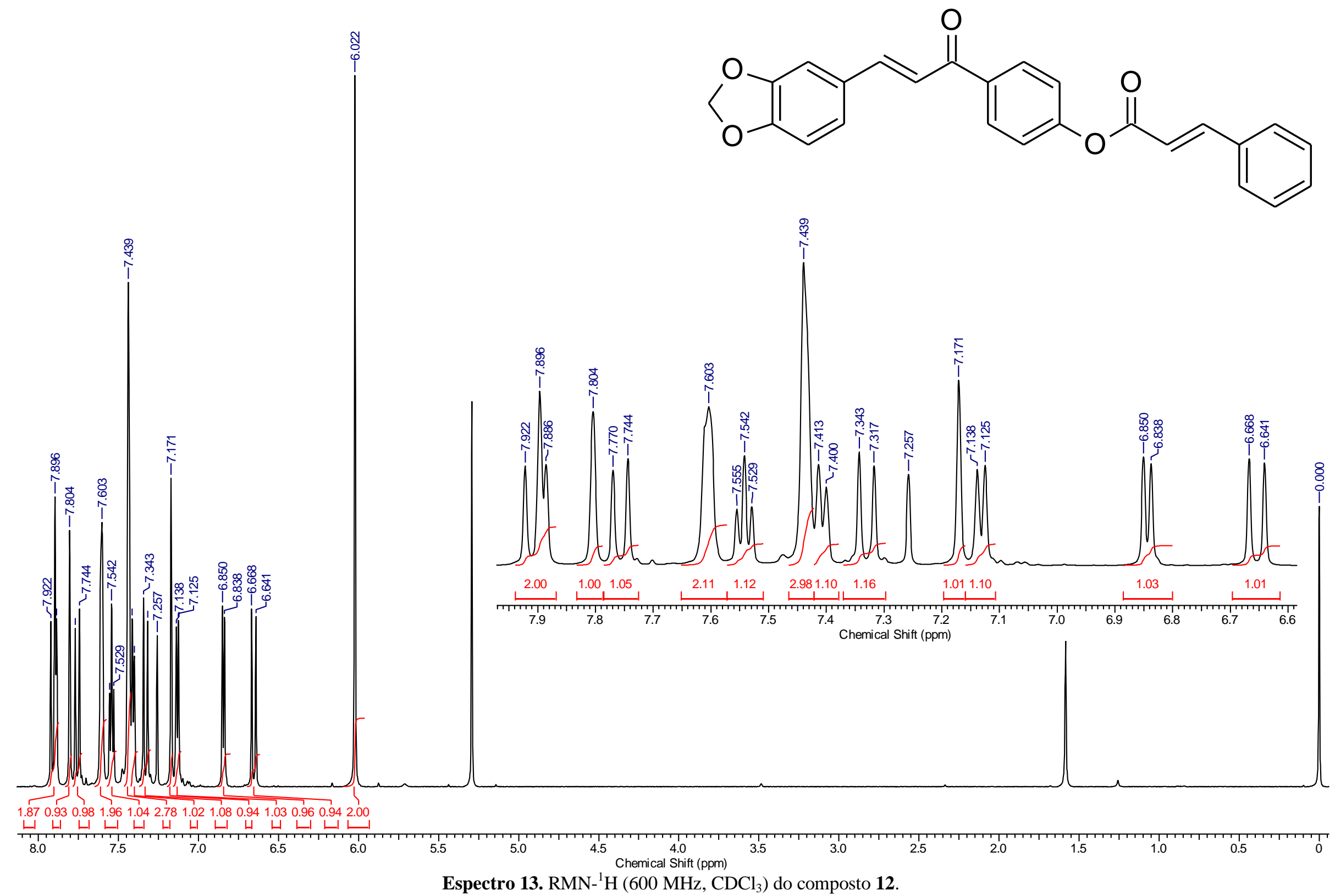




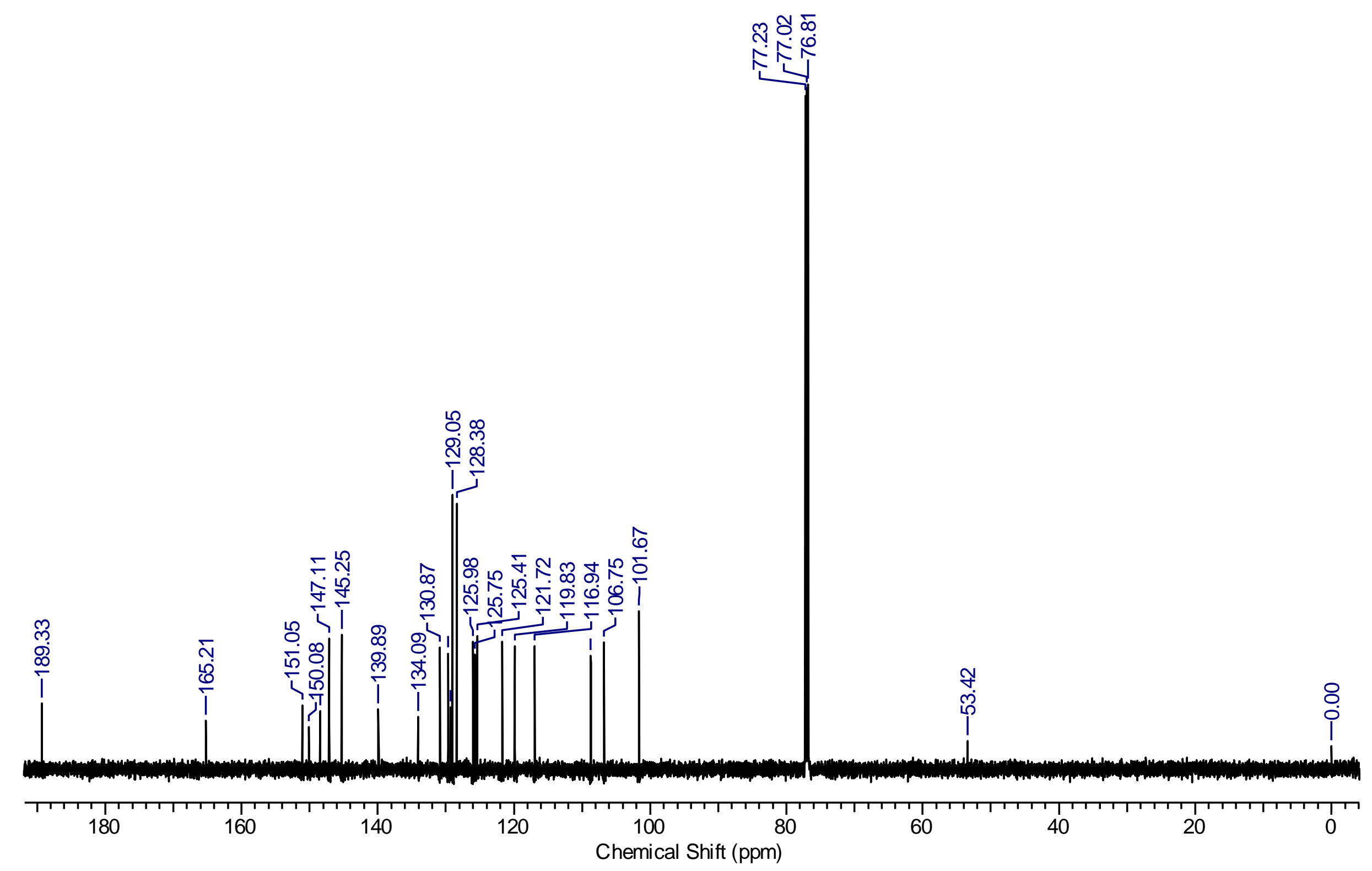

Espectro 14. RMH- ${ }^{13} \mathrm{C}\left(150 \mathrm{MHz}, \mathrm{CDCl}_{3}\right)$ do composto 12. 


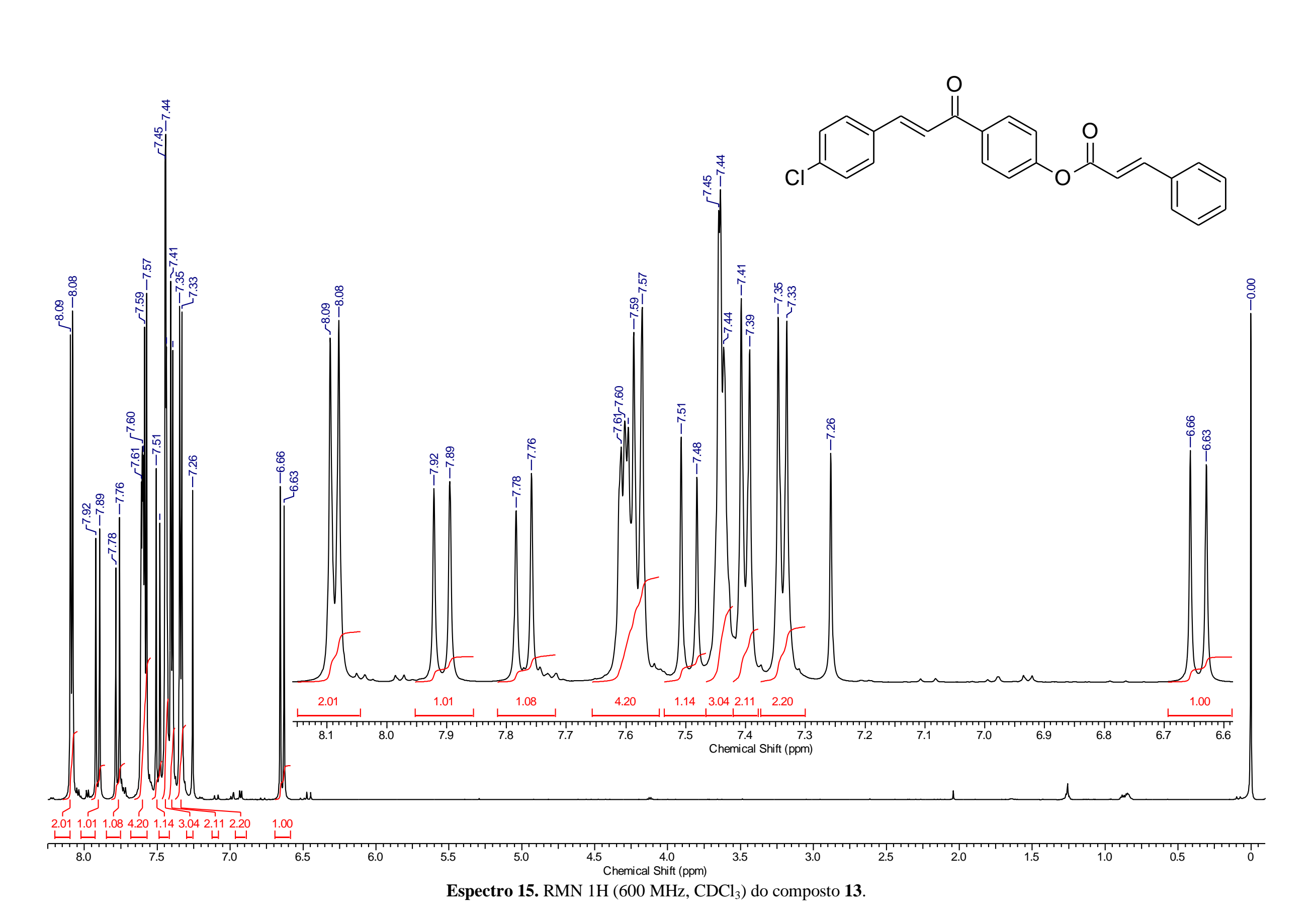




$$
4
$$




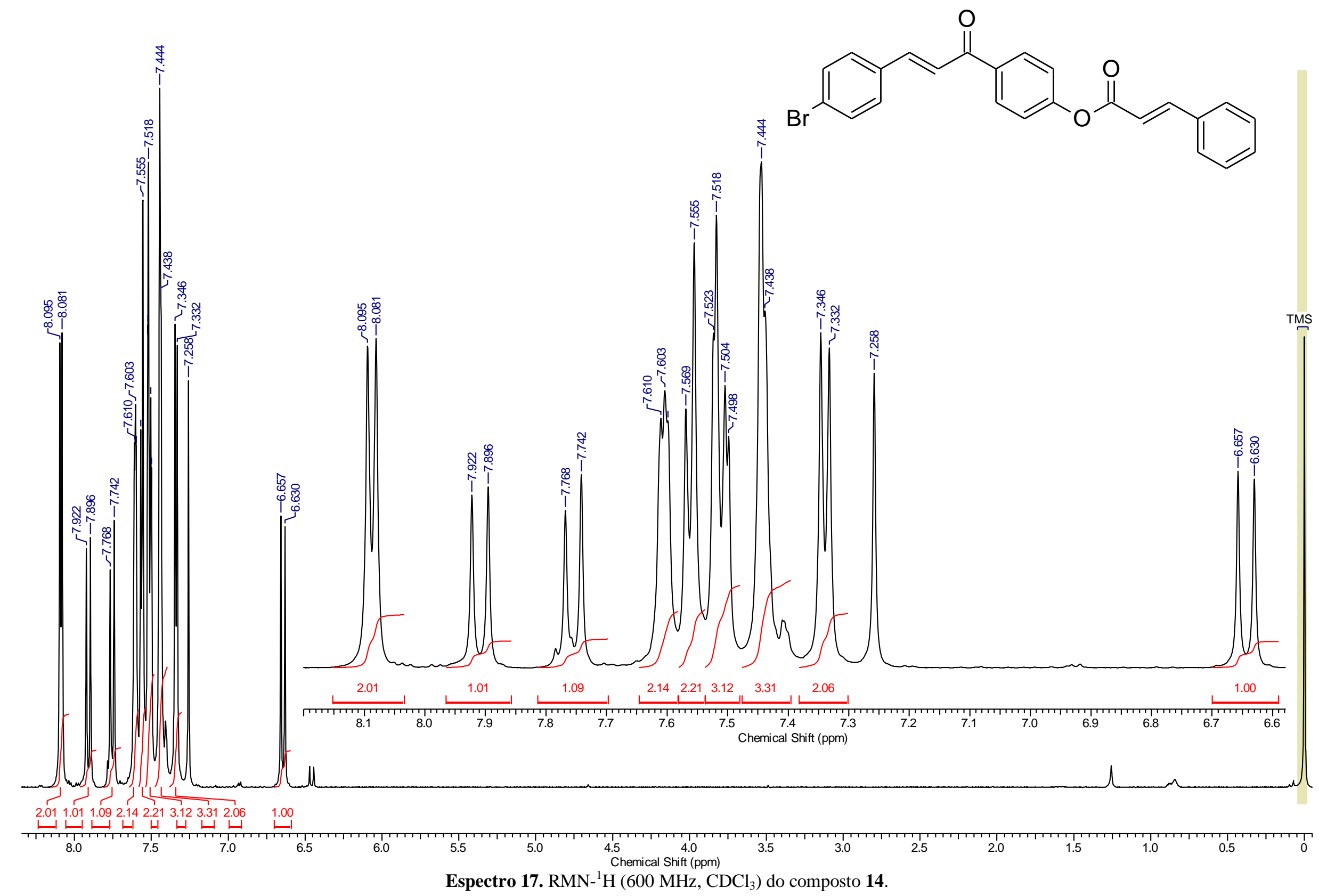




$$
\text { HI }
$$




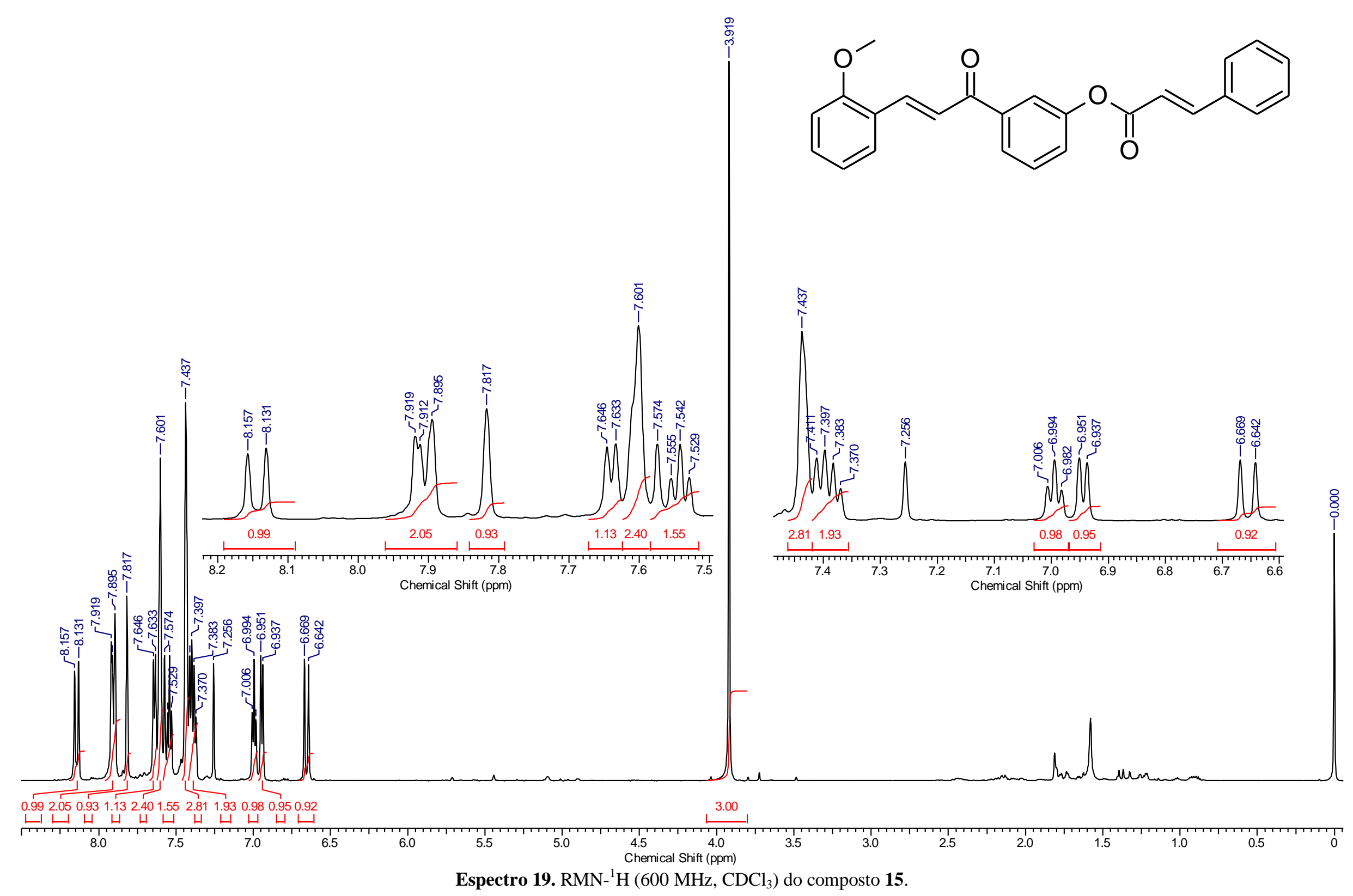




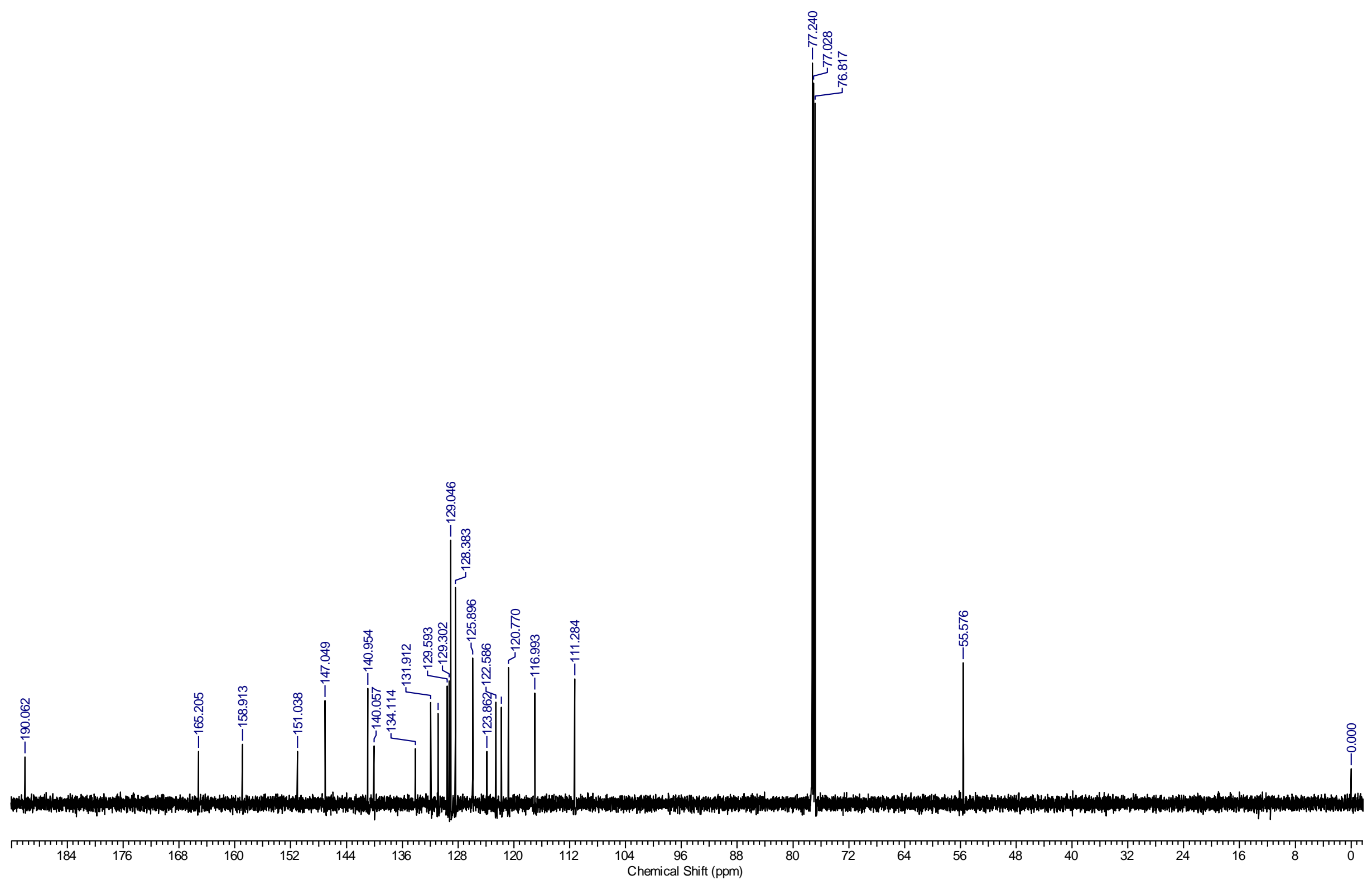

Espectro 20. $\mathrm{RMN}-{ }^{13} \mathrm{C}\left(150 \mathrm{MHz}, \mathrm{CDCl}_{3}\right)$ do composto 15 .

65 


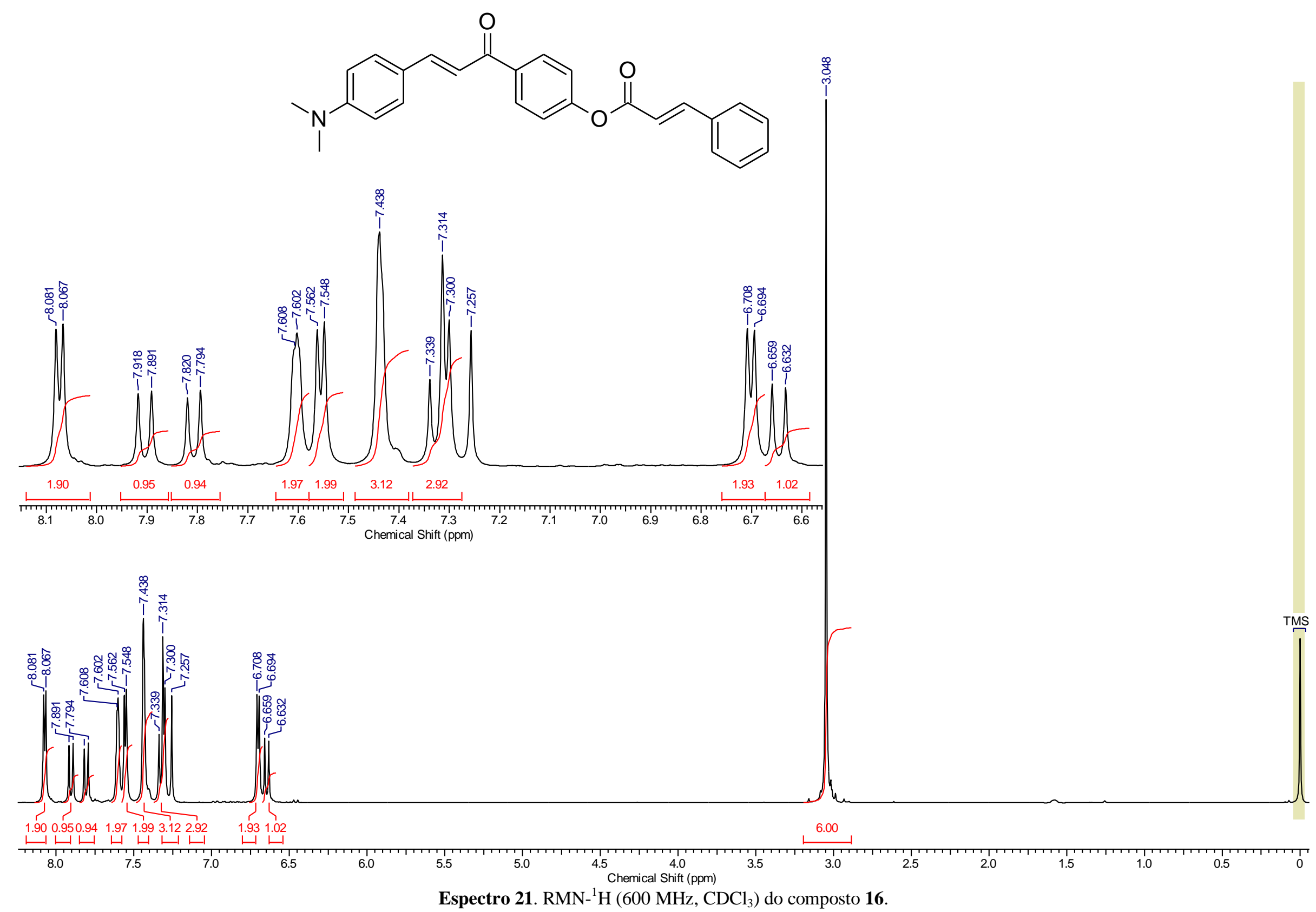




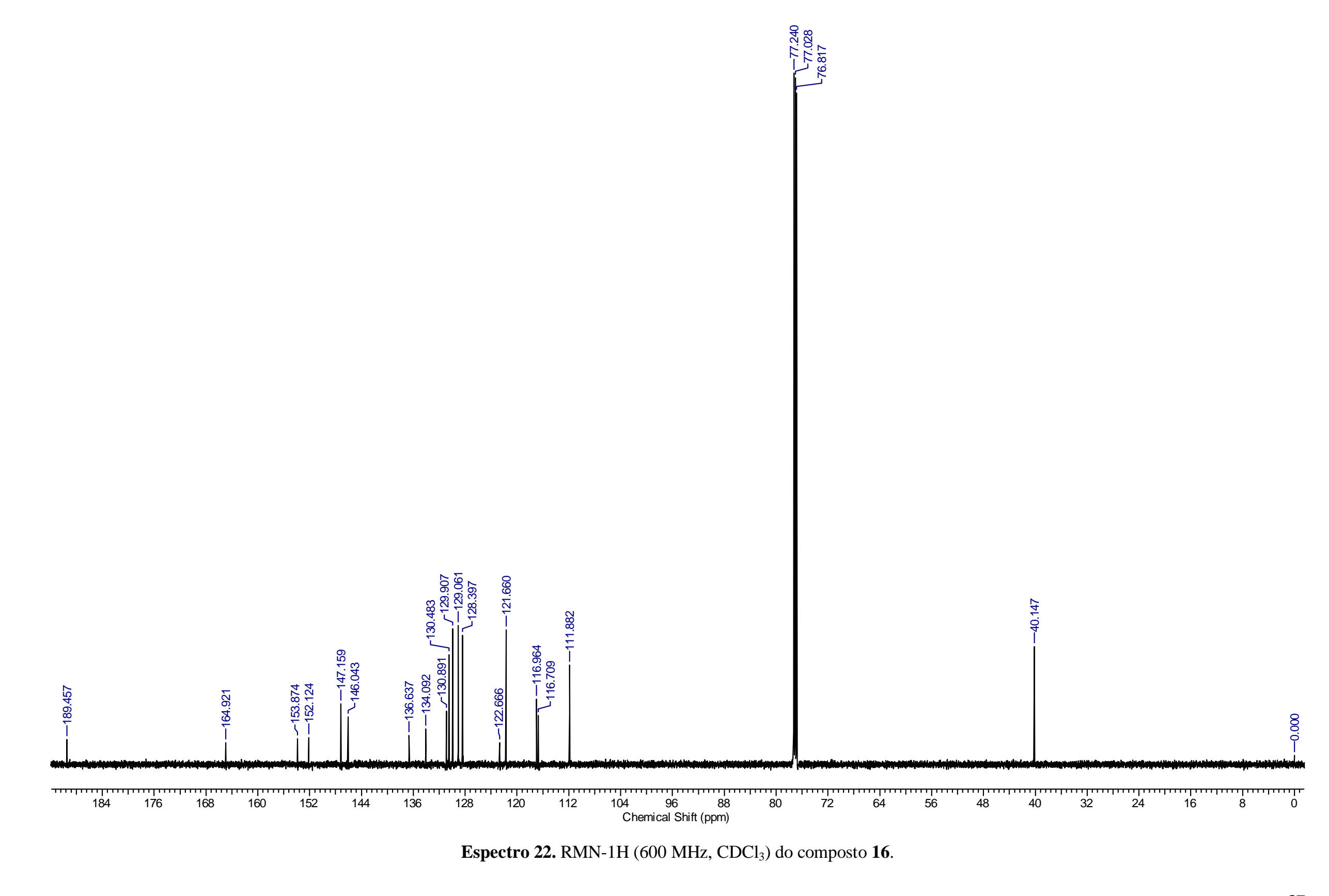


<smiles>CN(C)c1ccc(/C=C/C(=O)c2cccc(OC(=O)/C=C/c3ccccc3)c2)cc1</smiles>
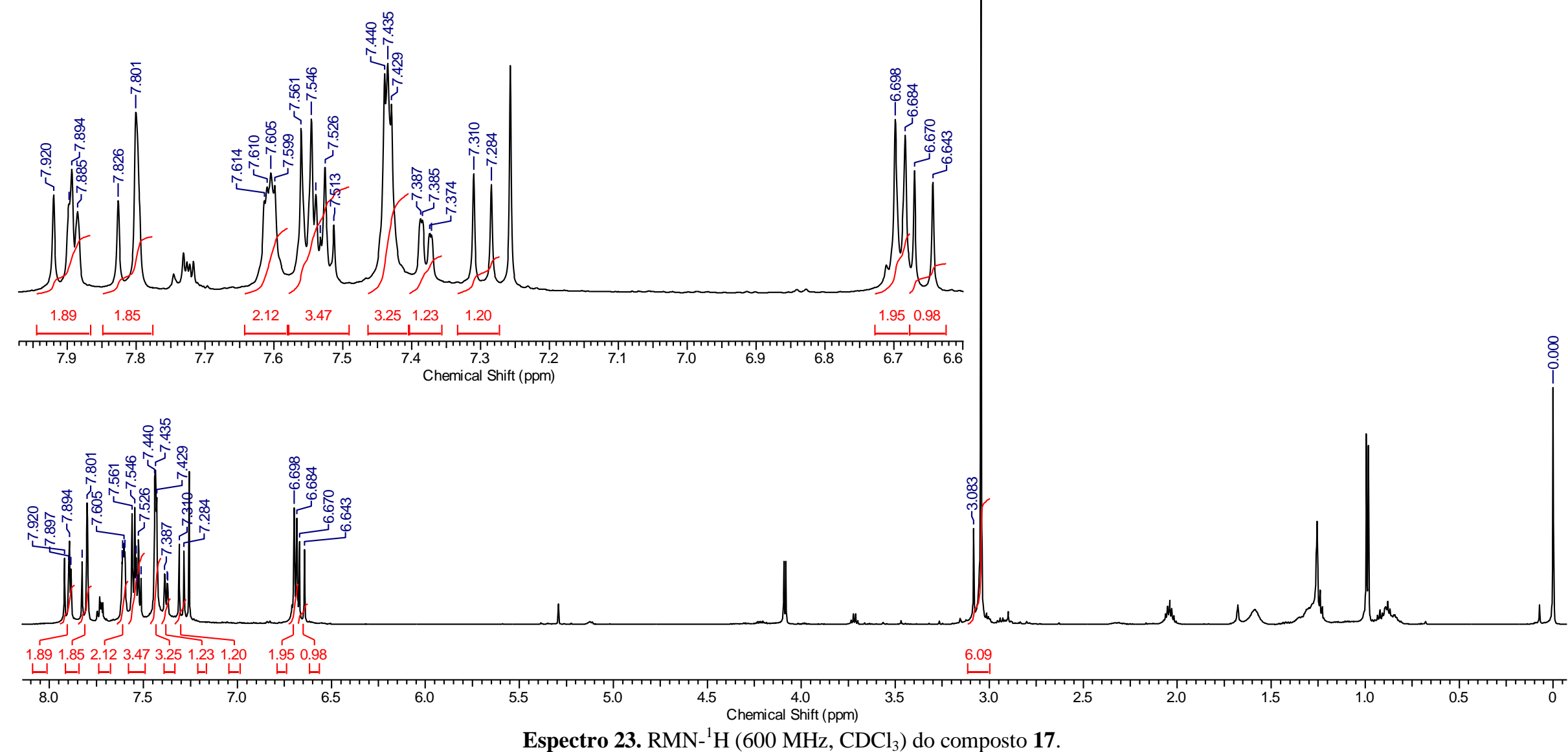


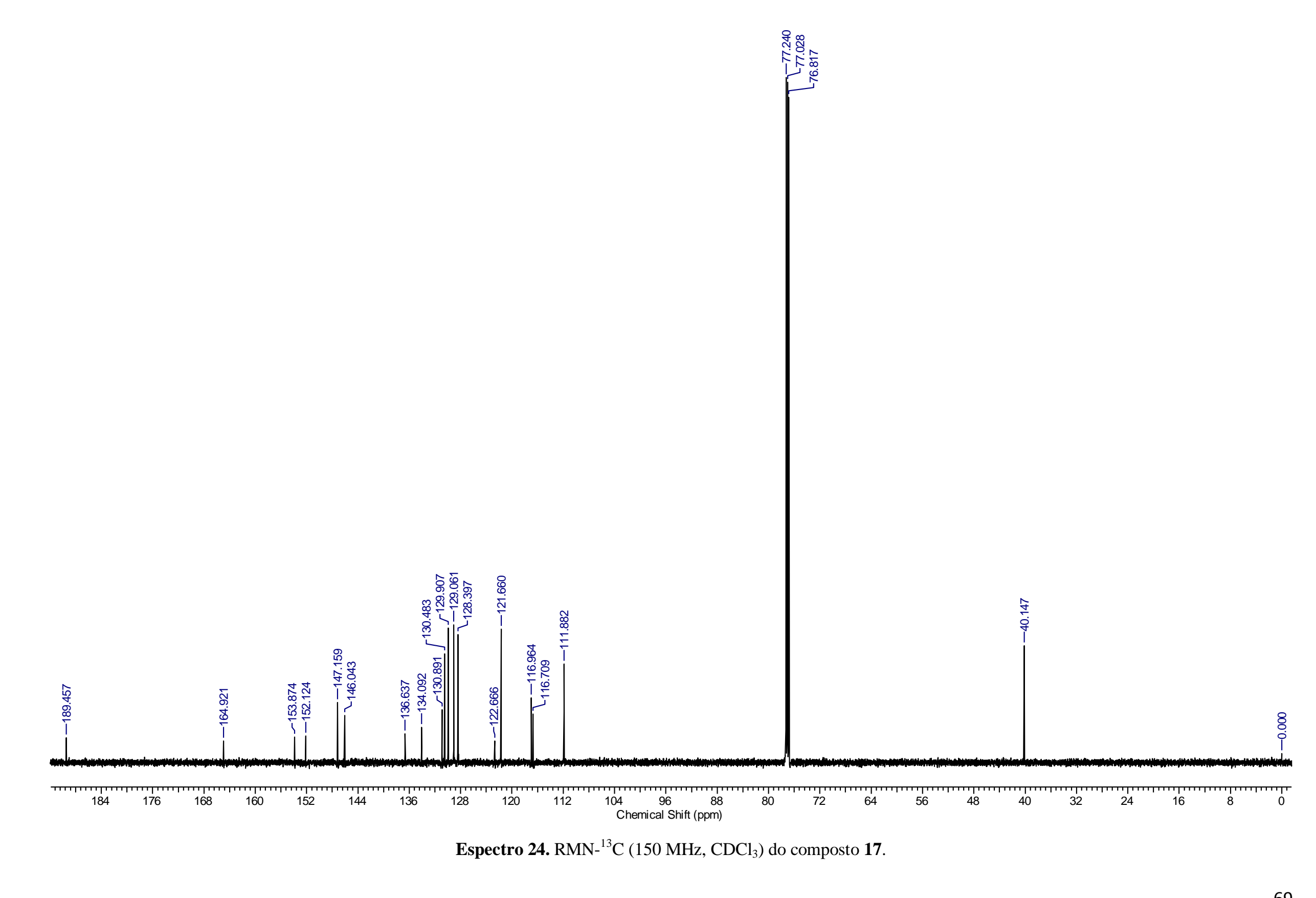






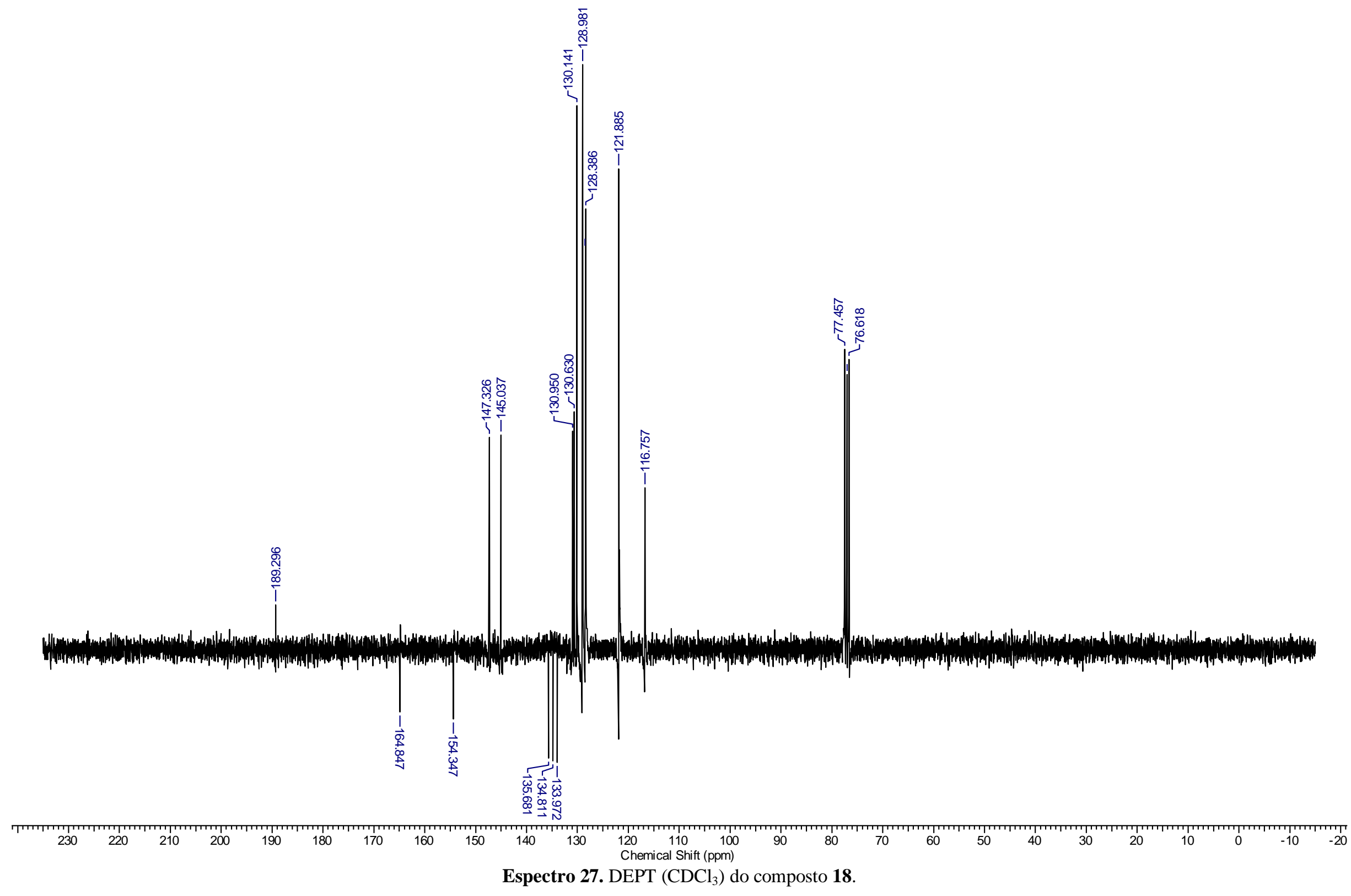




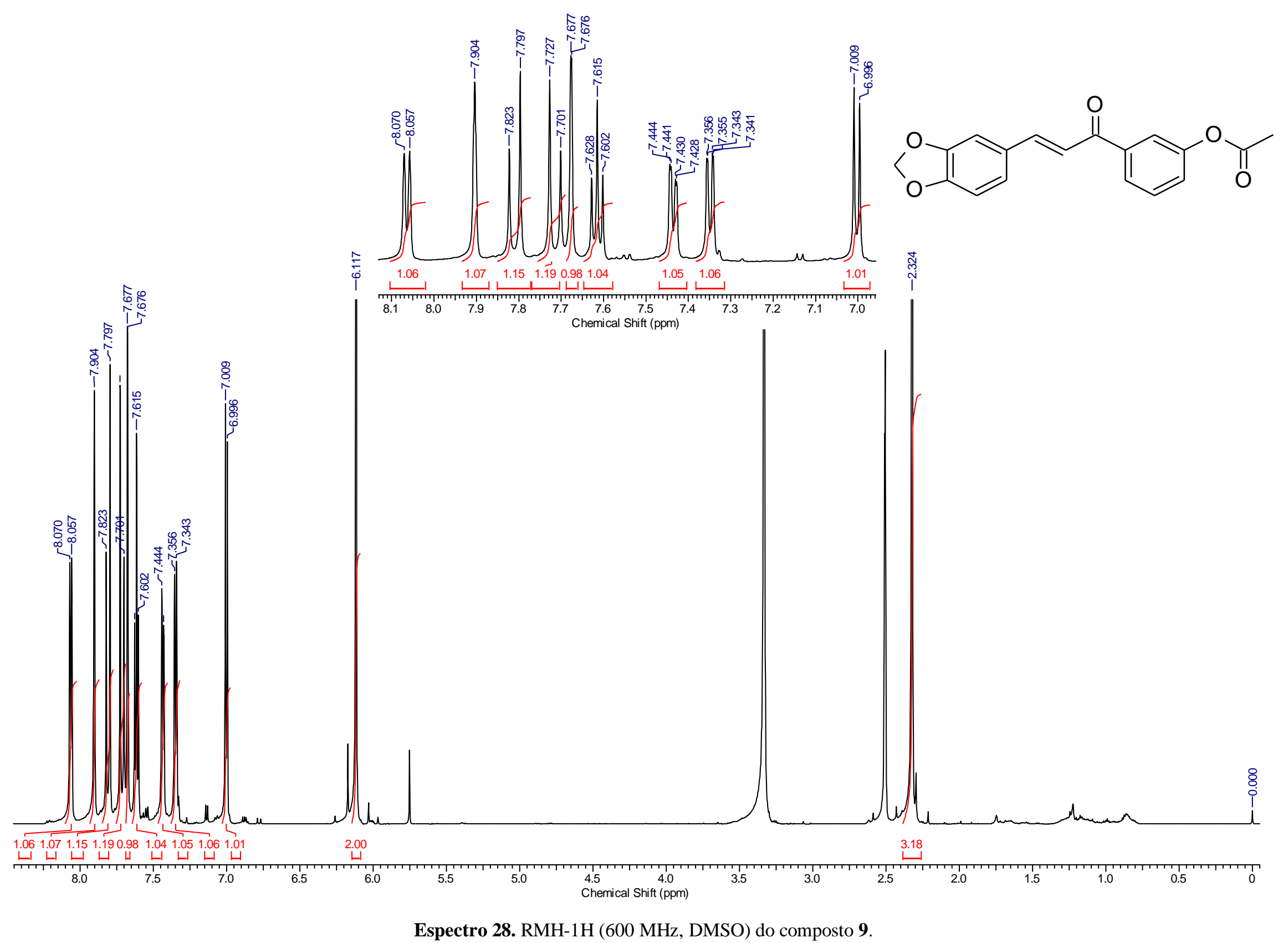




$$
\text { int }
$$




\subsection{Absorção e Emissão}
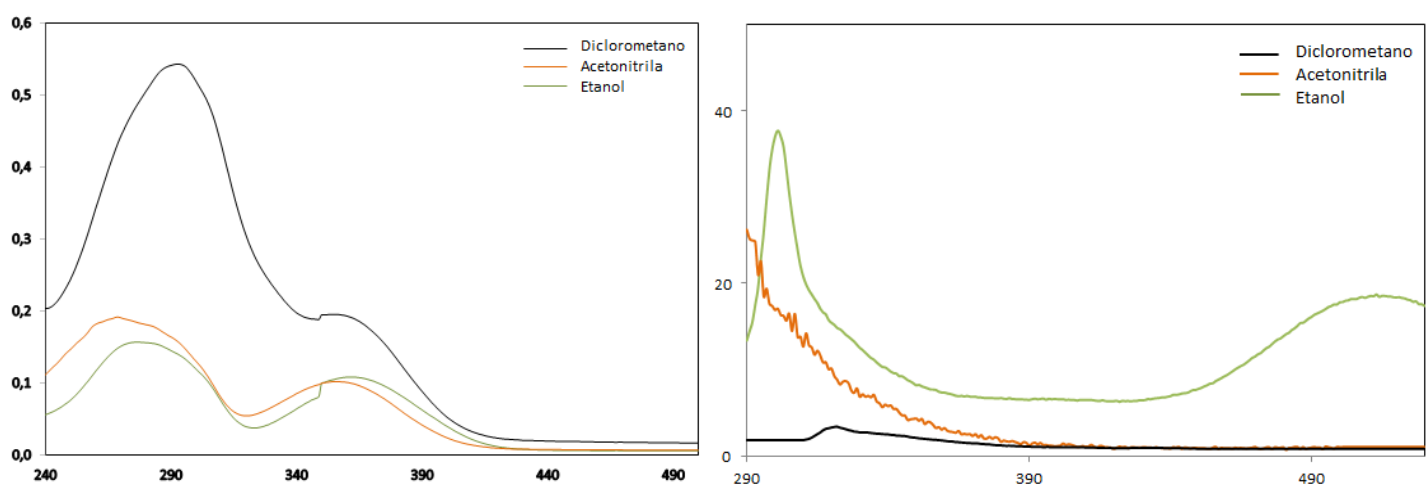

Espectro 30. Absorção e emissão do composto 11 (500-250 nm).
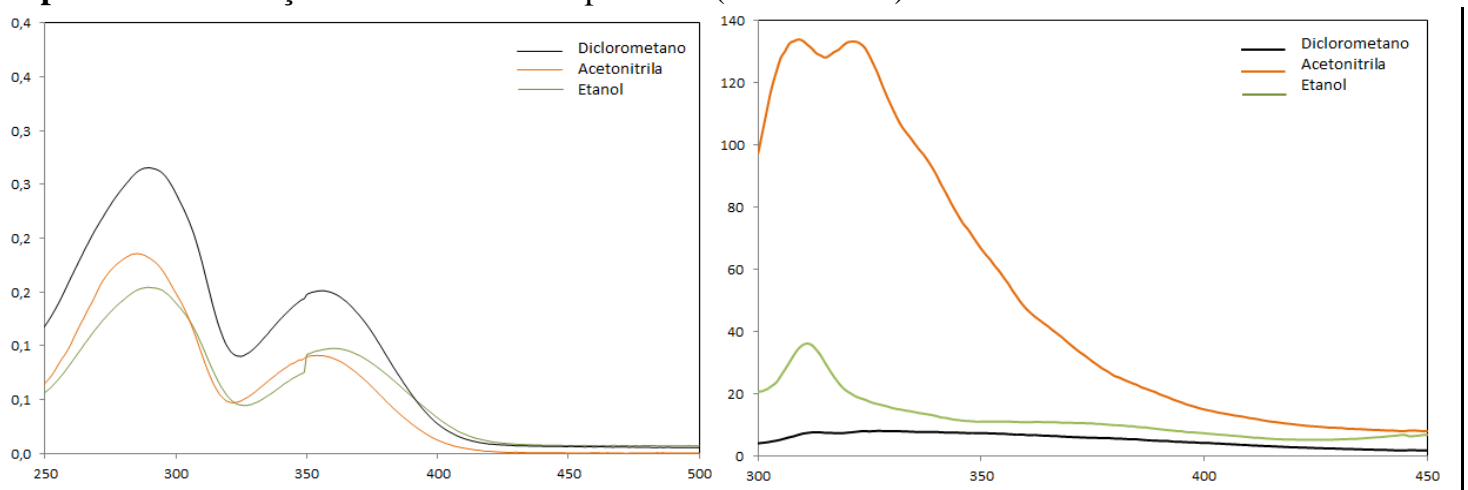

Espectro 31. Absorção e emissão do composto $12(500-250$ nm).
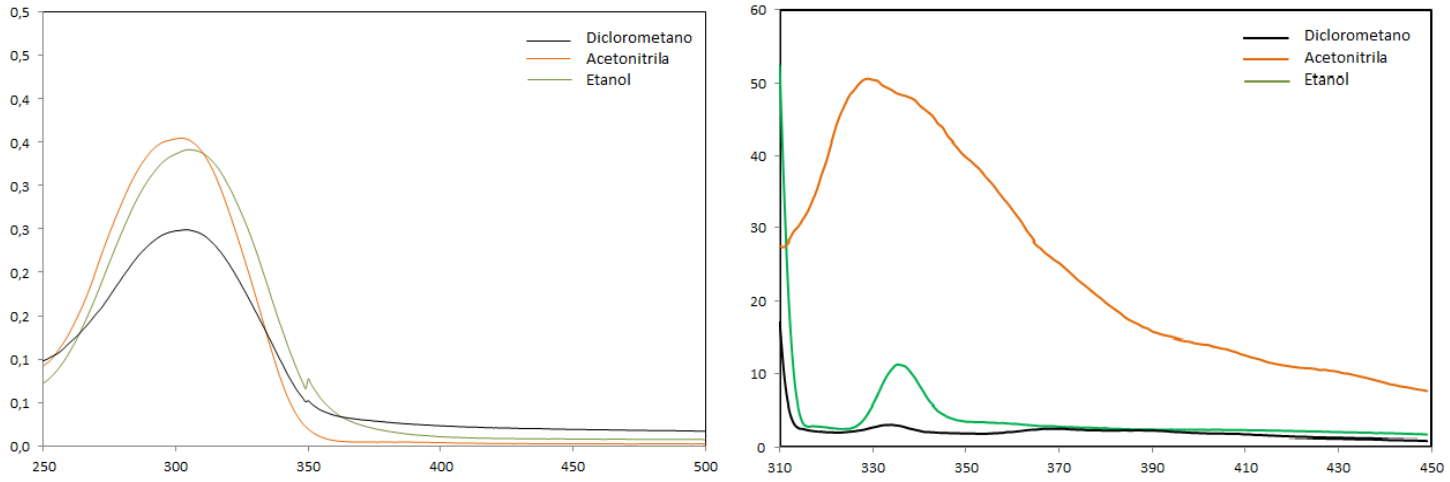

Espectro 32. Absorção e emissão do composto 13 (500-250 nm).
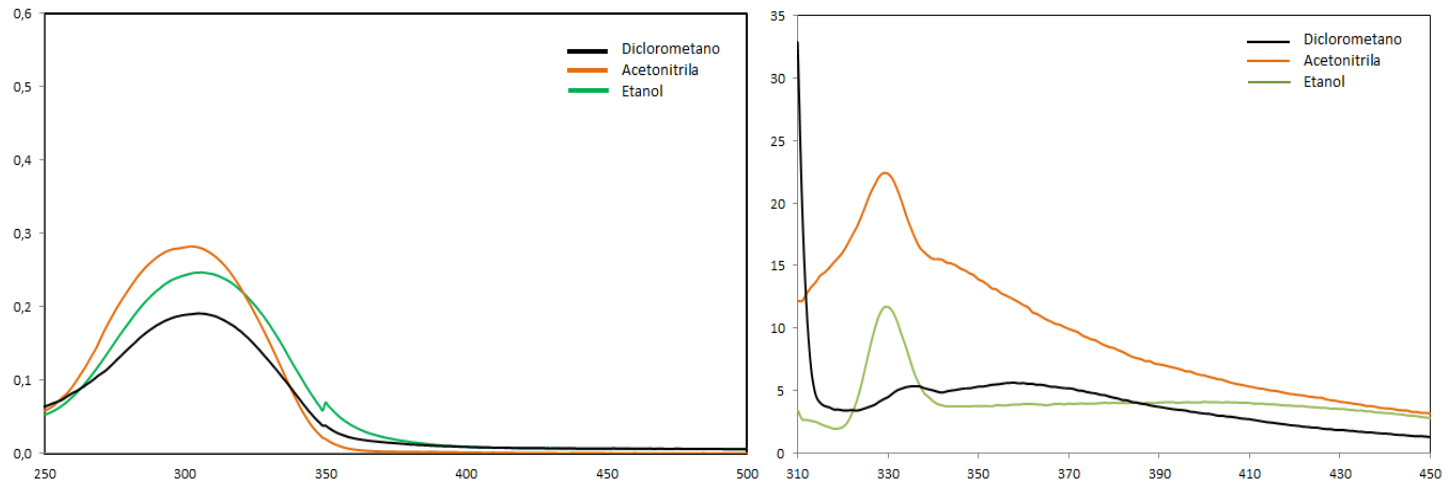

Espectro 33. Absorção e emissão do composto $14(500-250$ nm). 

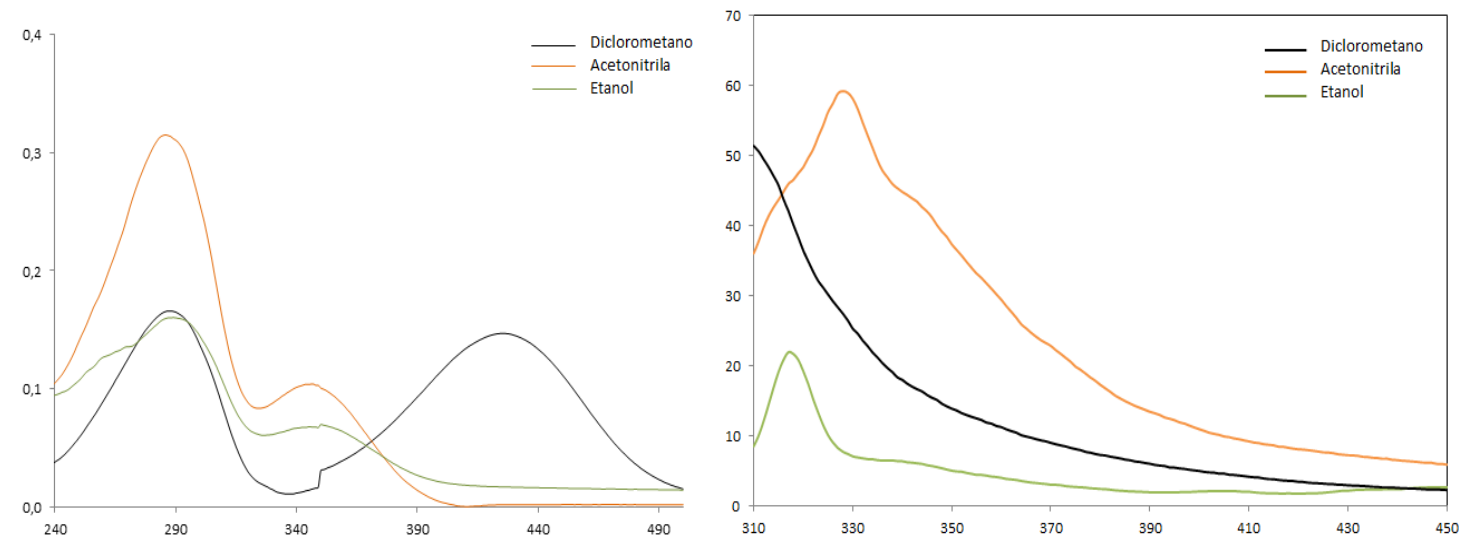

Espectro 34. Absorção emissão do composto 15 (500-250 nm).
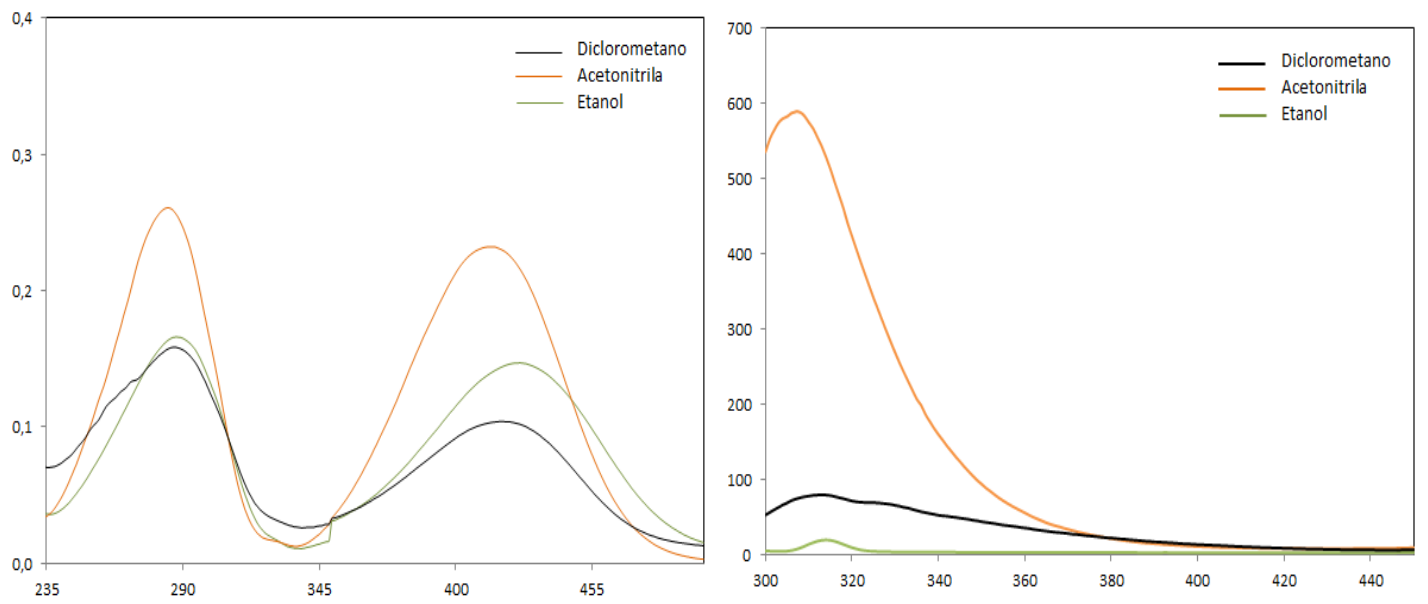

Espectro 35. Absorção e emissão do composto 17 (500-250 nm).
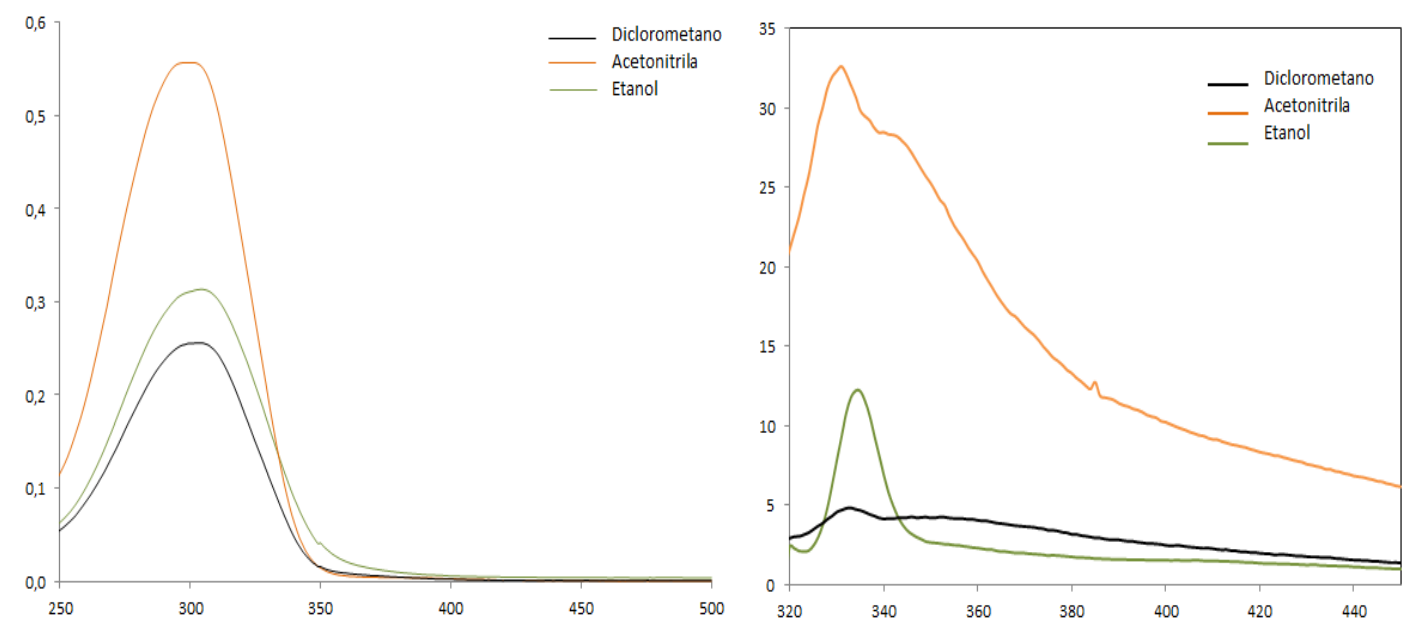

Espectro 36. Absorção e emissão do composto 18 (500-250 nm). 